\title{
1 Recent developments in element concentration and \\ 2 isotope ratio analysis of individual fluid inclusions by \\ 3 laser ablation single and multiple collector ICP-MS
}

4

5 Thomas Pettke ${ }^{1}$, Felix Oberli ${ }^{2}$, Andreas Audétat $^{3}$, Marcel Guillong ${ }^{4}$, Adam C.

6 Simon $^{5}$, Jacob J. Hanley ${ }^{6}$, Leonhard M. Klemm

7

81 University of Bern, Institute of Geological Sciences, Baltzerstrasse 1+3, $\mathrm{CH}-3012$

$9 \quad$ Bern, Switzerland pettke@geo.unibe.ch

102 ETH Zürich, Institute of Geochemistry and Petrology, Clausiusstrasse 25, CH-8092

11 Zürich, Switzerland

123 Bayerisches Geoinstitut, Universität Bayreuth, 95440 Bayreuth, Germany

134 ARC Centre of Excellence in Ore Deposits, Private Bag 126, Hobart, Tasmania,

147001 , Australia

155 Department of Geoscience, University of Nevada, 4505 S. Maryland Parkway, Las

16 Vegas, NV 89154-4010, USA

176 Saint Mary's University, Department of Geology, 923 Robie Street, Halifax, Nova

18 Scotia, Canada, B3H3C3

197 Gübelin Gem Lab Ltd., Maihofstrasse 102, CH-6006 Luzern, Switzerland

20

21 Corresponding author:

$22 \quad$ Pettke@geo.unibe.ch

Please cite as:

Pettke, T., Oberli, F., Audetat, A., Guillong, M., Simon, A. C., Hanley, J. J., and Klemm, L. M., 2012. Recent developments in element concentration and isotope ratio analysis of individual fluid inclusions by laser ablation

28 single and multiple collector ICP-MS. Ore Geology Reviews 44, 10-38. DOI: 10.1016/j.oregeorev.2011.11.001 
Abstract

Laser ablation inductively coupled plasma mass spectrometry (LA-ICPMS) has become a most powerful technique for the elemental analysis of individual, polyphase inclusions completely enclosed in minerals, be they solid or a solid-liquid-gas mixture at the time of measurement. Simultaneous, accurate quantification of major to ultra-trace element concentrations from $\mathrm{Li}$ to $U$ by well-controlled ablation of the entire fluid or melt inclusion content and successful use of largely matrix-independent external calibration protocols are unique features of this method.

This contribution reviews fluid inclusion fundamentals relevant for their bulk analysis by LA-ICP-MS and discusses key aspects of the analytical protocol. Emphasis is on figures of merit (precision, accuracy) obtained from the analysis of individual inclusions and fluid inclusion assemblages, and procedures and technical developments to improving data quality are elaborated. A new equation for the calculation of detection limits for LA-ICPMS analysis is presented, which closely follows IUPAC conventions.

Applications are reviewed with emphasis on the use of synthetic fluid inclusions in constraining metal solubility and distribution between co-existing phases. New data for natural bismuth "fluid" inclusions document the seamless transition to melt inclusion analysis by LA-ICP-MS, thus highlighting the fact that the procedures presented here are generally applicable to the analysis of inclusions in complex host minerals.

Isotope ratio analysis of individual fluid inclusions by multicollector ICPMS (MC-ICP-MS) is a recent development that requires fast transient signals to be accurately recorded by instrumentation designed for high-precision static measurements of long-lasting stable ion beams. We address the general principles based on $\mathrm{Pb}$ isotopes and review a first application to the Bingham Canyon porphyry Cu-AutMo deposit. A pilot study using about 50 synthetic fluid inclusions containing SRM $987 \mathrm{Sr}$ and variable $\mathrm{NaCl}, \mathrm{Ca}$, and $\mathrm{Rb}$ concentrations demonstrates that accurate ${ }^{87} \mathrm{Sr} /{ }^{86} \mathrm{Sr}$ isotope ratios can be 60 obtained on an individual Rb-poor fluid inclusion, at absolute $2 \sigma$ precisions of 610.0003 to 0.002 . A residual trend in ${ }^{87} \mathrm{Sr} /{ }^{86} \mathrm{Sr}$ as a function of the $\mathrm{Rb} / \mathrm{Sr}$ 
62 abundance ratio in the fluid inclusions suggests that interference correction of

$63 \quad{ }^{87} \mathrm{Rb}$ on mass 87 assuming identical mass bias coefficients for the two

64 elements may be inaccurate; however, the offset can be accurately corrected 65 for by regressing the data to zero ${ }^{87} \mathrm{Rb}$.

66 The versatility and detection power of LA-ICP-MS makes this technique

67 the method of choice for solute abundance and isotope ratio analysis of

68 individual fluid inclusions. Significant future progress can be achieved by

69 improvements in ion production, transmission and data recording efficiency

70 and by further improving control on inclusion ablation by pulsed laser beams.

71 Data quantification strategies may also have to be further refined to keep pace

72 with instrumental progress and innovation.

\section{Keywords}

- Laser ablation ICP-MS

- Fluid inclusions

- Analytical protocols

- Detection limit

- Hydrothermal ore deposit

\section{INTRODUCTION}

Fluids play a fundamental role in mass and heat transport in the Earth. The term "fluid" encompasses all phases that are not solid at the $\mathrm{P}-\mathrm{T}-\mathrm{X}$ (pressure-temperature-composition) conditions of the process of interest, including aqueous or carbonic solutions, silicate, sulphide or carbonate melts, and supercritical liquids. Minerals may incorporate tiny droplets of such fluids while they crystallize; hence, such fluid inclusions represent direct, fossil samples of the agents present during mineral growth. Thus, fluid inclusions hold a wealth of information on the composition and phase state of such mobile phases participating in geological processes. Fluid inclusions can be trapped in natural samples down to depths exceeding $200 \mathrm{~km}$ and can be synthesized at controlled experimental conditions (e.g., Roedder, 1984). The solute composition of fluid inclusions can provide key constraints on 
past processes of fluid-mediated chemical transfer in Earth systems, and solute isotope ratios may place robust constraints on the source(s) of fluids.

In-situ analysis of solutes from individual fluid inclusions by laser ablation (LA) has been explored for more than 30 years (Tsui and Holland 1979, Bennett and Grant 1980, Deloule and Eloy 1982). In more recent times, laser ablation inductively coupled plasma mass spectrometry (LA-ICP-MS) has become the method of choice for solute analysis of fluid inclusions due to its excellent detection and fast data acquisition capabilities (e.g., Rankin et al., 1992; Shepherd and Chenery, 1995; Moissette et al., 1996; Günther et al., 1998; Audétat et al., 1998; Heinrich et al., 1999; Loucks and Mavrogenes, 1999; Kamenetsky et al., 1999; Ulrich et al., 1999; Audétat et al., 2000a,b; Ulrich et al., 2002; Audétat and Pettke, 2003; Rusk et al., 2004; Klemm et al., 2004; Stoffell et al., 2004; Landtwing et al., 2005; Allan et al., 2005; Hanley et al., 2005a; Spandler et al., 2007; Klemm et al., 2007, 2008; Audétat et al., 2008; Ulrich and Mavrogenes, 2008; Piqué et al., 2008; Wilkinson et al., 2009, Seo et al., 2009; Richard et al., 2010; Audétat, 2010; Kouzmanov et al., 2010; Catchpole et al., 2011; Allan et al., 2011; Appold and Wenz, 2011). All elements of the periodic table but the noble gases, F, $\mathrm{O}, \mathrm{N}$ and $\mathrm{H}$ can be analyzed in fluid inclusions by LA-ICP-MS, but the limits of detection (LOD) vary largely between elements (e.g., Heinrich et al., 2003). Polyatomic species such as $\mathrm{CO}_{2}$ and $\mathrm{SO}_{2}$ are currently not measured in fluid inclusions by LA-ICP-MS, except for one pilot study reporting the analysis of alkanes and aromatic hydrocarbons from single petroleum inclusions (Volk et al., 2010). The in-situ analysis of individual fluid inclusions overcomes many of the problems inherent in bulk crush-leach techniques (e.g., Czamanske et al., 1963; Bottrell et al., 1988; Banks et al., 1991; Pettke and Diamond, 1995), most importantly because it avoids problems arising from the analysis of a priori unconstrained mixtures of fluid inclusion assemblages. The basic principles of the LA-ICP-MS analytical approach to element concentration determination of individual fluid or melt inclusions (Günther et al., 1998; Halter et al., 2002b; Heinrich et al., 2003; Allan et al., 2005) have remained largely unchanged; however, methods refinement has continuously improved the techniques and diversified the applications.

Previous literature (Günther, 2001; Heinrich et al., 2003; Pettke, 2006, 2008; Mason et al., 2008) has reviewed the history and the basics of LA-ICP-MS fluid/melt inclusion analytical techniques. Here, we first focus on briefly reviewing the concepts and principles, emphasize critical aspects of the technique, address recent analytical developments and illustrate progress made on fluid inclusion element concentration analysis using selected applications. We then introduce novel techniques for isotope ratio analysis of individual fluid inclusions. This review will not address the current state of other microbeam techniques, notably the nondestructive ones (e.g., RAMAN, PIXE, PIGE, SR-XRF or XANES), nor will it discuss other destructive techniques such as LA-ICP- optical emission spectroscopy (LA-ICP-OES) or laser induced breakdown spectroscopy (LIBS) that currently return inferior results for solute analysis of individual fluid inclusions (Pettke et al., 2000b; Fabre et al., 2002). Note, however, that LA-ICP-OES was the first method evaluated in detail for solute analysis of individual fluid 
inclusions (Ramsey et al., 1992) and, as such, initiated this line of analytical development. While the principles for fluid and melt inclusion analysis by LA-ICP-MS are fundamentally the same, melt inclusions are, at least partially, solid at room temperature when they are analyzed. Thus, measurements can be performed on glassy, exposed parts of homogeneous melt inclusions, whereby a tiny fraction of the inclusion - considered to be representative of the bulk inclusion - is analyzed in situ by various microbeam techniques (most importantly electron probe microanalysis, EPMA; secondary ion mass spectrometry, SIMS). Because melt inclusions will not be further addressed here, the reader is referred to the literature (e.g., Halter et al., 2002a; Danyushevsky et al., 2002; Pettke, 2006; Mason et al., 2008; or Audétat and Lowenstern, submitted) for detailed discussion.

Experience has shown that accurate analysis of fluid inclusions for chemical and isotopic compositions is largely limited by (a) the fluid inclusion ablation process and aerosol transport to the ICP, (b) limitations resulting from incomplete ionization and signal recording, and (c) by the internal standardization required for quantification of solute concentrations; hence, these aspects will be emphasized in this paper. Topic (a) equally applies to element concentration and isotope ratio analysis, while topics (b) and (c) are application-specific and thus will be addressed in the respective sections.

This manuscript is structured as follows. The peculiar sample characteristics of individual fluid inclusions and the concept of fluid inclusion assemblages are reviewed first, followed by a brief description of how LA-ICP-MS fluid inclusion analyses are performed. Then, various methods of producing fluid inclusion data, and sources of uncertainties, are explained in detail. Based on this, optimization techniques for obtaining the best-possible individual fluid inclusion measurements are outlined. This is followed by a section focusing on element concentration determination on individual fluid inclusions which also contains a discussion on detection limits (LOD) applicable to LA-ICP-MS in general and an assessment of measures that can be taken to specifically lower the LOD in fluid inclusion analysis. The section on selected applications then presents a previously unavailable review of applications employing synthetic fluid inclusions, and a new application on fluid/melt transition based on $\mathrm{Bi}$ inclusions. The following section is devoted to $\mathrm{Pb}$ isotope ratio analysis of individual fluid inclusions, discussing both analytical aspects and a first application to constraining the metal source(s) of porphyry-type ore deposits. We then present the results of our pilot study on $\mathrm{Sr}$ isotope ratio analysis of fluid inclusions based on synthetic fluid inclusion standards. The paper closes with a brief section on potential directions of future developments.

\section{Fluid inclusions: Peculiar sample characteristics}

Fluid inclusions are tiny droplets trapped as a single phase at elevated temperatures and pressures. The exception to this involves heterogeneous entrapment in a two or more phase stability volume (e.g., Roedder, 1984). Key to the applicability of fluid inclusion (and melt inclusion) chemical data for the characterization of paleo-fluids is that, after entrapment, 
the inclusions have behaved as a chemically closed systems, i.e., individual fluid inclusions did not lose or gain chemical components (isoplethic behaviour).

In inclusion research, the concept of fluid inclusion assemblages (see Goldstein and Reynolds, 1994, for an excellent review) is critical to inclusion analysis and interpretation. A fluid or melt inclusion assemblage comprises a series of inclusions entrapped the same time in a host mineral. Petrographically, geometric criteria are employed to argue for coeval entrapment of fluid inclusions, such as the entrapment of fluid inclusions along a host mineral growth zone or a fracture plane. Consequently, a fluid inclusion assemblage contains a series of individual fluid inclusions that are compositionally identical, i.e., each inclusion representing an isolated sample of this homogeneous fluid (Fig. 1A). This does not apply, however, for the case of heterogeneous entrapment addressed below. Compositional uniformity can be tested for by performing non-destructive fluid inclusion microthermometry, which is also a prerequisite for quantification of fluid inclusion LA-ICP-MS measurements (see below).

Figure $1 \mathrm{~A}$ shows a homogeneously entrapped fluid inclusion assemblage viewed at room temperature. At this temperature, individual fluid inclusions consist of several phases, and the phase volume proportions are identical for all individual fluid inclusions, provided equilibrium conditions prevailed during their formation. After entrapment as a single, homogeneous fluid phase at some $\mathrm{P}$ and $\mathrm{T}$, daughter minerals crystallize and other phases (e.g., a vapour bubble) unmix while the fluid inclusions cool isochorically (i.e., at constant volume and thus constant bulk density) to room temperature. It is this gas-liquid-crystal polyphase mixture of confined volume that we wish to analyze in bulk in order to reconstitute the one-phase chemical composition of the fluid inclusion at the time of entrapment. Even apparently simple aqueous, aqueo-carbonic or vapour-like fluid inclusions may contain major proportions of certain trace elements concentrated in tiny daughter minerals (Fig. 1B), which often are too small for microscopic detection, in particular when hidden beneath a large vapour bubble. It is therefore essential not to miss any fraction of the fluid inclusion content (solids, liquids or gases) during fluid inclusion ablation in order to quantitatively analyze the entire fluid inclusion. Best-possible control on the fluid inclusion ablation process is thus mandatory. Incomplete ablation of a fluid inclusion, e.g., due to uncontrolled rupturing or employing scanning laser ablation across the inclusion, will sample an unconstrained fraction of the bulk inclusion content and thus compromise the analysis.

There are many exceptions to the ideal fluid inclusion assemblage, however. Fluid inclusion assemblages can show variable phase proportions at room temperature and are thus compositionally heterogeneous. This may be a result of either heterogeneous entrapment (Fig. 1C), post-entrapment modification, or of accidental entrapment of solids during fluid inclusion formation.

Heterogeneously entrapped fluid inclusion assemblages can provide important geologic constraints, notably on element distribution between coexisting fluid phases or on metal solubilities at known temperatures (as directly derived from microthermometry). The best- 
known examples of heterogeneous entrapment are the so-called boiling assemblages (Fig. 1C; see also Diamond, 1990) for which relevant data have been obtained on both natural (e.g., Heinrich et al., 1992; Audétat et al., 1998; Heinrich et al., 1999; Ulrich et al., 1999; Klemm et al., 2004) and synthetic fluid inclusions (see below). Coexisting aqueous fluid inclusions and hydrous melt inclusions are another example for immiscible fluid phases for which compositional data may provide essential constraints (e.g., Audétat and Pettke, 2003; Zajacz et al., 2008). In either case, the analysis of individual fluid inclusions belonging to the endmember compositions of coexisting immiscible fluids (e.g., vapour and brine, aqueous and carbonic fluids, aqueous fluids and silicate melt) can provide insight into element distribution and transport during progressive fluid evolution.

Post-entrapment modification of fluid inclusion contents can affect bulk density and/or composition (e.g., Sterner and Bodnar, 1989; Bakker and Jansen, 1991; Audétat and Günther, 1999; Bodnar, 2003). This is a serious problem as it often passes unrecognized. Evidence for post-entrapment modification of bulk composition may be obtained from diverse sources. Brine inclusions of boiling assemblages that homogenize via salt dissolution rather than via bubble disappearance have been argued to be the result of post-entrapment loss of water, leading to an increase in their bulk salinity (e.g., Audétat and Günther, 1999; Klemm et al., 2008; Rusk et al., 2008). Loss of hydrogen may increase $f_{\mathrm{O} 2}$, promoting the crystallization of hematite, sulphate and carbonate daughter crystals in brine inclusions and inhibiting redissolution of chalcopyrite daughter crystals during heating (Mavrogenes and Bodnar, 1994; Hanley et al., 2008). Diffusional exchange between fluid inclusions and later external fluids may occur in both directions, resulting in loss or gain of elements (e.g., Sterner and Bodnar, 1989; Bakker and Jansen, 1991; Li et al., 2009; see also Kamenetsky and Danyushevsky, 2005; Portnyagin et al., 2008; Zajacz et al., 2009). A detailed discussion of post-entrapment modifications in fluid inclusions is beyond the scope of this paper, and the reader is referred to the abundant literature both from experimental and natural investigations. Because the extent of post-entrapment modification of fluid inclusions is a priori unconstrained it is best practice to avoid inclusions that show signs of modification such as irregular shapes, decrepitation halos, or poorly reproducible microthermometric behaviour for homogeneously entrapped assemblages (Audétat and Günther, 1999), unless such secondary processes are to be investigated.

\section{Brief recapitulation of how to analyze fluid inclusions by LA-ICP-MS}

This short section addresses the basic principles of fluid inclusion analysis by LA-ICPMS reviewed in detail previously (Heinrich et al., 2003; Pettke, 2008). It shall serve as a basis for the following sections, where relevant aspects will be addressed in more detail. Note that procedures and instrument optimization strategies may differ for the various LA-ICP-MS setups used. Fluid inclusion analysis by LA-ICP-MS involves the following steps. The content of the inclusion is liberated by drilling it out of the host mineral, and the aerosol is transported 
247 to the ICP-MS where analyte signals are recorded as specified in the analytical routine

248 (measurement method). For laser ablation of quartz-hosted fluid inclusions, a relatively high

249 energy density of between 10 and $25 \mathrm{~J} / \mathrm{cm}^{2}$ on the sample surface is required. Laser pulse

250 repetition rates are commonly between 7 and $10 \mathrm{~Hz}$, and the laser beam has to be larger than

251 the largest diameter of the inclusion to ensure complete ablation. The aerosol is transported

252 out of the ablation chamber using $\mathrm{He}$ as carrier gas, then mixed with $\mathrm{Ar}$ gas and introduced to

253 the mass spectrometer. Aerosol particles are atomized and ionized in the inductively coupled

254 plasma, the ions are then extracted from the plasma and filtered according to their mass-to-

255 charge ratio and finally registered by the detector system of the mass spectrometer. This way,

256 a transient signal of 5 to 50 seconds duration is produced (Fig. 2).

257 Quadrupole and single-collector sector field mass spectrometers are typically employed

258 for element concentration analysis. The former allows for very fast mass jumping between

259 elements in a range from $\mathrm{Li}$ to $\mathrm{U}$, a real advantage for the analysis of fast transient signals

260 produced from fluid inclusions, and returns LODs as low as $0.01 \mathrm{\mu g} \mathrm{g}^{-1}$ for the best-detected

261 elements. Whereas between 5 and 20 elements are typically analyzed for average-size liquid

262 inclusions, this number reduces for smaller inclusions or vapour inclusions, because resulting

263 signals are shorter. For 20 elements at $10 \mathrm{~ms}$ typical dwell time and 3 ms quadrupole settling

264 time, a total analysis time of $260 \mathrm{~ms}$ results for a single sweep with all elements measured

265 once. Signal duration of about $5 \mathrm{~s}$ would result in 20 measurements per element; longer

266 signals correspondingly return more data. If it is desirable to optimize recordings for specific

267 elements, e.g., ore metals in fluid inclusions, the dwell time can be increased, resulting in

268 lower LODs (see below). However, this will increase sweep duration; hence, a compromise

269 between fast scanning protocols (at $10 \mathrm{~ms}$ dwell time) and improved LODs for selected

270 elements has to be defined for each analytical session.

271 Quantification of the measurements requires the analysis of external standard materials

272 bracketing the fluid inclusion measurements in order to determine instrumental sensitivities for

273 the elements of interest and to correct for machine drift. In addition, an internal standard

274 element is required, whose concentration in the inclusion has to be independently known.

275 Using such an element, the relative sensitivity factor between inclusion and external standard

276 analysis is determined for each inclusion analysis, allowing for calculation of absolute element

277 concentrations in individual inclusions.

278 All elemental data reported in this paper were produced using a GeoLas (Lambda

279 Physik, Germany) pulsed $193 \mathrm{~nm}$ ArF excimer laser system coupled with an ELAN ICP

280 quadrupole mass spectrometer (DRCe or 6100 DRC, Perkin Elmer, Canada), at operating

281 conditions similar to those reported in Pettke (2008). As many different analytical setups have

282 been explored, each having its characteristic features, it will be the task of the operator to

283 determine which setup will most likely provide best overall analytical performance for a

284 particular application. The reader is referred here to the literature (largely addressed in

285 Pettke, 2008). 


\section{Data and figures of merit}

Best practice in LA-ICP-MS analysis of fluid inclusions is to analyze a series of individual inclusions belonging to an assemblage, thus allowing for repetitive analysis of individual samples of a fluid of constant composition. This is identical to analyzing several spots on a homogeneous solid. Consequently, the fluid composition of a fluid inclusion assemblage is best characterized by the mean or median and external error (based on reproducibility) of data obtained on individually analyzed fluid inclusions (Tables 1, 2). This enables the most robust characterization of element compositions in the fluid at the time of entrapment. Provided that careful fluid inclusion petrography was performed to establish the relative age sequence of fluid inclusion assemblage entrapment, such data monitor fluid evolution in the system of interest.

Data and figures of merit are only useful when the statistical and instrumental parameters used are disclosed. Such parameters should include whether standard deviation or standard error of the mean was used (as is often hidden behind the commonly used symbol $\sigma$ ), LOD calculation criteria (see below), and laser beam size, pulse repetition rate and energy density on sample surface employed during analysis. To arrive at accurate fluid inclusion compositions we specifically advocate the practice of employing average data on several fluid inclusions from the same assemblage because individual inclusion analyses are prone to outliers such as those listed in Tables 1, 2, or observed for Au in inclusion 3 or 28 of Fig. 3. If the number of analyses available for characterization of a fluid inclusion assemblage is small, the median may offer a more robust estimate, as it is less prone to outliers. In any case, outliers can only be identified through multiple analyses on inclusion assemblages (see examples in Pettke et al., 2004). The detailed rationale has been published by Pettke (2008) and will be used throughout this review.

It can be rather difficult to reliably estimate the uncertainty of an individual inclusion analysis, because it is affected by the quality of fluid inclusion ablation, which is not easily quantifiable, and potentially suffers from non-representative recording of the fast transient signal. The signal quality from ablation of an individual fluid inclusion can vary enormously because inclusions can be of very different size, shape and bulk salinity; hence, the amount of analyte available from an individual inclusion varies over more than three orders of magnitude in common applications (see below). For low count rate analytes near their respective LODs, counting statistics are the dominant contribution to the total uncertainty and thus provide a relatively robust minimum estimate (values given for Au in Table 2). For high count rate analytes, more elaborate uncertainty estimates are required (e.g., Halter et al., 2002b; Guillong et al., 2008b). These return minimum values, too, because the uncertainty related to the process of fluid inclusion ablation cannot be quantified. robust assessment of analytical error for both element concentration and isotope ratio determinations in fluid inclusions, rather than estimates based on internal precision of 
individual analyses. The external precision can be determined on a series of individually measured, compositionally identical inclusions belonging to the same fluid inclusion assemblage. In the absence of systematic analytical error, this represents, strictly speaking, a maximum uncertainty estimate because it is based on the assumption that all averaged fluid inclusions were compositionally identical. Counting-uncertainty weighted averaging is preferred for low count rate analytes (see e.g., Pettke et al., 2004; Pettke, 2008; Table 2), while simple averaging can be appropriate for high count rate analytes. The average/mean plus standard deviation/error of a fluid inclusion assemblage (after statistical outlier rejection) thus defines most reliably the composition and associated uncertainty of a fluid stage. The data in Table 1 serve as an illustration for such an approach. Here, successively entrapped fluid inclusion assemblages record the temporal evolution of fluid chemistry, e.g., $\mathrm{Cu}$ precipitation recorded by 4 successively entrapped inclusion assemblages (Fig. 3).

Synthetic fluid inclusions were used to assess the accuracy of fluid inclusion LA-ICPMS analysis (see Günther et al., 1998; Heinrich et al., 2003; Allan et al. 2005; Seo et al., 2011). Heinrich et al. (2003) have demonstrated that neither absolute nor volume-normalized signal intensities have any direct relation to absolute element concentrations within individual fluid inclusions. Consequently, attempts to derive element concentration data without the use of internal standardization may not even provide the correct order of magnitude.

The accuracy of LA-ICP-MS element concentration data of chemically complex fluid inclusions, to date, is mainly limited by the uncertainty associated with an independent estimate of the concentration of an element appropriate for internal standardization. For Na-KCa-Cl dominated fluid inclusions, the empirical algorithm proposed by Heinrich et al. (2003) for correction of microthermometrically determined $\mathrm{NaCl}_{\text {equiv }}$ values for the presence of other cations is appropriate. Fluid inclusions dominated by other salts yield lower accuracy (Heinrich et al., 2003), because experimental data for such systems are lacking at present. Allan et al. (2005) suggested that data reduced using the approach of Heinrich et al. (2003) tend to overestimate concentration and that procedures based on charge balance may be beneficial for typical ionic solutions. This and the internal standardization based on microthermometrically determined $\mathrm{Cl}$ concentrations require the correct measurement of $\mathrm{Cl}$ in inclusions. Because $\mathrm{Cl}$ needs to be analyzed as $\mathrm{Cl}^{+}$, poor sensitivities result due to the high first positive ionization energy of $12.97 \mathrm{eV}$. This translates to low signal-to-background ratios, which confines the use of $\mathrm{Cl}$ as an internal standard to high salinity inclusions only. But even with this technique, other problems are inherent to $\mathrm{Cl}$-based fluid inclusion quantification that may severely limit its general applicability (Guillong et al., 2011). Our experience with synthetic and natural inclusions of (Na-K-Ca-Fe $\pm \mathrm{Mg} \pm \mathrm{Mn}) \mathrm{Cl}$ fluid compositions has shown that use of corrected $\mathrm{Na}$ concentrations generally returns more accurate data compared to $\mathrm{Cl}$ based quantification approaches. Finally, the analytical data cannot be more accurate than the element concentration data and homogeneity of the external standards used for quantification. This fact is especially important when dealing with "uncommon" elements, such 
as $\mathrm{Te}, \mathrm{Pd}$ or $\mathrm{Pt}$, for which accurate and widely applicable standard reference materials are needed for external analyte calibration (Spandler et al., 2011; Jochum et al., 2011).

It is important to appreciate that with controlled ablation and correct analysis of individual fluid inclusions external standardization alone returns accurate element concentration ratios. Moreover, if it can be assumed that major element concentrations do not significantly change across a series of successively entrapped fluid inclusion assemblages, measured variations in trace or ore element concentration ratios are correct in sense and magnitude, even without accurate internal standardization (Fig. 3B). This is often the case for single stage porphyry-type ore fluids that precipitate metals at high $\mathrm{T}$ over an extended period (for Cu-Au deposits: see $\mathrm{Na}, \mathrm{K}, \mathrm{Fe}, \mathrm{Mn}$ in Table 1; also, Ulrich et al., 2002; Rusk et al., 2004; Landtwing et al., 2005, 2010; Klemm et al., 2007; Kouzmanov et al., 2010; for Mo deposits: Klemm et al., 2008). For cases where microthermometry cannot return $\mathrm{NaCl}_{\text {equiv }}$ values for internal standardization, this may be the only useful approach to follow, e.g., for vapour inclusions (e.g., Landtwing et al., 2005) or for $\mathrm{CO}_{2}$ bearing inclusions that have no liquid $\mathrm{CO}_{2}$ stable at final clathrate dissolution (Diamond, 1992). The fundamental assumption behind this is that element sensitivity ratios do not vary between the LA-ICP-MS analysis of external standard and sample materials. This has been shown to be also true, at least within uncertainty, for synthetic fluid inclusion analysis when appropriate analytical procedures including robust plasma conditions (see below) were employed.

\section{Technical aspects of LA-ICP-MS fluid inclusion analysis}

The peculiar sample characteristics of fluid inclusions define the specific technical demands on the LA-ICP-MS systems and the procedures to be used for analysis. Below we address several reasons why LA-ICP-MS is currently the method of choice for fluid inclusion solute chemical and isotopic analysis. - Of foremost importance is the fact that LA-ICP-MS analyzes a volume rather than a surface; hence, the entire fluid inclusion content is available for analysis. This way, inclusions containing gas, liquid and crystals that separated after entrapment on cooling of the onephase fluid inclusion can be analyzed altogether to reconstitute its bulk composition (Fig. 1). Other microbeam techniques requiring solid material for analysis (e.g., EPMA) cannot be employed. SIMS does sputter away sample material, but the "drilling rate" is very slow. This and the strong matrix dependence of signal quantification are probably the main reasons why SIMS analysis of individual fluid inclusions so far has not exceeded the stage of reconnaissance study (Nambu and Sato, 1981; Diamond et al., 1991). - LA-ICP-MS has a key advantage, in that it allows independent optimization of two fundamentally different processes, (i) sample liberation by laser ablation and (ii) ion production, analyte filtering and signal recording in an ICP-MS. This is an enormous advantage over most other in-situ analytical techniques (e.g., SIMS or LIBS) where ion

401 production or light emission is directly related to sample ablation. This dual optimization 
potential opens the possibility of considerably reducing matrix effects on signal quantification as further outlined below.

Note, however, that not only the analyte of interest, but also the complete sample matrix is present during LA-ICP-MS analysis. Pre-extraction or concentration of the analyte as employed for precise isotope ratio determination by solution nebulisation ICP-MS or thermal ionization MS (TIMS) is not feasible. Consequently, issues such as element fractionation and matrix-dependent signal bias (addressed below) or matrix-related polyatomic interference problems (a fluid inclusion-specific discussion can be found in Pettke, 2008) need special attention.

Figure 2 illustrates the general principle of fluid inclusion laser ablation. The aim of ablation is to liberate the entire fluid inclusion content (avoiding any loss during ablation) and to produce a transient fluid inclusion signal that can be correctly recorded by the mass spectrometer used. While this is simple in principle, it is often difficult to achieve in practice. Importantly, the ablation quality of quartz varies significantly, sometimes even for a given sample, and it has so far not been possible to link this diverse behaviour to specific analytical parameters. Allan et al. (2005) also concluded that the errors in their fluid inclusion data most likely relate to the laser ablation sampling process. The following points should thus all be considered in order to obtain adequate results (Fig. 4A):

420 (i) The visible light optics of the system need to be as good as possible in transmitted light 421 mode, so that $10 \times 10 \times 5 \mu$ fluid inclusions within the sample can be clearly seen on a TV 422 monitor. A petrographic microscope is optimal.

423 (ii) The absorbance of the laser beam by the host mineral and the fluid inclusion phases depends on the laser wavelength and needs to be maximized to allow for well controlled drilling through the host mineral and ablation of the fluid inclusion content. For quartz, this is achieved by use of short-wave UV radiation (193-213 nm). When inclusions explode during the ablation process (i.e., open in an uncontrolled manner), an unconstrained fraction of the inclusion content is lost, rendering such an analysis useless (Fig. 4B). To date, commercially available $193 \mathrm{~nm}$ ArF excimer laser systems providing constant, high energy density across the entire ablation spot are achieving adequate control on the laser ablation process for quartz-hosted fluid inclusion analysis (see Pettke, 2008, and below). Successful applications of $213 \mathrm{~nm} \mathrm{Nd:YAG} \mathrm{laser} \mathrm{systems} \mathrm{for} \mathrm{fluid} \mathrm{inclusion} \mathrm{analysis} \mathrm{are} \mathrm{also} \mathrm{reported} \mathrm{in} \mathrm{the} \mathrm{literature,}$ notably for host minerals other than quartz (Scambelluri et al., 2001; Stoffell et al., 2004; Stoffell et al., 2008; Wilkinson et al., 2009; Berry et al., 2009).

(iii) The laser beam size needs to be adjustable in small steps in order to select a beam size that is slightly larger than the largest diameter of the inclusion. The final beam size needs to be larger than the inclusion to ensure complete ablation of the inclusion, but at the same time it should be kept as small as possible to maximize the contribution of the inclusion relative to the host to the mixed fluid inclusion plus host signal section (Fig. 2), thus minimizing the LOD

441 (iv) The ablation chamber has to accommodate the sample and reference material(s) and 

short washout times (1-3 seconds) as is beneficial for all LA-ICP-MS applications.

Laser ablation of an individual fluid inclusion, even when carried out ideally, produces transient signals of limited duration, that may vary unevenly over several orders of magnitude during a signal duration of typically 5 - 40 seconds (Fig. 4A), or, for elements concentrated in tiny daughter crystals, possibly even during much shorter intervals. Because the entire, heterogeneous inclusion is ablated, the entire signal needs to be integrated for quantification. Partial signal integration is not viable because it uses an unknown and thus nonrepresentative fraction of the entire polyphase sample (recall that we want to quantify the bulk inclusion content that was a single fluid phase at the time of entrapment). The length of the signal primarily depends on inclusion size and shape, on laser ablation conditions and on the aerosol transport system used. Note that even for apparently well-controlled fluid inclusion ablations (as visually judged on screen; e.g., analysis 26jjc08 in Table 2), a large fraction of some elements, $\mathrm{Au}$ in this case, may be lost, as is indicated by the measured $\mathrm{Au}$ concentration of below $0.035 \mu \mathrm{g} \mathrm{g}^{-1}$, significantly lower than the average Au content of 0.080 $\pm 0.020 \mu \mathrm{g} \mathrm{g}^{-1}$ of this fluid inclusion assemblage.

Among the several techniques applied for fluid inclusion analysis, two merit more detailed consideration, the step-wise opening technique (Günther et al., 1998; Allan et al., 2005) and the straight ablation technique (Pettke, 2008). A step-wise increase of laser beam diameter during fluid inclusion ablation considerably improves control on the ablation process for quartz-hosted inclusions (Günther et al., 1998), thus minimizing inclusion loss due to rupturing, but, unfortunately, has three serious drawbacks.

464 (i) Surface contamination, if present (and it often is, see illustrations in Pettke, 2008) cannot be properly separated from the inclusion signal. Such contamination can often not be removed even by most careful cleaning with organic solvents or inorganic acids prior to laser ablation analysis, because the polishing process generates a thin film $(<200 \mathrm{~nm})$ of likely amorphous material that consists of a mixture of sample material and contaminants (see also Marschall and Ludwig, 2004). Gangue quartz interspersed with soft ore minerals (e.g., native gold, chalcopyrite or molybdenite) is most susceptible to surface contamination. Pre-ablation cleaning with the laser beam is also not a viable option as such pre-ablation at large beam size may already induce fluid inclusion rupturing.

473 (ii) Every fluid inclusion has a confined mass that will be analyzed over a longer time interval

474 when using the step-wise opening procedure. This will return lower signal-to-background 475 intensity ratios that translate into elevated LODs when compared to straight ablation (see 476 below).

477 (iii) Very fast change of beam size is essential to maintaining high signal-to-background 478 ratios. A manually controlled crater size selection is thus optimal because commercially 479 available motorized aperture change systems are often too slow and/or have a rather limited 480 choice on beam diameters. An elegant, custom-made device for fluid inclusion ablation in 481 quartz minimizing breakout has been described by Guillong and Heinrich (2007b). They 
designed an iris diaphragm, allowing for fast and continuous increase of beam size from ca. 8 $\mu \mathrm{m}$ to the final beam size required for fluid inclusion ablation, either prior to opening the inclusion (resulting in straight ablation; see below) or during fluid inclusion ablation (corresponding to the stepwise ablation technique). An alternative technique, the so-called traverse opening method (Gagnon et al., 2003) enhances the influence of surface contamination (as with all scanning protocols that operate without pre-ablation) and does not provide for adequate control on the completeness of fluid inclusion ablation, resulting in reduced accuracy.

Straight ablation of fluid inclusions uses a beam size larger than the largest diameter of the inclusion for ablation, set prior to opening the inclusion (Fig. 4). This way, the potential for surface contamination is minimized and the signal to background ratio for the inclusion signal is maximized, thus returning lower LODs (Pettke, 2008). The benefits from stepwise opening regarding optimal control on the ablation process can still be maintained, if the laser beam can be enlarged in stepwise fashion to its final size before the fluid inclusion is hit (Fig. 4A); this technique strongly reduces the likelihood of fluid inclusion explosion during ablation. Here, it is even more important to have fastest possible beam size change (i.e., by manual control). We contend that this is currently best practice for the analysis of individual fluid inclusions.

Signal intensity versus time plots provide a reliable basis to judge the quality of laser ablation of a fluid inclusion. Ideally, the fluid inclusion content is liberated "layer by layer" as for solids. Because ideal fluid inclusions are isometric and given minimal signal "smearing" by the aerosol transport system, the resulting signal would be Gaussian-like as illustrated in Figure 4A. Importantly, the signal rise is slower than that observed at beam size change, and the signal decay is fast but also slower than that observed when the laser is switched off (too slow signal decay, i.e., pronounced signal "smearing", is to be avoided because it elevates LODs). Fast transient signal spikes that (rise and) decay as fast as the signal of the host mineral on beam shut-off are highly indicative of uncontrolled ablation (e.g., when the fluid inclusion has exploded; Fig. 4B). Because it cannot be determined what fraction of inclusion content may have been lost, such analyses may be seriously compromised.

Active focusing during fluid inclusion ablation when using the GeoLas ablation system maximizes the transport of fluid inclusion content to the ICP-MS. Because of fairly conical

513 beam shape (see Fig. 2 in Heinrich et al., 2003, for a sketch), material loss to the crater walls

514 is minimized; hence, problems arising from incomplete fluid inclusion sampling are minimized. Most likely, such an imaging system also minimizes depth-related element fractionation.

Aqueo-carbonic fluid inclusions (three-phase at room T) always show particularly short transient signals upon opening (Fig. 5; note the log scale on the intensity axis); hence, more

518 than $90 \%$ of the solute content is liberated during the first signal burst. This characteristic 519 signal pattern results from the internal overpressure in such inclusions at room temperature. 
down to the fluid inclusion, be absorbed there, heat the inclusion and thus further increase internal pressure to the bursting point at the time the inclusion is reached. Consequently, three-phase aqueo-carbonic fluid inclusions can only be analyzed for a limited number of elements (say, less than 10) to ensure representative recording of the initial fast transient signal peak that dominates the bulk solute signal (e.g., Klemm et al., 2004; Pettke et al., $2000 \mathrm{~b})$. How representatively these fast transient signals are actually recorded is again best evaluated on the basis of the distribution of results from a series of fluid inclusions belonging to a homogeneous assemblage.

Another important factor to consider is the suitability of fluid inclusions selected for LAICP-MS analysis. The following guidelines may be helpful.

531 (i) Optimum inclusion size is between 10 and $40 \mu \mathrm{m}$. Larger inclusions are generally not beneficial because it is often rather difficult to analyze them at controlled ablation conditions due to more frequent quartz break out at larger beam sizes.

534 (ii) Inclusions need to be located at an optimum depth beneath the sample surface. The larger the inclusion, the larger is its optimum depth for analysis. A $10 \mu \mathrm{m}$ sized inclusion is ideally located ca. $20 \mu \mathrm{m}$ below surface, a $40 \mu \mathrm{m}$ sized inclusion about $50 \mu \mathrm{m}$; shallow inclusions such as preferred for RAMAN or microthermometric analysis are not suitable. For deepseated inclusions, the potential for surface contamination is minimized because the inclusion can be ablated using the straight ablation technique. Moreover, the likelihood for inclusion explosion is reduced for deeper inclusions. In case the inclusions are buried too deeply, however, signal tailing occurs, which increases LODs. Deep-seated inclusions also bear the dangers of incomplete sampling of the fluid inclusion contents and of element fractionation induced by deep laser drilling (see Guillong et al., 2011). (iii) Inclusions need to be well isolated from each other, so that an individual inclusion can be drilled out without connecting to neighbouring inclusions (see Pettke, 2008). While the best currently available laser systems allow for excellent spatial resolution of the laser ablation process, stray light may modify the gas speciation in adjacent inclusions (Lambrecht et al., 2008), which may prevent their use for further petrological investigation. (iv) Optimum fluid inclusions are spherical, given that cylindrical inclusions at optimal orientation do not exist. Such inclusions provide the largest possible mass of material available per unit time, i.e., maximized signal to background intensity ratios for inclusion solutes, because these are least diluted by co-ablated host mineral material. This translates to higher sensitivities and thus lower LODs, notably for inclusions hosted by minerals that contain significant amounts of trace elements in common with the inclusion (compare Halter

555 et al., 2002b).

556 (v) The amounts of solutes available for analysis are of importance, as they do not necessarily correlate with the size of the fluid inclusion. For example, a $30 \mu \mathrm{m}$ vapour

558 inclusion (e.g., $0.1 \mathrm{~g} / \mathrm{cm}^{3}$ density) has one order of magnitude less solutes by mass than a 559 high density inclusion of the same size $\left(1.0 \mathrm{~g} / \mathrm{cm}^{3}\right)$. Given that the ablation speed of a fluid 560 inclusion is largely controlled by the host mineral ablation rates, high density inclusions return 
higher sensitivities and thus lower LODs, for this specific example up to one order of magnitude. Less dense vapour inclusions correspondingly yield even higher LODs. (vi) Minimum thickness of the sample section is about $100 \mu \mathrm{m}$, preferably thicker (transmitted light inspection permitting). If inclusions are too close to the lower surface of the section, they may simply rupture through the lower surface during ablation. Moreover, for quartz hosts, a significant fraction of light, even when using $193 \mathrm{~nm}$ lasers, penetrates a $100 \mu \mathrm{m}$ thick quartz section and thus can interact with the glue beneath or even the section support glass (because of the high energy density required for controlled ablation of some quartz types). This may add unrelated material to the fluid inclusion signal, or melting of glue may obscure real-time observations that are important for assessment of ablation quality.

We emphasize that selection of ideal fluid inclusion material likely accounts for $>50 \%$ of the success of a LA-ICP-MS fluid inclusion investigation. Petrographic inspection of a large selection of fluid inclusion samples to choose the best material available for analysis is

574 therefore highly rewarding.

\section{Element concentration analysis by single-collector ICP-MS}

Multi-element analysis of an individual fluid inclusion aims at returning significant concentration data for as many elements as possible from the short transient signal as introduced above. Therefore, in principle, all the sample solutes reaching the ICP should be completely converted to single-charged cations, and these ions should all be recorded by the mass spectrometer. This cannot be achieved, however, since different masses have to be measured sequentially and because of limitations in transmission of the instruments. It is therefore a challenge for the analyst to optimize the ICP-MS instrumental part in such a fashion that the cations recorded by the detector are representative for the bulk composition of the fluid inclusion analyzed. This may sound simple, but is far from trivial.

The function of the ICP is to break down the aerosol particles resulting from laser ablation to atoms and to ionize these. In practice, most recent research has demonstrated that this is currently a weak point in LA-ICP-MS analysis in general (e.g., Günther and Hattendorf, 2005). Most well known in LA-ICP-MS are problems collectively referred to as elemental fractionation, i.e., variations in element-specific sensitivities resulting from variable LA-ICP-MS analytical conditions (e.g., Fryer et al., 1995; and countless subsequent publications). Elemental fractionation has historically been assigned to processes occurring at the laser ablation site (e.g., Fryer et al., 1995; Mank and Mason, 1999). However, it has

593 become more and more apparent that plasma processes are equally relevant for elemental

594 fractionation (e.g., Guillong and Günther, 2002). This insight has encouraged Günther and 595 Hattendorf (2005) to establish optimization criteria for "robust plasma conditions"; i.e.,

596 conditions where ion production in the ICP is uniform and as complete as possible. At such 597 conditions, fractionation effects resulting from incomplete ionization are minimized. Pettke

598 (2006) has provided a detailed summary of criteria relevant to the analysis of polyphase 
inclusions aimed at minimizing matrix-dependence related to external calibration. Following such recommendations, use of well characterized external standard materials (SRM) for

601 quantification, such as the SRM 610 and 612 glasses from NIST, can return accurate fluid

602 inclusion element concentration data for most elements. It has become clear, however, that the type of aerosol produced at the laser ablation site is also extremely important. An ideal

604 aerosol would be chemically uniform, of $<10 \mathrm{~nm}$ grain size and of narrow size distribution

605 such that it can become quantitatively atomized and ionized in a plasma source. Aerosols of very broad size distribution (up to $1 \mu \mathrm{m}$ ) with particles having size-dependent chemical composition (most recently Glaus et al., 2010) are unlikely to be completely ionized even in a perfectly optimized ICP, considerably reducing analytical accuracy.

Single collector mass spectrometers with quadrupole mass filters are currently preferred for fluid inclusion multi-element analysis because they allow for the fastest highsensitivity measurement over a range from $\mathrm{Li}$ to $\mathrm{U}$. The ion extraction systems of common quadrupole mass spectrometers are designed to measure positive ions. However, singlecollector instruments suffer from one serious drawback, namely that during the recording of a particular isotope, all other isotopes pass the system unrecorded. The more isotopes are to be measured, the lower is thus the duty cycle for a given isotope, i.e., the fraction of the entire signal time spent for measuring a given isotope. Representative recording of fast transient signals is thus critical, and various aspects relevant to the design of appropriate data recording protocols have been discussed in detail in Pettke (2008). This discussion also dealt with the so-called jump routine, in which the isotope of an element such as Au that is

620 especially prone to form micro-nuggets in fluid inclusions, is measured every other integration cycle in a sweep. However, tests have since revealed that Perkin Elmer Elan mass spectrometers when operated in "jump routine" mode actually measure the isotopes specified in the analytical method strictly in mass-ascending order, failing to properly implement the jump routine. Worse still, the data readout then reports the data as defined in the analytical method and not in the sequence actually recorded during measurement. Therefore, the jump routine results as reported in Pettke (2008) actually correspond to data recorded by an extended dwell time routine (see below). This specific example can be taken as a warning that the analyst cannot be careful enough during procedure optimization and that instrument functionality needs to be continuously evaluated, in particular, when non-disclosure of the source code for instrument control prevents the user from properly verifying such functionality.

To our knowledge, there is only one comprehensive data reduction software for fluid inclusion analysis available to date, named SILLS (Guillong et al., 2008b;

$633 \mathrm{http}: / / \mathrm{www}$.geopetro.ethz.ch/research/orefluids/software). This user-friendly package allows

634 the reduction of transient LA-ICP-MS data for inclusions and homogeneous solids alike,

635 based on procedures and equations taken from Longerich et al (1996), Halter et al. (2002b),

636 Heinrich et al. (2003) and Allan et al. (2005) that are fully exposed. Other software that is in use for inclusion data reduction is AMS (Mutchler et al., 2008; 
http://www.geochem.geos.vt.edu/fluids/laicpms/ams.shtml) and Exlam2000, available at no cost (Zacharias and Wilkinson, 2007).

Data reduction follows a stepwise procedure that includes a correction for host mineral contributions on background-corrected signal intensities, followed by calculation of apparent element concentrations based on the external standard used. The intermediate results are then converted to fluid inclusion element concentrations by using an internal standard, e.g., $\mathrm{Na}$ from microthermometrically determined $\mathrm{NaCl}_{\text {equiv }}$ concentrations corrected for the presence of other major salt cations. Finally, each calculated element concentration is compared to its analysis-specific "LOD". This procedure is described in detail in Heinrich et al. (2003; summarized in their Fig. 10) and is based on the relationship (Longerich et al., 1996)

$$
\begin{aligned}
\mathrm{C}_{\mathrm{i}}(\text { sam }) / \mathrm{C}_{\mathrm{IS}}(\text { sam })= & \mathrm{C}_{\mathrm{i}}(\text { std }) / \mathrm{C}_{\mathrm{IS}}(\mathrm{std}){ }^{*} \\
& \left(\mathrm{I}_{\mathrm{i}}(\mathrm{sam}){ }^{*} \mathrm{I}_{\mathrm{IS}}(\mathrm{std})\right) /\left(\mathrm{I}_{\mathrm{IS}}(\mathrm{sam}){ }^{*} \mathrm{I}_{\mathrm{i}}(\mathrm{std})\right) / \\
& \left(\mathrm{S}_{\mathrm{i}}(\mathrm{sam}){ }^{*} \mathrm{~S}_{\mathrm{IS}}(\mathrm{std})\right) /\left(\mathrm{S}_{\mathrm{IS}}(\mathrm{sam}){ }^{*} \mathrm{~S}_{\mathrm{i}}(\mathrm{std})\right)
\end{aligned}
$$

where $\mathrm{C}$ is the concentration of the subscripted element $\mathrm{i}$ or internal standard element IS in the materials referred to in brackets (sam is sample, std is external standard material), I refers to the background-corrected intensities (count rate in counts per second, cps) and $\mathrm{S}$ denotes sensitivity (in cps per $\mu \mathrm{g}$ analyte per gram of material). The sensitivity ratios $S_{x}(\operatorname{sam}) / S_{x}($ std) are taken to be identical for all elements including the IS element, given robust ICP-MS optimization. Therefore, although $S_{x}(s a m) / S_{x}(s t d)$ is unknown, the sensitivity terms cancel, and the concentrations of all elements in the sample $\left(C_{i}\right)$ can be calculated when $C_{I S}(s a m)$ and the concentrations of all elements in the external standard $\left(C_{i}(s t d)\right)$ are known. In other words, the internal standard constraint is required to define the analysis-specific relative sensitivity factor (one factor for all analytes per analysis) by which the sensitivities determined on the external standard material are converted to those obtained during a given sample analysis. In the general case, this can be achieved either through independent knowledge of an element concentration in the sample ( $\mathrm{Na}$ from microthermometry for fluid inclusions) or by adjustment of the sum of all analyzed cations, e.g., for silicates or melt inclusions to $100 \mathrm{wt} \%$ element oxide minus those not analyzed (Leach and Hieftje, 2000; Halter et al., 2002b).

Evaluation criteria regarding the detection limit of an element, i.e., its presence or absence in a given analysis, have to be calculated for each element in every inclusion individually. One needs to be aware of the fact, however, that many different (and inconsistent) "definitions" for "detection limit" do exist in LA-ICP-MS. One often cited approach in LA-ICP-MS is that of Longerich et al. (1996), who defined "LOD" as three times the

671 calculated (expected) standard deviation of baseline corrected readings in the absence of the analyte of interest:

$$
\text { "LOD }{ }_{i} "\left(\mu g g^{-1}\right)=3^{*} \operatorname{stdev} \mathrm{l}_{\mathrm{i}}(\mathrm{bkg}) *(1 / \mathrm{N}(\mathrm{bkg})+1 / \mathrm{N}(\mathrm{an}))^{0.5} / \mathrm{S}_{\mathrm{i}}
$$

674 where stdev $\mathrm{l}_{\mathrm{i}}(\mathrm{bkg})$ stands for the precisely known standard deviation of the background count 
analysis-specific as derived from the external standard multiplied by the relative sensitivity factor), and $\mathrm{N}$ refers to the number of measurements (i.e., sweeps) integrated for the background and analyte (an) signal intervals, respectively. The above example returns the element concentration threshold value above which measured element concentrations are deemed to be resolved from background at the $99.9 \%$ confidence level as selected by the factor 3 (note that this is a one-sided interval of the distribution function; Currie, 1995). However, equation 2 returns an LOD value of zero for zero counts in the background interval, which is not sensible.

In the case that $5 \%$ of wrong positive detections are accepted (i.e., having detected something although nothing is present, corresponding to $95 \%$ confidence), the factor in equation 2 would reduce from 3 to 1.645. It is important to note that such confidence levels as specified here only apply for normally distributed background readings.

Following IUPAC terminology (Currie, 1995) "LOD" as defined above in equation 2, however, would translate to "critical value" or "critical level" $\left(\mathrm{L}_{C}\right)$, representing the minimum significant value of an estimated net concentration. The "detection limit" or "minimum detectable value" $\left(L_{D}\right)$ as defined by IUPAC (Currie, 1995) is the true background corrected mean signal or concentration value of a sample required to yield measurement data, for which the probability to fall below $L_{c}$ equals a specified value, e.g., $5 \%$ (corresponding to the probability of false negative detections, i.e., of having nothing detected although something is present). Assuming that $L_{C}$ and $L_{D}$ are both based on the same probability level of wrong detection or rejection and that the variance of normally distributed measurements between $\mathrm{L}$

$697=0$ and $L=L_{D}$ is constant, $L_{D}=2{ }^{*} L_{C}$. For this case, $L_{C}$ is calculated according to equation (2), using a numerical factor appropriate for the desired probability level (from the one-sided tail of the normal distribution function).

For very low count rates as obtained in modern ICP-MS instruments, Poisson rather than normal distribution statistics should be applied for estimation of $L_{C}$ and $L_{D}$. Useful approximations for these parameters are given by Currie $(1968,1995$; see also Tanner and Günther, 2009; Tanner, 2010):

$$
\mathrm{L}_{\mathrm{C}}=1.645{ }^{*} \sigma_{0} \text {, and } \mathrm{L}_{\mathrm{D}}=3.29{ }^{*} \sigma_{0}+2.71\left(=2 * \mathrm{~L}_{\mathrm{C}}+2.71\right)
$$

where $L_{C}$ and $L_{D}$ are given in terms of the sums of background corrected counts acquired over the interval of analyte signal measurement. $\sigma_{0}$ is the standard deviation of this sum as expected for a measurement with zero analyte (see equation 4 below). Note that the numerical coefficients 1.645 and $2.71=1.645^{2}$ relate to $5 \%$ probabilities of false positive $\left(L_{C}\right)$ and false negative $\left(L_{D}\right)$ detections as derived from normal distribution statistics. In the current

711 require use of coefficients taken from the Poisson distribution function (see Currie, 1968,

712 Tanner, 2010). 
$\sigma_{0}$ depends on the background count rate and the actual times spent on counting the background and analyte sections of the signal. If $R_{b k g}$ is the (precisely known) mean background count rate given in cps, $\mathrm{N}_{\mathrm{bkg}}$ and $\mathrm{N}_{\mathrm{an}}$ are the number of sweeps for the background and analyte integration sections, and DT is the dwell time (measurement duration per sweep for a given isotope, in s) used for recording element $i$, then the variance of the baseline-corrected (net) signal counts expected for a sample with zero analyte is

$$
\sigma_{0}^{2} \text { (in counts) }=R_{\mathrm{bkg}}{ }^{*} D T{ }^{*} N_{\mathrm{an}}\left(1+\mathrm{N}_{\mathrm{an}} / \mathrm{N}_{\mathrm{bkg}}\right)
$$

The detection limit $L_{D}$ as expressed by equation (3) can be converted to $\mu g g^{-1}$ as required for LA-ICP-MS:

$$
\left.L_{D, i}\left(\mu g^{-1}\right)=L_{D, i} \text { (in counts }\right) /\left(N_{a n}{ }^{*} D_{T}{ }^{*} S_{i}\right)
$$

Division by $N_{a n}{ }^{*} D T_{i}$ is required to convert counts into mean cps for the length of integration of the net analyte signal. Division by $S_{i}$ transposes $L_{D}$ given in cps into $L_{D}$ expressed in $\mathrm{Mg} \mathrm{g}^{-1}$. The complete LOD equation for general LA-ICP-MS analysis of element $\mathrm{I}$ at $95 \%$ confidence then reads

$$
L_{D, i}\left(\mu g g^{-1}\right)=\left(3.29 \text { * }\left(R_{b k g, i}{ }^{*} D T_{i}{ }^{*} N_{a n}{ }^{*}\left(1+N_{a n} / N_{b k g}\right)\right)^{0.5}+2.71\right) /\left(N_{a n}{ }^{*} D T_{i}{ }^{*} S_{i}\right)
$$

A numerical comparison of results calculated for $L_{C}$ (critical limit at $99.9 \%$ confidence, analogous to "LOD" in equation 2) and $L_{D}$ (detection limit, 95\% confidence, corresponding to equation 6) demonstrates that the former yields lower values for low count signals (Fig. 6), for short analyte signals by a factor of two or more (Fig. 7; keeping stdev(bkg), N(bkg), S and DT constant). For low count rates and longer signals, values based on $L_{C}$ at $99.9 \%$ confidence are lower by $20 \%$ only, for higher count rate background signals, the results are similar. Note that different confidence levels are compared in Figs. 6 and 7, owing to the conventional use of $3 \sigma$ in equation 2 to quantify the LOD in LA-ICP-MS analysis.

Figure 8 illustrates the LODs for Au calculated for a series of natural brine inclusions (Table 2; Fig. 3). This example represents the combined effects of analyte dwell time, variation of the background signal, fluid inclusion size and shape, fluid inclusion signal duration and analyte sensitivity that grossly vary for a series of natural fluid inclusion analyses. Recall that all parameters except dwell time and the background measurement are mutually dependent on each other. Nevertheless, the general trend persists that "LODs"

742 calculated using equation 2 are lower (because $L_{D} \geq 2{ }^{*} L_{C}$ according to statistical

743 expectation), more so for short fluid inclusion signals. This example illustrates that for fast

744 transient signals, too, the "LOD" formulation by Longerich et al. (1996) returns lower values,

745 as documented for constant background above (Fig. 7).

This evaluation further illustrates that different LOD criteria can be, and often are, employed (e.g., $L_{C}$ or $L_{D}, 84 \%, 98 \%$ or $99.9 \%$ confidence regions for $\sigma$ multipliers of 1,2 or

748 3), returning "LOD" values that may vary over more than one order of magnitude for a given 
The above considerations allow to identify parameters relevant in lowering LODs in fluid inclusion analysis. Note that lowering LODs also significantly improves the precision of low-abundance element concentration determinations. Recall that the LODs are strongly element-dependent because the analyzed isotopes are variably abundant in nature and because instrument sensitivities vary strongly for different elements.

Given that element intensities are expressed as count rates (i.e., cps) to accommodate variable dwell times, and because short dwell times, commonly $10 \mathrm{~ms}$, are preferred for representative recording of short transient inclusion signals in multi-element mode (Pettke et al., 2000b), analytical uncertainties for low-intensity signals are inevitably high. For constant numbers of background and analyte signal sweeps, $L_{D}$ approximately scales with the inverse of the square root of DT (see equation 6). Consequently, increasing selectively the dwell times for a given element will translate into a lower $L_{D}$. Such an extended dwell time routine does not only improve on $L_{D}$, but also increases the likelihood of representative recording of element signals that are prone to originate from micronuggets in the sample (e.g., Au in many fluid inclusions; see also Fig. 1B). Also note that an optimal recording of the analyte signal to be used for internal standardization is mandatory because inaccuracies of the measurement of the internal standard element directly transfer to all other "unknown" element concentrations.

The sensitivity term $S_{i}$ is obviously such that increasing sensitivity and keeping all else constant decreases LODs. The most important procedures to enhance sensitivity in LA-ICPMS are to increase the amount of ablated and transported material per unit time (namely by increasing the laser beam diameter, the repetition rate and/or the laser energy). If this is not possible, e.g., for the analysis of inclusions of an a priori limited sample volume, other methods have been described, e.g., the use of $\mathrm{He}$ in the ablation chamber (e.g., Eggins et al., 1998; Günther and Heinrich, 1999), the reduction of the interface pressure (Günther et al., $1997,1998)$ and/or the addition of specific gases to the aerosol carrier gas, e.g., $\mathrm{H}_{2}$ when using Elan ICP-MS instruments (Guillong and Heinrich, 2007a). Not only the analyte signals but also the gas backgrounds are variably affected by the above modifications (compare the background signal for ${ }^{29} \mathrm{Si}$ in Fig. 4 run with $\mathrm{H}_{2}$ admixture and Fig. 5 without $\mathrm{H}_{2}$ ). The sum of these effects will determine whether an improvement in signal-to-noise ratio can be achieved with a given LA-ICP-MS instrumental setup, potentially lowering the LODs significantly and improving the external reproducibility of ultra-trace concentration measurements.

For a given fluid inclusion ablation, Fig. 9 illustrates the effect of the choice of the length of signal intervals, each indicated by the black arrows, on the resulting LODs (Fig. 9A). The resulting "LOD"s calculated by equation $2\left(\mathrm{~L}_{C}, 99.9 \%\right.$ confidence) and equation $6\left(\mathrm{~L}_{\mathrm{D}}, 95\right.$ $\%$ confidence) are expressed as the ratios of $L_{C}$ (equation 2$) / L_{D}$ (equation 6 ) for the different 786 signal durations (Fig. 9B). Note that different confidence levels are again compared in Fig. 9 787 on purpose, in tune with conventional use. Each of these sample signal intervals returns 
different sample and internal standard sensitivities as determined from the combined inclusion plus host signal ( $\mathrm{S}_{\mathrm{i}}(\mathrm{sam})$ and $\mathrm{S}_{\mathrm{IS}}(\mathrm{sam})$ ), resulting in different LODs. Because the analyte concentration within an inclusion is constant, calculated sensitivities are thus proportional to count rate, yielding LODs which are then inversely proportional to count rate. For high background count rates (e.g., $\mathrm{Na}$ ) the LOD is very similar between the two equations (ratios 1) independent of the signal duration. For low background count rates $(\mathrm{Pb}=0.3 \mathrm{cps} ; \mathrm{Au}=$ $0.006 \mathrm{cps} ; \mathrm{Ba}=0 \mathrm{cps}$ ), equation 6 always returns higher LODs. Moreover, when decreasing the signal interval duration, the ratio of LODs decreases, indicating a similar behaviour as found for constant signals (Fig. 7). Note that for $\mathrm{Ba}$, the ratio of LOD values is always zero because of the zero LOD value returned by equation 2 .

Integrating only the high-intensity part of the entire transient fluid inclusion signal for minimizing the LODs is extremely dangerous, because cutting at the low-intensity wings of the transient $\mathrm{Na}$ signal (commonly used to defining the fluid inclusion signal interval) may cause loss of large fractions of other analyte signals (notably from tiny daughter crystals; Fig. 1B) that may sit on the inclusion bottom and thus be ablated very late during fluid inclusion ablation. Careful inspection of all the analyte signals is thus mandatory for proper signal interval selection. These considerations illustrate why fluid inclusions returning a "Gaussianlike" signal shape of limited dispersion and without significant signal tailing are considered ideal, yielding minimized LODs.

Because the amount of solutes available for analysis is highly variable between individual fluid inclusions from a given assemblage, tabulated element concentration data are lower for some inclusions than the LODs of the same element for other inclusions. This

811 variation has significant consequences:

812 (i) For the analysis of low fluid metal contents, measurements on a limited number of 813 inclusions with a large amount of solutes at optimum size, shape and depth in the host mineral are much more important for a reliable determination than measurements on nerous small inclusions.

816 (ii) Because the quality of an individual fluid inclusion analysis strongly depends on inclusion 817 size, shape and depth in host mineral, element concentrations of a fluid inclusion assemblage 818 are best determined as uncertainty-weighted average data (Pettke, 2006). This way, element concentration data from well analyzed, large fluid inclusions are more significant in determining the average, the effect of which often is that uncertainty-weighted element concentration averages tend to be lower when compared to simple averages (e.g., Pettke et al., 2004).

There are cases where independent determination of an element concentration within the fluid inclusion as required for internal standardization is not possible. Such cases are encountered for example in microthermometry of $\mathrm{CO}_{2}$ bearing fluid inclusions that do not contain liquid $\mathrm{CO}_{2}$ at final $\mathrm{CO}_{2}$ clathrate hydrate dissolution (Diamond, 1992) or fluid inclusions where ionic species do not predominate. In the latter case, mass balance 
constraints have been employed to estimate an element concentration to be used for internal standardization (e.g., Scambelluri et al., 2004; Spandler et al., 2007), or the results were simply given as concentrations of the inclusion plus host mineral mixture (at unknown mixing proportions that vary between different analyses), in an attempt to approximate fluid compositions (Ferrando et al., 2009). Some applications, however, may only require element abundance ratios to constrain the processes of interest, e.g., ore metal precipitation across a sequence of successively entrapped fluid inclusion assemblages. Note that element abundance ratios do not depend on internal standardization. Landtwing et al. $(2005,2010)$ used $\mathrm{Cu} / \mathrm{Na}$ abundance ratios for vapour inclusions (where the tiny film of liquid was insufficient for reliable microthermometry) to demonstrate that a two orders of magnitude concentration decrease of $\mathrm{Cu}$ in the brines during $\mathrm{Cu}$ ore deposition is also reflected by the associated vapour inclusions. Klemm et al. (2008) used scatterplots of $\mathrm{Cs} /(\mathrm{Na}+\mathrm{K}+\mathrm{Mn}+\mathrm{Fe})$ vs. $\mathrm{Mo} /(\mathrm{Na}+\mathrm{K}+\mathrm{Mn}+\mathrm{Fe})$ to define two Mo-bearing fluid stages with different $\mathrm{Cs}$ contents, indicative of two isolated events of fluid expulsion from progressively fractionating source magma. Rather than normalizing the metal content to Na only, the sum of major cations was used because their concentration remained largely constant across ore mineral precipitation (see also Fig. 3B). These examples emphasize the usefulness of element abundance ratios in fluid inclusions that can be accurately determined for host mineral corrected data by use of external standardization only.

Finally, we like to emphasize that accurate fluid inclusion data can only be obtained when the mixed inclusion plus host mineral signal is accurately corrected for host mineral contribution. While for quartz-hosted inclusions, such a correction may not be significant for many elements, results for $\mathrm{Li}, \mathrm{Ti}, \mathrm{Al}, \mathrm{B}, \mathrm{Ga}$ and $\mathrm{Sn}$ will be in excess without correction for host quartz contribution (e.g., Flem et al., 2002; Landtwing and Pettke, 2005; Allan et al., 2007; Rusk et al., 2011). Obviously, other elements too require correction when inclusions are hosted in other minerals, by techniques that are identical to those outlined in detail for melt inclusions by Halter et al. (2002b). Attempts to quantify fluid element concentrations without correction for host mineral contribution may not even provide a correct magnitude.

\section{Selected applications and recent developments}

857 The application-driven LA-ICP-MS fluid inclusion analytical developments have largely been 858 based on materials from magmatic-hydrothermal (porphyry-type) ore deposits, resulting in 859 more than 50 publications to date. These will not be comprehensively reviewed here, and the 860 reader is referred to the corresponding literature. More recently, applications have diverged 861 towards the quantification of specific elements (e.g., S; Guillong et al, 2008a; Seo et al., 2009, 862 2011) or other hydrothermal systems (e.g., Klemm et al., 2004; Beuchat et al., 2004; Kostova 863 et al., 2004; Luders et al., 2005; Piqué et al., 2008; Stoffell et al., 2008; Heijlen et al., 2008; 864 Bertelli et al., 2009; Su et al., 2009; Williams et al., 2010; Richard et al., 2010; Catchpole et 865 al., 2011; Appold and Wenz, 2011). Most recently, the analysis of sulphur, chlorine and 
bromine in quartz-hosted fluid inclusions by LA-ICP-MS has been investigated in detail (Seo et al., 2011; Guillong et al., 2008a). Halogens are difficult to measure and quantify by ICPMS. They need to be analyzed as positive ions, with comparatively large first ionization potentials, thus returning elevated LODs due to low sensitivity, notably for $\mathrm{Cl}$. Moreover, as for $\mathrm{S}$, the absence of a reliable silicate glass SRM, potential contamination from tubing and/or the ablation cell at variable and occasionally high levels during background and ablation intervals, and polyatomic interferences all may compromise accuracy (Guillong et al., 2008a). A well characterized scapolite crystal $\left(\mathrm{Na}_{4} \mathrm{Al}_{3} \mathrm{Si}_{9} \mathrm{O}_{24} \mathrm{Cl}-\mathrm{Ca}_{4} \mathrm{Al}_{6} \mathrm{Si}_{6} \mathrm{O}_{24} \mathrm{SO}_{4}\right)$ can be used as a reference material, and the ablation cell needs to be carefully cleaned before analysis (Seo et al., 2011). Synthetic fluid inclusions were used to determine analytical figures of merit such as precision (1SD; S: 15-44 \%, Cl: 7-20 \%, Br: 12-26 \%), accuracy and LODs (in $\mu \mathrm{g} / \mathrm{g}$ employing equation 2; S: $60, \mathrm{Cl}: 250, \mathrm{Br}: 15)$ of the method. In natural brine inclusion assemblages the precision of $\mathrm{Br} / \mathrm{Cl}$ ratios (4- $9 \% 1 \mathrm{SD}$ ) was found to be adequate to determine the source of salinity in different ore-forming fluids. All the above contributions dealt with fluid inclusions hosted in various minerals transparent to visible light.

LA-ICP-MS can also be used to analyze fluid inclusions hosted in opaque minerals, with Kouzmanov et al. (2010) reporting a first application. Near-infrared microscopy was used to locate fluid inclusions in pyrite and enargite, and combined transmitted and reflected light was then employed to map the fluid inclusions relative to the surface features observed in reflected light mode. Inclusions were then ablated in reflected light mode by positioning the ablation spot according to the mapped positions. Solutes in the fluid inclusion assemblages successively entrapped in quartz and pyrite-enargite showed evolving concentrations, interpreted to result from successive pulses of compositionally distinct fluid passing through the ore body. Such an approach allows the analysis of metals in individual fluid inclusions hosted in the ore minerals of interest and produces the data needed to assess the general validity of the assumption (though often supported by robust petrographic evidence) that quartz-hosted fluid inclusions do represent trapped ore-forming fluid. While the latter most likely applies to porphyry-type ore deposits, evidence has been presented, for example for orogenic Au deposits (Pettke and Frei, 1996) and MVT deposits (Stoffell et al., 2008; Wilkinson et al., 2009), that mineralization may involve highly transient episodes of ore-metal rich fluid ingress in the much longer-lived hydrothermal activity of an ore deposit. Clearly, further investigations are required to clarify this important issue.

\section{Experimental investigations of fluids at high pressure and temperature}

Synthetic fluid inclusions are employed in experimental efforts to quantify element mobility and speciation in magmatic-hydrothermal fluids as a function of pressuretemperature-composition (PTX). Such studies were historically confined to the one-phase

902 fluid field (i.e., vapour, brine, or supercritical fluid) at temperatures and pressures of no more 903 than a few hundred MPa (e.g., Chou and Eugster, 1977; Candela and Holland, 1984; Whitney 
( $<\sim 5 \mathrm{wt} . \% \mathrm{NaCl}_{\text {equiv }}$ ), the quenched fluid is extracted from the charge and analyzed at ambient conditions, and it is either demonstrated or simply assumed that the solute load of the quenched fluid is equivalent to the solute load at the experimental PTX conditions, i.e., that no solutes precipitated upon quench. Precipitation upon quench has been demonstrated to occur at higher pressures, resulting in an underestimation of the solute's elemental concentration (Green, 1973) unless the fluid can be extracted from the autoclave at run P and T conditions (e.g., Bourcier and Barnes, 1987; Seyfried et al., 1987). To experimentally determine the solute load of aqueous fluids at higher pressures or of fluids of higher salinity, experiments have been performed in an aqueous fluid \pm melt \pm crystal(s) system, and the solute composition of the single-phase aqueous fluid has been determined by mass difference between initial and final crystal or melt (e.g., Anderson and Burnham, 1965; Manning, 1994; Manning and Boetcher, 1994; Newton and Manning, 2000; Newton and Manning, 2002). This method can yield accurate mineral solubilities owing to the ability to quantify masses with $1 \sigma$ reproducibility down to $0.002 \mathrm{mg}$ (Newton and Manning, 2000). However, quench-induced crystallization of the melt, in charges where only melt and aqueous fluid co-existed, or dissolution-reprecipitation processes along thermal gradients within the charges during run introduce uncertainty in quantifying melt chemistry and, thus, affect the accuracy of mass balance calculations required to quantify fluid element solubilities. The mass balance technique also precludes the ability to investigate element mobility in assemblages that are saturated with immiscible $\mathrm{C}-\mathrm{O}-\mathrm{H}-\mathrm{S}$ fluids, e.g., vapour and brine.

Over the past decades, experimentalists have increasingly turned to the method of synthetic fluid inclusions to study fluids at pressures and temperatures relevant to the evolution of magmatic-hydrothermal systems (e.g., Sterner and Bodnar, 1984; Bodnar and Sterner, 1985, 1987; Bodnar et al., 1985; Diamond, 1992). Synthetic fluid inclusions can be produced at run PT by (i) trapping fluid(s) in pre-fractured mineral host phases such as quartz (e.g., Simon et al., 2004, 2005, 2006, 2007, 2008a,b, 2009; Hanley et al., 2005b; Hack and Mavrogenes, 2006, Spandler et al., 2007; Simon and Pettke, 2009; Lerchbaumer and Audétat, 2009; Frank et al., 2011), (ii) trapping fluid(s) in self-healing mineral hosts that are fractured during the experiment after the charge reached steady-state conditions ( $\mathrm{Li}$ and

934 Audétat, 2009; Zajacz et al., 2010, 2011), (iii) trapping fluid(s) along the etched or pre-drilled surface of a mineral during the formation of overgrowths (Loucks and Mavrogenes, 1999; Duc-Tin et al., 2007; Li and Audétat, 2009), and (iv) trapping fluid(s) in coexisting silicate melt as the melt is quenched through the glass transition temperature (e.g., Frank et al., 2002; Hanley et al., 2005b; Simon et al., 2007). Table 3 provides details from experimental studies, which have used synthetic fluid inclusions to sample fluid(s) at elevated PT conditions in order to quantify solute compositions and element speciation in fluids at high $\mathrm{P}$ and T by LA-ICPMS or other microbeam techniques. the ability to constrain directly the partitioning of metals between immiscible fluid phases (e.g.,

944 liquid - vapour - melt) and the speciation of metals in aqueous fluid(s) at magmatic- 
945 hydrothermal conditions. These experimental investigations have been stimulated by solute data from natural magmatic-hydrothermal systems that indicate specific element distribution patterns between coexisting phases, e.g., the partitioning of $\mathrm{Cu}$ and $\mathrm{Au}$ between vapour and brine (e.g., Heinrich et al., 1992; Audétat et al., 1998; Heinrich et al., 1999; Ulrich et al., 1999) or metal distribution between coexisting aqueous fluid and silicate melt (e.g., Audétat et al., 2000a; Audétat and Pettke, 2003; Zajacz et al., 2008) or silicate and sulphide melts (e.g. Halter et al., 2002a) or even halide melts (Hanley et al., 2005a, 2008). Data accumulated from various ore deposits have improved constraints on element partitioning between coexisting phases, for example for the Mole Granite (using PIXE, Heinrich et al., 1992; using LA-ICPMS, Audétat et al.,1998, 2000a,b), the porphyry deposits of Bajo de la Alumbrera, Argentina (Ulrich et al., 1999, 2002; Halter et al., 2002a), the Bingham Canyon, Utah (Redmond et al., 2004; Landtwing et al., 2005, 2010), or Butte, Montana (Rusk et al., 2004, 2008), and the Bismarck skarn deposit, Mexico (using PIXE; Baker et al., 2004).

An understanding of the relative abilities of vapour and brine to scavenge and transport ore metals in various environments is required to accurately model the evolution of hydrothermal ore formation. The studies described in Table 3 document the significant progress made based on synthetic fluid inclusions in the past decade. The results have lent support for a much stronger role of magmatic vapour for scavenging and transporting ore metals than was assumed before. Other studies have been performed to elucidate the relative roles of chlorine and sulphur on metal complexation and partitioning. Importantly, these data validate the hypothesis, formulated from the analysis of boiling assemblages in natural systems (e.g., Heinrich et al., 1999; Seo et al., 2009), that sulphur is an important metal ligand in high-temperature magmatic-hydrothermal fluid. Several studies have employed synthetic fluid inclusions in order to investigate metal speciation in one-phase fluid, and the role of varying PTX on metal-sulphur complexes. Direct information about metal speciation has been obtained by using synchrotron based techniques to study bonding coordination between metals and ligands (e.g., Berry et al., 2006), whereas indirect information has been obtained by using LA-ICP-MS to measure changes in the concentration of a particular metal (e.g., Au) as the metal-complexing ligand (e.g., S) is systematically varied. The results from these speciation studies have advanced our knowledge on metal complexation considerably. The general picture now emerges that both sulphur and chlorine are essential during the evolution of magmatic-hydrothermal systems.

\section{An uncommon application: Bismuth melt inclusions}

A rather uncommon example of "fluid inclusions" is represented by droplets of bismuth melt, trapped in hydrothermal vein minerals. Occurrences of native bismuth have been reported from various magmatic-hydrothermal environments ranging from massive sulphide deposits to epithermal vein-type deposits. They are of great interest to economic geologists because bismuth grades typically correlate strongly with Au grades. Since bismuth remains 
at $300{ }^{\circ} \mathrm{C}$; e.g., Nathans and Leidner, 1962) it has been proposed that bismuth melts may act as efficient scavenger of $\mathrm{Au}$ from hydrothermal fluids or pre-existing sulphide minerals (Douglas et al., 2000). This model is supported by petrographic studies on natural samples (e.g., Ciobanu et al., 2006; Oberthür and Weiser, 2008), and has proven to be thermodynamically feasible by Tooth et al. (2008). However, quantitative determination of the Au-contents of naturally occurring bismuth melts has always been hampered by the fact that these melts unmix into various phases upon cooling to room temperature, such that bulk compositions are difficult to estimate. The accurate quantification of sulphide melt compositions, both from experiment and from exposed sulphide melt inclusions of natural samples suffers from the same problem. Laser-ablation ICP-MS analysis of entire inclusions provides the ideal solution.

The following example of bismuth melt inclusions analyzed from the $\mathrm{Sn}-\mathrm{W}(-\mathrm{Cu}, \mathrm{Pb}, \mathrm{Zn}$, $\mathrm{Bi}, \mathrm{Au}, \mathrm{Ag}$ )-mineralized Mole Granite, Australia, serves to illustrate the large potential of this method. In the Mole Granite area (see Audétat et al., 2000a,b, for details), inclusions of bismuth melt were found in fluorite of a hydrothermal vein in the surrounding sediments (sample Taro20), in a large topaz crystal within quartz-topaz greisen (Bism3.3), and in a quartz crystal from a diffuse vein within quartz-topaz greisen (Gold4). The latter sample is particularly interesting because it was collected from a former Au-Bi mine. According to old reports the ore of this mine contained up to $3 \mathrm{wt} \% \mathrm{Bi}$ and 30-120 g/t Au.

From each occurrence, five to nine bismuth inclusions completely enclosed in the host mineral were analyzed. A typical signal of an inclusion analyzed from sample Bism3.3 is shown in Fig. 10. The LA-ICP-MS analyses were quantified by normalizing the sum of all major and minor elements ( $\mathrm{Bi}, \mathrm{Te}, \mathrm{As})$ to $100 \mathrm{wt} \%$. An overview of the results is given in Table 4. The fact that the calculated element concentrations within a given sample are well reproducible (Table 4) strongly suggests that the Bi-melt was homogeneous at the time of entrapment. On the other hand, some minor and trace element contents vary strongly from locality to locality. By far the highest Au contents are observed in the sample from the former gold mine (Gold4), and the Au/Bi-ratio in the analyzed inclusions $\left(2 \times 10^{-3}\right)$ matches the Au/Biratio of the ore $\left(1-4 \times 10^{-3}\right)$. The Au content of bismuth melt inclusions may thus serve as an indicator of nearby gold ore.

This application also illustrates the smooth transition between fluid inclusion and melt inclusion LA-ICP-MS analysis. The principles and procedures addressed in this review are equally valid and useful for bulk melt inclusion analysis in cases where reliable inclusion homogenization cannot be achieved, a prerequisite for the analysis of exposed parts of melt inclusions by microbeam techniques. Such examples include sulphide melt inclusions that always produce multiple quench phases, and crystallized silicate inclusions from watersaturated igneous systems that often have lost water or $\mathrm{H}$ by diffusion since entrapment; hence, homogenization at entrapment $\mathrm{P}$ and $\mathrm{T}$ in the lab cannot be achieved. A quick overheating of such melt inclusions for homogenization may also not be an option because an 
falsifying its bulk composition (see Pettke et al., 2004, for an example). Successful examples of combined fluid and melt inclusion applications are reported in the literature (e.g., Audétat et al., 2000a; Audétat and Pettke, 2003; Zajacz et al., 2008; Audétat et al., 2008), thus illustrating the unique capabilities of LA-ICP-MS for inclusion chemical analysis.

\section{Isotope ratio analysis by MC-ICP-MS}

Constraints on the sources of fluids help identify provenance of components, thus constraining processes of chemical and heat transfer in the Earth. Radiogenic isotopes are a prime tool for this, notably because different sources often possess distinct signatures. For heavier isotopes in particular, mass dependent fractionation during geological processes (e.g., fluid boiling of crystallization from fluid) does not modify the isotopic signatures much (unlike for light to middle mass stable isotopes, e.g., $\mathrm{H}, \mathrm{C}, \mathrm{O}, \mathrm{Li}, \mathrm{B}, \mathrm{Cl}, \mathrm{Cr}, \mathrm{Ni}, \mathrm{Cu}$ ). Moreover, radiogenic isotope ratios may provide constraints on the age of the source (see below).

To obtain precise isotope ratio measurements by laser ablation, multiple collector ICPMS instruments are preferred over sequentially recording single collector instruments where noise in the ion signal from laser ablation and plasma flicker limits isotope ratio analytical precision to $>0.1 \%$ uncertainty (e.g., Appelblad et al., 2001, and references therein). Moreover, simultaneous signal detection drastically improves the duty cycle, a key advantage for the analysis of an individual fluid inclusion with a priori limited sample amount and thus limited signal duration. This section summarizes current procedures to accurately analyze individual inclusions for $\mathrm{Pb}$ and $\mathrm{Sr}$ isotope ratios by LA-MC-ICP-MS. The detailed techniques for $\mathrm{Pb}$ isotope ratio analysis have been published elsewhere (Pettke et al., 2011), while specific procedures for $\mathrm{Sr}$ isotope ratio analysis of fluid inclusions of a pilot study are presented below. All data were acquired using a $193 \mathrm{~nm}$ ArF excimer laser system (GeoLas 200Q, Lambda Physik, Germany) with computer-controlled sample stage connected to either a Nu Plasma or a Nu Plasma 1700 MC-ICP-MS instrument (Nu Instruments Ltd, Wrexham, UK).

\section{Lead isotope ratio analysis of individual fluid inclusions}

The challenge of analyzing an individual fluid inclusion for isotope ratios lies in the fact that it contains a strictly limited mass of analyte, of the order of $0.1 \mathrm{ng}$ of $\mathrm{Pb}$ for magmatichydrothermal fluid inclusions $40 \times 40 \times 30 \mu \mathrm{m}$ in size and containing a few $1000 \mu \mathrm{g} \mathrm{g}^{-1} \mathrm{~Pb}$. This tiny amount is to be measured as a highly transient signal varying in intensity over some 3 orders of magnitude during a 10 - $30 \mathrm{~s}$ time interval (Fig. 11). This is opposite to common solution-based MC-ICP-MS analysis where stable ion beams are recorded over 10 - 20 minutes. Note that commercial instruments have been developed to accurately record such constant signals as produced from solution nebulisation and, hence, the fast transient signals generated from laser ablation of an individual fluid inclusion need special measures. The 
1060

requirements for controlled ablation of an individual fluid inclusion outlined above remain valid, of course.

The results of extensive methods development have been reported in Pettke et al. (2011). They used synthetic fluid inclusions of known Pb isotopic composition, ca. $5400 \mu \mathrm{g}$ SRM $981 \mathrm{~Pb}$ per g of 17 wt-\% Na-K-Cl solution, $\mathrm{Pb}$ concentrations typically encountered for magmatic-hydrothermal fluids (e.g., Landtwing et al., 2005; Klemm et al., 2007, Audétat et al., 2008). The inclusion analyses were performed in static time-resolved mode using modified instrument control and data reduction software, collecting ${ }^{200} \mathrm{Hg}^{2}{ }^{202} \mathrm{Hg}^{2}{ }^{203} \mathrm{TI}^{204}(\mathrm{Hg}, \mathrm{Pb})-{ }^{205} \mathrm{TI}-$ ${ }^{206} \mathrm{~Pb}_{-}{ }^{207} \mathrm{~Pb}-{ }^{208} \mathrm{~Pb}$ in $0.2 \mathrm{~s}$ readings simultaneously in 8 Faraday cups calibrated daily for their preamplifier gains. Only the signal on mass 204 required interference correction of ${ }^{204} \mathrm{Hg}$. Polyatomic interferences were not significant, even when analyzing SRM 610 from NIST, a glass doped with nominally $500 \mathrm{\mu g} \mathrm{g}^{-1}$ of all trace elements. This suggests that, for chemically complex natural fluid inclusions, polyatomic ion interferences may also not be significant in this mass range, at least not at the precision so far achieved. In any case, however, testing is required for specific applications in order to verify this assumption.

Methods development identified several sources of isotope ratio bias, such as mass fractionation and delayed amplifier response. Instrumental mass bias in $\mathrm{Pb}$ isotope ratio analysis is successfully accounted for by within-run correction based on measured ${ }^{205} \mathrm{TI}^{203} \mathrm{TI}$ from desolvated aerosol admixed to the laser ablation aerosol prior to ionization in the ICP (Fig. 11). Recording the data on Faraday detectors has revealed strong isotope ratio bias originating from differences in response among the amplifiers used for recording the individual ion beams (e.g., Hirata et al., 2003). Our investigations show that numerical correction schemes can compensate for most of the bias except for extremely fast changes in signal intensities such as generated from explosion of fluid inclusions or upon beam size increase during stepwise opening of the fluid inclusion. The latter signal types are thus better avoided. Data obtained from controlled, smooth ablations reveal isotope ratios that evolve from light to heavy across the transient signal when corrected for Faraday amplifier response by algorithms described in Pettke et al. (2011). This effect is ascribed to laser ablation-induced $\mathrm{Pb}$ isotope fractionation of the order of $0.5 \%$ per a.m.u.

To obtain accurate isotope ratios, the entire transient inclusion signals need to be integrated and processed. The best way to integrate the data for a given fluid inclusion ablation is bulk signal integration (e.g., Evans et al., 2001), i.e., to sum up all the individual readings and then take the isotope ratios and process these. This procedure has several benefits over the individual reading integration method as applied for solution nebulisation analysis, namely (1) high-intensity readings become much more important than low-intensity and possibly highly fractionated and/or imprecise readings in determining the isotope ratio of the inclusion (isotopic ratios based on individual readings show enhanced variance, and results may be distorted if isotopic beams behave non-proportionally across the ablation interval), (2) the effect of bias in amplifier response largely cancels out when the entire signal 
is integrated; hence, instrument-specific amplifier response correction is not a prerequisite for obtaining accurate bulk inclusion isotopic data at useful precision, and (3) laser ablation induced isotope fractionation also cancels out for bulk signal integration of fluid inclusions (Pettke et al., 2011). However, bulk signal integration does not provide a straightforward means to determine analytical uncertainties, e.g., mean and standard error as commonly obtained from sets of reading-by-reading ratio evaluation in solution-based isotope ratio measurements. Minimum uncertainties for isotope ratios calculated by bulk signal integration for an individual inclusion can, however, be estimated from a Gaussian combination of ion statistics and baseline noise.

Figure 12 documents a set of 20 compositionally identical fluid inclusions containing SRM $981 \mathrm{~Pb}$ individually analyzed for $\mathrm{Pb}$ isotopic ratios. As with element concentration data, it is best practice to determine the average and associated uncertainty for a given fluid inclusion assemblage. For the synthetic fluid inclusions containing $0.01-0.1 \mathrm{ng} \mathrm{Pb}$ per inclusion, 2 standard deviation uncertainties on inclusion-to-inclusion reproducibility are ca. $0.08 \%$ for ${ }^{208} \mathrm{~Pb} /{ }^{206} \mathrm{~Pb}$ and ${ }^{207} \mathrm{~Pb} /{ }^{206} \mathrm{~Pb}$, and ca. $0.5 \%$ on ratios normalized to ${ }^{204} \mathrm{~Pb}$, the lower precision of the latter resulting from the low intensity ${ }^{204} \mathrm{~Pb}$ ion beam. The analyses are accurate at these uncertainties. Natural fluid inclusion assemblages containing up to $1 \mathrm{wt} \%$ $\mathrm{Pb}$ were since analyzed even more precisely, with ca. $0.05 \% 2 \mathrm{SD}(\mathrm{n}=11)$ for ${ }^{208} \mathrm{~Pb} /{ }^{206} \mathrm{~Pb}$ and ${ }^{207} \mathrm{~Pb} /{ }^{206} \mathrm{~Pb}$, and ca. $0.13 \%$ for $\mathrm{Pb}$ isotope ratios normalized to mass 204 . Acceptably reproducible results ( $\pm 0.1 \%$ and $0.7 \%$, respectively) can be obtained for inclusions containing as little as $0.005 \mathrm{ng} \mathrm{Pb}$ with the current procedure and using Faraday detectors for data recording.

In a first application (Pettke et al., 2010), brine inclusions from successive $\mathrm{Cu} \pm \mathrm{Au}$ and Mo ore-forming stages of the late Eocene giant porphyry-type Cu-Mo-Au deposit of Bingham Canyon, Utah, were analyzed to investigate the common inference that $\mathrm{Mo}$, unlike $\mathrm{Cu}$ and $\mathrm{Au}$, originates from lower crustal sources, a model largely based on research performed on Climax-type Mo deposits. The Bingham porphyry deposit is exceptionally well suited for such an investigation because molybdenite precipitated in late veins cutting the Cu-Au stockwork veining and associated dike emplacement; hence, the two ore stages are texturally well separated.

The constant $\mathrm{Cu} \pm \mathrm{Au}$ and $\mathrm{Mo}$ ore-forming fluid $\mathrm{Pb}$ isotope signature (Fig. 13) demonstrates a common source for these ore metals, however. The $\mathrm{Pb}$ isotopic signatures are conspicuously non-radiogenic, with averages for individual fluid inclusion assemblages restricted to $17.494<{ }^{206} \mathrm{~Pb} /{ }^{204} \mathrm{~Pb}<17.534,15.553<{ }^{207} \mathrm{~Pb} /{ }^{204} \mathrm{~Pb}<15.588,38.204<$ ${ }^{208} \mathrm{~Pb} /{ }^{204} \mathrm{~Pb}<38.311,0.88805<{ }^{207} \mathrm{~Pb} /{ }^{206} \mathrm{~Pb}<0.88955$, and $2.1803<{ }^{208} \mathrm{~Pb} /{ }^{206} \mathrm{~Pb}<2.1853$. Such a non-radiogenic $\mathrm{Pb}$ isotopic composition plotting to the left of the Geochron is rare for Phanerozoic rocks and has never been reported for Cenozoic, classical subduction-related calc-alkaline magmas, with or without associated porphyry-type ore deposits. 
A U-Th-Pb evolution model (Fig. 14), in which the parental magma is derived by melting a subcontinental lithospheric mantle that had been metasomatized by subduction fluids about 1.8 billion years ago, reproduces the $\mathrm{Pb}$ isotope signatures measured in the ore fluids, while satisfying independent geochemical and geodynamic boundary conditions. Importantly, such a model provides an alternative view to the commonly-held assumption of a lower crustal Mo source, and it accounts for the apparent richness in incompatible elements and for the alkaline affinity of the ore-forming magmatic-hydrothermal system at Bingham. Consequently, this source of ancient, metasomatized mantle may be key to this globally most prominent Mo ore province located in the Rocky Mountains.

\section{Strontium isotope ratio analysis of individual fluid inclusions}

This section summarizes the results of our pilot investigation on the feasibility and systematics of $\mathrm{Sr}$ isotope ratio analysis of individual fluid inclusions. In contrast to lead isotope ratio analysis described above, correction for instrumental mass bias of $\mathrm{Sr}$ does not a priori require external bracketing by a reference standard or admixture of an element of neighbouring mass possessing an invariant isotope ratio. The existence of invariant isotope ratios such as ${ }^{88} \mathrm{Sr} /{ }^{86} \mathrm{Sr}$ allows for internal mass bias correction, which enhances the precision and accuracy of the results. This advantage is however partially offset by the presence of isobaric interferences at essentially all $\mathrm{Sr}$ masses. In a recent review of $\mathrm{Sr}$ isotope ratio measurement by LA-ICP-MS, Vroon et al. (2008) have summarized published work that stresses the importance of proper correction for such interferences. Among the interfering ion species listed, $\mathrm{Rb}, \mathrm{Kr}, \mathrm{Ca}$ argides and/or Ca dimers can play a major role for ratio bias, because Ar used as a plasma gas typically contains non-negligible, variable amounts of $\mathrm{Kr}$, and $\mathrm{Rb}$ and $\mathrm{Ca}$ are present in a wide range of geologic materials, including fluid inclusions. Doubly charged ions of $\mathrm{Dy}, \mathrm{Er}, \mathrm{Yb}$, Lu or oxides of $\mathrm{Zn}$ and Ga may also be important.

In addition to these problems, analysis of $\mathrm{Sr}$ in fluid inclusions has to cope with very limited sample amounts resulting in fast transient ion signals biased by amplifier response, as is the case for the $\mathrm{Pb}$ measurements described above. In this feasibility study, we have produced and analyzed synthetic fluid inclusions in quartz, prepared from various mixtures of NIST SRM $987 \mathrm{Sr}$ and variable amounts of ultrapure $\mathrm{RbCl}$ in $\mathrm{NaCl}$ solution matrices. Inclusions were trapped in quartz at $700^{\circ} \mathrm{C}$ and $1 \mathrm{kbar}$ using a conventional hydrothermal cold seal apparatus. Several synthetic inclusion standards were produced at these conditions, with $\mathrm{Sr}$ concentrations ranging from $\sim 3000-7000 \mathrm{ppm}$ and $\mathrm{Rb}$ concentrations ranging from $\sim 100-900 \mathrm{ppm}\left({ }^{87} \mathrm{Sr}{ }^{87} \mathrm{Rb}\right.$ ranging from $\sim 1$ to 14$) . \mathrm{CaCl}_{2}$ was added in one experiment (Ca/Na $=2.2$ and $\mathrm{Ca} / \mathrm{Sr}=11$ ) to simulate the compositions of natural brine inclusions. Isotope geochemical applications require an accurate measurement of the ${ }^{87} \mathrm{Sr} /{ }^{86} \mathrm{Sr}$ ratio, which then, in the case of older samples, needs to be combined with an accurate determination of the $\mathrm{Rb} / \mathrm{Sr}$ ratio in order to determine initial ${ }^{87} \mathrm{Sr} /{ }^{86} \mathrm{Sr}$ ratios or formation age information (via isochron dating). The following presentation of our current methods will be confined to the 
measurement of sample ${ }^{87} \mathrm{Sr} /{ }^{86} \mathrm{Sr}$. Discussion of approaches to accurately correct for in-situ produced ${ }^{87} \mathrm{Sr}$ is presented elsewhere (Hanley et al., in preparation).

Laser ablation is carried out as described for $\mathrm{Pb}$ analysis above. Simultaneous Faraday readings at masses $88,87,86,85,84$ and 83 are continuously recorded at $0.2 \mathrm{~s}$ integration intervals in time-resolved mode, covering first a baseline section measured on-mass for ca. $60 \mathrm{~s}$ with laser-beam off, which yields combined information on gas and electronic backgrounds. Then the laser beam is switched on, generating an aerosol from host quartz, which modifies the gas background (e.g., lowering $\mathrm{Kr}$ beam intensities) and initially may also contain contaminants from the sample surface. When the fluid inclusion becomes exposed a transient signal generated from its contents is superimposed on the host quartz signals, the readings being recorded until the inclusion becomes completely exhausted.

Based on this record, data reduction is then carried out off-line according to the following steps:

(i) Corrections for incongruent amplifier response to signal variation are applied to the sequence of individual reading channels using procedures detailed in Pettke et al. (2011; "quadratic tau correction"). This minimizes ratio trends correlating with steep signal intensity gradients (Fig. 15).

(ii) The tau-corrected data are corrected for background by subtraction of the mean signal intensities determined for the data section recorded with laser off. This correction removes electronic offsets and steady-state blank contributions, in particular the bulk of Kr interference at masses 83, 84 and 86 . Such an on-peak background correction has the advantage of not requiring assumptions regarding the mass fractionations state of the ionic species involved. (iii) The Kr ion intensities are suppressed in the presence of laser ablation aerosol, resulting in negative baseline-corrected ${ }^{83} \mathrm{Kr}$ values for the fluid inclusion signal. These are then used for compensation of this effect on all masses interfered by $\mathrm{Kr}$ and for cancelling random fluctuations of $\mathrm{Kr}$ beam intensities during ablation (e.g. Waight et al., 2002; Burla et al., 2009). This is done by the peak-stripping technique, for which $\mathrm{Kr}$ isotopic composition is approximated by that of air and instrumental mass bias by that simultaneously determined for $\mathrm{Sr}$. If $\mathrm{Ca}$ is also present at higher concentrations, such as in carbonates or certain brine inclusions, the ratio triplet $88 / 86,84 / 86$ and $83 / 86$ can be used for simultaneous correction of interference by $\mathrm{Ca}$ argides (or $\mathrm{Ca}$ dimers) and $\mathrm{Kr}$, and determination of the mass fractionation coefficient for $\mathrm{Sr}$ (see Burla et al., 2009, supporting online information). This technique expands earlier approaches by Woodhead et al. (2005) and Jackson and Hart (2006). We note that for our fluid inclusion measurements the $\left({ }^{46} \mathrm{Ca}^{40} \mathrm{Ar}\right)^{+}$contribution to mass 86 was of the order of a few ppm only and thus not significant. In contrast, interference of $\left({ }^{43} \mathrm{Ca}^{40} \mathrm{Ar}\right)^{+}$on ${ }^{83} \mathrm{Kr}$ is important and, if neglected, would result in strongly biased $\mathrm{Kr}$ interference corrections. (iv) After elimination of isobaric interferences by $\mathrm{Kr}$ and $\mathrm{Ca}$ compounds, $\mathrm{Rb}$ contribution at mass 87 is removed by the peak stripping technique, based on the net ${ }^{85} \mathrm{Rb}$ intensity and mass bias determined for $\mathrm{Sr}$. 
Figure 15 shows results obtained from a reading-by-reading evaluation of the measurements based on the above scheme, both for a synthetic fluid inclusion (Fig. 15A,B) and for a natural brine inclusion originating from the Sudbury Igneous Complex (Hanley et al., 2005a, and in preparation; Fig. 15C,D). The synthetic fluid inclusion (Fig. 15A,B) is characterized by a relatively high measured bulk ${ }^{85} \mathrm{Rb} /{ }^{86} \mathrm{Sr}$ ratio of 1.98 , which requires a substantial interference correction of $107 \%$ on average for the ${ }^{87} \mathrm{Sr} /{ }^{86} \mathrm{Sr}$ ratio relative to the corrected value ( 0.710245 for SRM 987). We note that the baseline- and $\mathrm{Kr}$-corrected ${ }^{86} \mathrm{Sr}$ and ${ }^{85} \mathrm{Rb}$ beam intensities show two maxima during ablation at roughly similar locations, but show considerable variation in proportion across the ablation sequence. The initial rise of ${ }^{85} \mathrm{Rb}$ is faster than that of ${ }^{86} \mathrm{Sr}$, and the proportions of the two beams at their maxima are disparate (comparable to the behaviour of $\mathrm{Tl}$ and $\mathrm{Pb}$ reported in Pettke et al., 2011), suggesting that $\mathrm{Rb}$ and $\mathrm{Sr}$ are not equally distributed across the inclusion, with $\mathrm{Rb}$ predominantly residing in the fluid and $\mathrm{Sr}$ partially forming solid phases (e.g. $\mathrm{SrCl}_{2}$ ), as confirmed by SEM. In view of the large corrections required by $\mathrm{Rb}$ interference it is of interest to examine whether such variation in $\mathrm{Rb} / \mathrm{Sr}$ could potentially lead to bias in the interferencecorrected ${ }^{87} \mathrm{Sr} /{ }^{86} \mathrm{Sr}$ ratios. Such bias, however, is not evident from the tau-corrected data displayed Fig. 15B, at least not at the limited precision of the LA data. The inhomogeneous signal structure of the ${ }^{87} \mathrm{Sr} /{ }^{86} \mathrm{Sr}$ ratios for tau-uncorrected data (Fig. 15A), in contrast, does not allow to evaluate whether bias is introduced by the ${ }^{87} \mathrm{Rb}$ correction.

In the case of natural fluid inclusions from old geological environments such as from the $1.85 \mathrm{Ga}$ old Sudbury Igneous Complex (Fig. 15CD), $\mathrm{Sr}$ in fluids and precipitates may not be in isotopic equilibrium due to contrasting radiogenic increments by radioactive decay of ${ }^{87} \mathrm{Rb}$ in phases characterized by distinct $\mathrm{Rb} / \mathrm{Sr}$ ratios (unless the inclusions were completely homogenized using microthermometry prior to LA analysis, which is not the case for the inclusions addressed here). Whereas the ${ }^{87} \mathrm{Sr} /{ }^{86} \mathrm{Sr}$ data in Fig. $15 \mathrm{C}$ show pronounced variation correlating with signal structure, the flat distribution of the ratios after tau correction (Fig. 15D) suggests Sr isotopic equilibrium among the ablated phases, at least to the degree of current analytical resolution. Whether such apparent $\mathrm{Sr}$ isotopic equilibrium is a primary feature of this particular inclusion (as possibly supported by the approximately proportional trends of both ${ }^{86} \mathrm{Sr}$ and ${ }^{85} \mathrm{Rb}$ ) or whether polyphase fluid inclusion contents have recently equilibrated internally remains open.

Further information on the accuracy of $\mathrm{Sr}$ isotope ratio determination in fluid inclusions can be gained from a set of 51 on synthetic fluid inclusion analyses displayed in Fig. 16. In order to enhance the precision of the mean values obtained for individual inclusions, data reduction steps (i) to (iv) as outlined above were applied to baseline-corrected ion beam currents integrated over selected signal sections rather than to individual readings (bulk signal integration; cf. Pettke et al., 2011). As this procedure just produces a single data set per 1252 individual inclusion, expected analytical uncertainties (shown as $2 \mathrm{~s}$ error bars in Fig. 16) were calculated by Monte Carlo techniques, assigning normally distributed random errors to 
in a synthetic fluid inclusion can safely be assumed to be in $\mathrm{Sr}$ isotopic equilibrium, the uncertainty of ${ }^{87} \mathrm{Sr} /{ }^{86} \mathrm{Sr}$ can be minimized by selection of an optimal interval from the ablation sequence, e.g. by a simple numerical search algorithm, avoiding the low precision tails of the measurements. For $\mathrm{Sr}$, an optimized data section will be characterized by elevated $\mathrm{Sr}$ beam intensities and, in the case of samples with elevated $\mathrm{Rb}$ contents and non-proportional behaviour of $\mathrm{Rb}$ and $\mathrm{Sr}$ during ablation, by lower than average $\mathrm{Rb} / \mathrm{Sr}$ ratios. Applied to the fluid inclusion data shown in Fig. 15A,B for example, the algorithm has thus given more weight to the second signal maximum as indicated by the lower cut-off value of ${ }^{86} \mathrm{Sr}$ on its down-going slope as compared to that of the rising slope of the first maximum.

From the positive correlation of ${ }^{87} \mathrm{Sr} /{ }^{86} \mathrm{Sr}$ with ${ }^{85} \mathrm{Rb} /{ }^{86} \mathrm{Sr}$ in Fig. 16 it is evident that final calculated ${ }^{87} \mathrm{Sr} /{ }^{86} \mathrm{Sr}$ results are not fully invariant with respect to $\mathrm{Rb} / \mathrm{Sr}$. This conclusion is supported by an error weighted least squares linear fit, which results in a slope of $0.00088 \pm$ 0.00036 , significantly different from zero slope. The best fit line intersects the ordinate at $0.71028 \pm 0.00019$, identical to the nominal value of SRM 987 (0.710245). Furthermore, the MSWD value of 0.91 indicates good agreement between statistical expectation (based on our Monte Carlo approach) and observed variance of the data. The correlation between ${ }^{87} \mathrm{Sr} /{ }^{86} \mathrm{Sr}$ and ${ }^{85} \mathrm{Rb} /{ }^{86} \mathrm{Sr}$ could be eliminated, if an adjusted ${ }^{85} \mathrm{Rb} /{ }^{87} \mathrm{Rb}$ value of 2.58676 rather than the canonical value of 2.59265 for SRM $984 \mathrm{Rb}$ (Catanzaro et al., 1969) were used for interference correction on mass 87 . The adjusted value is very close to the value of 2.5875 determined by Jackson and Hart (2006) for their laser ablation experiments on melt inclusions. Such a lower ${ }^{85} \mathrm{Rb} /{ }^{87} \mathrm{Rb}$ value could either indicate that the isotopic composition of SRM $984 \mathrm{Rb}$ is actually heavier than the canonical value, or that there is a minor systematic difference between the exponential mass bias coefficients ( $\beta$ values) for $\mathrm{Sr}$ and $\mathrm{Rb}$. The former explanation is rather unlikely, as Nebel et al. (2005) did not find any significant deviations from the SRM 984 standard value in their study of potential isotopic fractionation of $\mathrm{Rb}$ in natural materials. If the deviations result from distinct $\beta$ values, then $\beta_{\mathrm{Rb}}=\beta_{\mathrm{Sr}}+0.098$ holds on average for our data set. Such an offset in mass bias between the two elements is relatively small compared to average $\beta_{\mathrm{Sr}}$ values of ca. -1.85 determined for our sample set, but has serious implications for the accuracy of interference-corrected ${ }^{87} \mathrm{Sr} /{ }^{86} \mathrm{Sr}$ ratios in samples with high $\mathrm{Rb} / \mathrm{Sr}$, and, in the case of geologically older samples, for correction of insitu accumulated radiogenic ${ }^{87} \mathrm{Sr}$.

Our results document that individual fluid inclusions can be analyzed accurately for ${ }^{87} \mathrm{Sr} /{ }^{86} \mathrm{Sr}$ isotope ratios for $\mathrm{Rb}$-poor fluids (i.e., for $\mathrm{Rb} / \mathrm{Sr}$ ratios smaller than about 0.13 ). Laser ablation ICP-MS data of individual fluid inclusion are less precise than those of other phases such as carbonates, largely resulting from fast transient signal recording of relatively low signal intensities as well as from uncertainty contribution by interference corrections. In the case of low $\mathrm{Rb} / \mathrm{Sr}$ calcic brine inclusions, however, this method may become a powerful tool

1292 for tracing ancient fluid flow and source(s) given the analytical precision provides for sufficient 


\section{PROSPECTS}

We currently identify five major areas where significant progress in the LA-ICP-MS analysis of fluid inclusions could be achieved. They are (i) improving the data recording efficiency (i.e., duty cycle) of ICP-MS instruments, (ii) improved ion production and transmission in the ICP-MS, (iii) a better control on the processes of inclusion ablation and aerosol production, (iv) improvements in data quantification and, finally, (v) a better characterization of standard reference materials for concentrations of elements (e.g., Te, Br, $\mathrm{Cl}, \mathrm{Ga}$ ) that are often important in fluid inclusion research but not commonly used in LA-ICPMS.

(i) As with any single collector instrument, only one analyte is recorded at any point in time; hence, all other analytes pass unrecorded. Multiple collector ICP-MS instruments allow for simultaneous recording of analytes, although only in a rather limited mass (or precisely $\mathrm{m} / \mathrm{z}$ ) range. It would be ideal to record all analytes of interest simultaneously, e.g. from Li to $U$ for fluid inclusion analysis. While optical emission spectrometers record all light emissions simultaneously, their sensitivity and thus detection power is inadequate for fluid inclusion trace element analysis (cf. Pettke et al., 2000b). Time-of-flight mass spectrometry allows for quasi-simultaneous recording of all analytes but also suffers from inappropriate detection limits (e.g., Bleiner et al., 2000) and abundance sensitivity problems (Tanner \& Günther, 2009). Most recently, a new sector field ICP-MS has been launched (in late 2010; Spectro Analytical Instruments, $\mathrm{GmbH}$ ) that simultaneously records the mass spectra for all elements from lithium to uranium in 4800 channels. This would dramatically improve on representative recording of fast transient signals and on analyte duty cycles and, thus, can become extremely interesting. It remains to be seen whether this instrument will achieve or surpass the performance of other state-of-the art instruments.

(ii) Improvements in ion production and notably transmission have remained a long-held desire amongst analytical chemists, notably because still far more than $99 \%$ of analyte is lost during measurement. To our knowledge, there is no anticipated breakthrough in the near future, however. Alternatively, for MC-ICP-MS, the use of multiple ion counters can significantly reduce the amount of analyte required for isotope analysis, but accuracy has been shown to be somewhat limited (to ca. $\pm 0.1 \%$ uncertainty) due to multiplier gain stability and linearity issues (Paul et al., 2005). This is about an order of magnitude higher than the analytical precision obtained for ${ }^{208} \mathrm{~Pb} /{ }^{206} \mathrm{~Pb}$ and ${ }^{207} \mathrm{~Pb} /{ }^{206} \mathrm{~Pb}$ ratios on SRM 610 glass (Pettke et al., 2011); hence, ion counting, would be of advantage for the analysis of very low- $\mathrm{Pb}$ samples and ratios involving ${ }^{204} \mathrm{~Pb}$ only.

(iii) Femtosecond-laser ablation (fs-LA) has been the hope for breakthrough in laserablation based analytical techniques for several years. While advantages over nanosecond (ns) laser systems have been documented for isotope ratio analysis using MC-ICP-MS (e.g., Horn et al., 2007), the results remain inconclusive with regard to fast transient signal analysis using single collector ICP-MS (e.g., Koch et al., 2007). To our knowledge, a rigorous 
evaluation for fluid inclusion analysis is still due. While fs laser ablation likely minimizes heat dissipation into the sample and thus heating of the inclusion prior to opening, other phenomena cast doubt on whether such a laser source will provide a better controlled inclusion ablation process. Problems may arise from cracking of the material at the crater bottom (for monazite: Seydoux-Guillaume et al., 2010), probably associated with the process of phase explosion, which potentially represents a disadvantage for ablation control. More importantly, Glaus et al. (2010) report that fs-LA-generated aerosols consist of a bimodal mixture of agglomerated nanoparticles and larger, spherical particles, irrespective of matrix and wavelength used for ablation. These different particle types may be chemically distinct; hence, their total decomposition and ionization in the ICP would be essential to obtaining a non-biased compositional result. For such a large range in particle sizes (a few nanometer to several hundred $\mathrm{nm}$ diameter) current ICPs may not achieve complete ionization at a given ion extraction depth in the plasma. Therefore, the possibility of ICP-induced element fractionation cannot be excluded to date; hence, non-matrix-matched calibration strategies as required for fluid inclusions may thus be severely compromised for fs-LA-ICP-MS.

Nevertheless, Volk et al. (2010) claim that fs laser pulses can be used to liberate unaltered oil from individual inclusions hosted in quartz, emphasizing that pyrolysis artefacts were not observed. The considerable amount of material deposited in and around the ablation crater shown in their Figure $2 \mathrm{c}$ might indicate, however, that there might be disadvantages with respect to metal solute analyses on aqueous fluid inclusions. Borisova et al. (2008) report analytical results by fs laser ablation for melt inclusions fully enclosed in host to a precision of $0.0 \mathrm{X} \mu \mathrm{g} / \mathrm{g}$, without having performed a host mineral correction on the mixed inclusion plus host analysis. This makes it hard to conclude whether the use of fs laser ablation may indeed be beneficial compared to ns laser ablation for melt inclusion analysis.

(iv) Fluid inclusion data quantification requires the accurate knowledge of one element abundance in the inclusion to be used as the internal standard, as determined by an independent method. Particle-induced X-ray emission (PIXE) has repeatedly been used to quantify element concentrations in fluid inclusions. This is a very laborious approach, and assumptions on the shape and dimensions of a given inclusion (to obtain its mass of liquid at the temperature of analysis) and on depth below sample surface lead to considerable analytical uncertainty that, in an ideal case, was claimed to be no better than $\pm 10 \%$ (probably $1 \sigma$; Kurosawa et al., 2003). The determination of the Na concentration in a given fluid inclusion by combined microthermometry and salt correction based on the actual LA-ICP-MS analysis (Heinrich et al., 2003) is accurate for fluid compositions that closely correspond to pure $(\mathrm{Na}-\mathrm{K}-\mathrm{Ca}-\mathrm{Cl})$ solution; hence, the mean and analytical uncertainty determined on an assemblage average is representative. For chemically more complex aqueous and aqueocarbonic fluid inclusions, a more accurate multi-component description of the liquidus surface of ice and the final dissolution of clathrate, hydrohalite and halite would be highly desirable, but equations of state for fluids with $>3$ components are not available to date. Instead, Allan et al. (2005) proposed that a charge balance data reduction approach may be superior to the 
use of $\mathrm{Na}$ as the internal standard; this, however, requires accurate determination of $\mathrm{Cl}$ in the fluid inclusion, which is a difficult task. Similarly, the quantification of high-P silicate rich fluid compositions is also difficult because of the inability to determine one element concentration in the inclusion by a non-destructive method as required for internal standardization. One way is to estimate an element concentration within the inclusion based on experimentally determined element distribution coefficients between fluid and host mineral; however, the uncertainty remains whether the experimental conditions are truly representative for the sample material investigated. Novel approaches for the determination of the internal standard required for deriving absolute element concentration data from LA-ICP-MS analysis of individual inclusions are needed to improve data accuracy for chemically complex fluid inclusions.

(v) The accuracy of element concentration data for the external calibration materials may limit the accuracy of fluid inclusion analysis, notably for poorly characterized elements such as Te, Ga, Ge, Re, Au, W when using SRM 610 and 612 glass from NIST. For other elements like $\mathrm{Cl}, \mathrm{S}, \mathrm{Br}$, the SRM glasses are not suitable, because calibration signals are not much different from background levels. Alternative, well-determined calibration materials are therefore required (e.g., homogeneous sulphide standards for sulphide-hosted inclusions), and it would thus be desirable that such materials become generally available.

\section{ACKNOWLEDGMENTS}

TP thanks Henry Longerich, who cautioned about the possibility that the sequence of data report in the Elan ICP-MS instruments may not correspond to the sequence of data acquisition during measurement. MG thanks Martin Tanner for discussing LOD calculation. We thank Chris Heinrich for great input and discussion throughout the past years. We acknowledge the initiative of Murray Allan to program a fluid inclusion data reduction scheme (in Matlab) that has become the SILLS package. We thank Brian Rusk and Sebastien Meffre for their reviews that helped to clarify aspects in the manuscript. Continued funding by the Swiss National Science Foundation (current project PP00P2-124370 to TP) is greatly acknowledged. ACS thanks the US NSF (grant EAR 0609550) and the UNLV High Pressure Science and Engineering Center (HiPSEC) via the U.S. Department of Energy Cooperative Agreement Nos. DE-FC08-01NV14049 and DE-FC8806NA2768. 


\section{References}

Allan, M.M., Yardley, B.W.D., 2007. Tracking meteoric infiltration into a magmatic-hydrothermal system: A cathodoluminescence, oxygen isotope and trace element study of quartz from Mt. Leyshon, Australia. Chemical Geology 240, 343-360.

Allan, M.M., Morrison, G.W., Yardley, B.W.D., 2011. Physicochemical Evolution of a Porphyry-Breccia System: A Laser Ablation ICP-MS Study of Fluid Inclusions in the Mount Leyshon Au Deposit, Queensland, Australia. Economic Geology 106, 413-436.

Allan, M.M., Yardley, B.W.D., Forbes, L.J., Shmulovich, K.I., Banks, D.A., Shepherd, T.J., 2005. Validation of LA-ICPMS fluid inclusion analysis with synthetic fluid inclusions. American Mineralogist 90, 1767-1775.

Anderson, G.M., Burnham, C.W., 1965. The solubility of quartz in supercritical water. American Journal of Science 263, 494-511.

Appelblad, P.K., Rodushkin, I., Baxter, D.C., 2001. Sources of uncertainty in isotope ratio measurements by inductively coupled plasma mass spectrometry. Analytical Chemistry 73, 2911-2919.

Audétat, A.,Lowenstern, J.B., 2011. Melt inclusions, Treatise on Geochemistry 12 (in review).

Audétat, A., 2010. Source and evolution of molybdenum in the porphyry Mo(-Nb) deposit at Cave Peak, Texas. Journal of Petrology 51, 1739-1760.

Audétat, A., Günther, D., 1999. Mobility and $\mathrm{H}_{2} \mathrm{O}$ loss from fluid inclusions in natural quartz crystals. Contributions to Mineralogy and Petrology 137, 1-14.

Audétat, A., Pettke, T., 2003. The magmatic-hydrothermal evolution of two barren granites: a melt and fluid inclusion study of the Rito del Medio and Canada Pinabete plutons in northern New Mexico (USA). Geochimica et Cosmochimica Acta 67, 97-121.

Audétat, A., Günther, D., Heinrich, C.A., 1998. Formation of a magmatic-hydrothermal ore deposit: insights with LAICP-MS analysis of fluid inclusions. Science 279, 2091-2094.

Audétat, A., Günther, D., Heinrich, C.A., 2000a. Magmatic-hydrothermal evolution in a fractionating granite: a microchemical study of the Sn-W-F-mineralized Mole Granite (Australia). Geochimica et Cosmochimica Acta 64, 3373-3393.

Audétat, A., Günther, D., Heinrich, C.A., 2000b. Causes for large-scale metal zonation around mineralized plutons: Fluid inclusion LA-ICP-MS evidence from the Mole Granite, Australia. Economic Geology 95, 1563-1581.

Audétat, A., Pettke, T., Heinrich, C.A., Bodnar, R.J., 2008. The composition of magmatic-hydrothermal fluids in barren versus mineralized intrusions. Economic Geology 103, 877-908.

Baker, J., Peate, D., Waight, T., Meyzen, C., 2004. Pb isotopic analysis of standards and samples using a Pb-207$\mathrm{Pb}-204$ double spike and thallium to correct for mass bias with a double-focusing MC-ICP-MS. Chemical Geology 211, 275-303.

Baker, T., Van Achterberg, E., Ryan, C., Lang, J.R., 2004. Composition and evolution of ore fluids in a magmatichydrothermal skarn deposit. Geology 32, 117-120.

Bakker, R.J., Jansen, J.B.H., 1991. Experimental post-entrapment water loss from synthetic $\mathrm{CO}_{2}-\mathrm{H}_{2} \mathrm{O}$ inclusions in natural quartz. Geochimica et Cosmochimica Acta 55, 2215-2230.

Bali, E., Audétat, A., Keppler, H., 2011. The mobility of U and Th in subduction zone fluids: an indicator of oxygen fugacity and fluid salinity. Contributions to Mineralogy and Petrology 161, 597-613.

Banks, D.A., Davies, G.R., Yardley, B.W.D., McCaig, A.M., Grant, N.T., 1991. The chemistry of brines from an Alpine thrust system in the central Pyrenees: an application of fluid inclusion analysis to the study of fluid behaviour in orogenesis. Geochimica et Cosmochimica Acta 55, 1021-1030.

Bennett, J.N., Grant, J.N., 1980. Analysis of fluid inclusions using a pulsed laser micro-probe. Mineralogical Magazine 43, 945-947.

Berry, A.J., Harris, A.C., Kamenetsky, V.S., Newville, M., Sutton, S.R., 2009. The speciation of copper in natural fluid inclusions at temperatures up to 700 degrees C. Chemical Geology 259, 2-7.

Berry, A.J., Hack, A.C., Mavrogenes, J.A., Newville, M., Sutton, S.R., 2006. A XANES study of Cu speciation in hightemperature brines using synthetic fluid inclusions. American Mineralogist 91, 1773-1782.

Bertelli, M., Baker, T., Cleverley, J.S., Ulrich, T., 2009. Geochemical modelling of a Zn-Pb skarn: Constraints from LA-ICP-MS analysis of fluid inclusions. Journal of Geochemical Exploration 102, $13-26$.

Beuchat, S., Moritz, R., Pettke, T., 2004. Fluid evolution in the W-Cu-Zn-Pb San Cristobal vein, Peru: fluid inclusion and stable isotope evidence. Chemical Geology 210, 201-224.

Bleiner, D., Hametner, K., Günther, D., 2000. Optimization of a laser ablation-inductively coupled plasma "time of flight" mass spectrometry system for short transient signal acquisition. Fresenius Journal of Analytical Chemistry $368,37-44$.

Bodnar, R.J., 2003. Reequilibration of fluid inclusions. In: Fluid inclusions: Analysis and interpretation (Samson, I.M., Anderson, A., Marshall, D., eds.). Mineralogical Association of Canada Short Course Series Volume 32, 213231. 
Bodnar, R.J., Sterner, S.M., 1985. Synthetic fluid inclusions in natural quartz. II. Application to PVT studies. Geochimica et Cosmochimica Acta 49, 1855-1859.

Bodnar, R.J., Sterner, S.M., 1987. Synthetic fluid inclusions. In: Hydrothermal Experimental Techniques, (Ulmer, G.C., Barnes, H.L., eds.). John Wiley \& Sons, New York, 423-457.

Bodnar, R.J., Burnham, C.W., Sterner, S.M., 1985. Synthetic fluid inclusions in natural quartz. III. Determination of phase equilibrium properties in the system $\mathrm{H}_{2} \mathrm{O}-\mathrm{NaCl}$ to $1000 \mathrm{C}$ and 1500 bars. Geochimica et Cosmochimica Acta $49,1861-1873$

Borisova, A.Y., Freydier, R., Polve, M., Salvi, S., Candaudap, F., Aigouy, T., 2008. In situ multi-element analysis of the Mount Pinatubo quartz-hosted melt inclusions by NIR femtosecond laser ablation-inductively coupled plasma-mass spectrometry. Geostandards and Geoanalytical Research 32, 209-229.

Bottrell, S.H., Yardley, B., Buckley, F., 1988. A modified crush-leach method for the analysis of fluid inclusion electrolytes. Bulletin de Minéralogie 111, 279-290.

Bourcier, W.L., Barnes, H.L., 1987. Rocking autoclaves for hydrothermal experiments I. The flexible reaction-cell system. In: Hydrothermal experimental techniques (Ulmer, G. C., Barnes, H. L. eds.). Hydrothermal experimental techniques. John Wiley \& Sons.

Bouse, R.M., Ruiz, J., Titley, S.R., Tosdal, R.M., Wooden, J.L., 1999. Lead isotope compositions of Late Cretaceous and early Tertiary igneous rocks and sulfide minerals in Arizona: Implications for the sources of plutons and metals in porphyry copper deposits. Economic Geology 94, 211-244.

Burla, S., Oberli, F., Heimhofer, U., Wiechert, U., Weissert, H., 2009. Improved time control on Cretaceous coastal deposits: new results from $\mathrm{Sr}$ isotope measurements using laser ablation. Terra Nova 21, 401-409.

Candela, P.A., Holland H.D., 1984. The partitioning of copper and molybdenum between silicate melts and aqueous fluids. Geochimica et Cosmochimica Acta 48, 373-380.

Catchpole, H., Kouzmanov, K., Fontbote, L., Guillong, M., Heinrich, C.A., 2011. Fluid evolution in zoned Cordilleran polymetallic veins - Insights from microthermometry and LA-ICP-MS of fluid inclusions. Chemical Geology 281, 293-304

Catanzaro, E.J., Murphy T.J., Garner, E.L., Shields, W.R., 1969. Absolute isotopic abundance ratio and atomic weight of terrestrial rubidium. Journal of Research of the National Bureau of Standards, Sect. A, 73A, 511-516.

Ciobanu C.L., Cook N.J., Damian F., Damian G., 2006. Gold scavenged by bismuth melts: an example from Alpine shear-remobilizates in the Highis massif, Romania. Mineralogy and Petrology 87, 351-384.

Chou, I.C., Eugster, H.P., 1977. Solubility of magnetite in supercritical chloride solutions. American Journal of Science 277, 1296-1314.

Currie, L.A., 1968. Limits for qualitative detection and quantitative determination. Analytical Chemistry 40, 586-593.

Currie, L.A., 1995. Nomenclature in evaluation of analytical methods including detection and quantification capabilities (IUPAC Recommendations 1995). Pure \& Applied Analytical Chemistry 67, 1699-1723.

Czamanske, G.K., Roedder, E., Burns, F.C., 1963. Neutron activation analysis of fluid inclusions for copper, manganese, and zinc. Science 140(356), 401-403.

Danyushevsky, L.V., McNeill, A.W., Sobolev, A.V., 2002. Experimental and petrological studies of melt inclusions in phenocrysts from mantle-derived magmas: an overview of techniques, advantages and complications. Chemical Geology 183, 5-24.

Diamond, L.W., 1990. Fluid inclusion evidence for P-V-T-X evolution of hydrothermal solutions in late-Alpine goldquartz veins at Brusson, northwest Italian Alps. American Journal of Science 290, 912-958.

Diamond, L.W., 1992. Stability of $\mathrm{CO}_{2}$ clathrate hydrate $+\mathrm{CO}_{2}$ liquid $+\mathrm{CO}_{2}$ vapour+aqueous $\mathrm{KCl}-\mathrm{NaCl}$ solutions experimental determination and application to salinity estimates of fluid inclusions. Geochimica et Cosmochimica Acta 56, 273-280.

Diamond, L.W., Jackman, J.A., Charoy, B., 1991. Cation ratios of fluid inclusions in a gold-quartz vein at Brusson, Val d'Ayas, northwestern Italian Alps: comparison of bulk crush-leach results with SIMS analyses of individual inclusions. Chemical Geology 90, 71-78.

Doe, B.R., Tilling, R.I., Hedge, C.E., Klepper, M.R., 1968. Lead and strontium isotope studies of the Boulder Batholith, southwestern Montana. Economic Geology 63, 884-906.

Douglas N., Mavrogenes J., Hack A., England R., 2000. The liquid bismuth collector model: an alternative gold deposition mechanism. $15^{\text {th }}$ Australian Geological Convention, Geological Society of Australia, Abstract 135.

Duc-Tin, Q., Audétat, A., Keppler, H., 2007. Solubility of tin in (Cl, F)-bearing aqueous fluids at 700 degrees C, 140 MPa: a LA-ICP-MS study on synthetic fluid inclusions. Geochimica et Cosmochimica Acta 71(13), 3323-3335.

Eggins, S.M., Kinsley, L.P.J., Shelley, J.M.G., 1998. Deposition and element fractionation processes during atmospheric pressure laser sampling for analysis by ICP-MS. Applied Surface Science 129, 278-286.

Evans, R.D., Hintelmann, H., Dillon, P.J., 2001. Measurement of high precision isotope ratios for mercury from coals using transient signals. Journal of Analytical Atomic Spectrometry 16, 1064-1069. 
Fabre, C., Boiron, M.C., Dubessy, J., Chabiron, A., Charoy, B., Crespo, T.M., 2002. Advances in lithium analysis in solids by means of laser- induced breakdown spectroscopy: An exploratory study. Geochimica et Cosmochimica Acta $66,1401-1407$

Ferrando, S., Frezzotti, M.L., Petrelli, M., Compagnoni, R., 2009. Metasomatism of continental crust during subduction: the UHP whiteschists from the Southern Dora-Maira Massif (Italian Western Alps). Journal of Metamorphic Geology 27, 739-756.

Frank, M.R., Candela, P.A., Piccoli, P.M., Glascock, M.D., 2002. Gold solubility, speciation, and partitioning as a function of $\mathrm{HCl}$ in the brine-silicate melt-metallic gold system at $800^{\circ} \mathrm{C}$ and $100 \mathrm{MPa}$. Geochimica et Cosmochimica Acta 66, 3719-3732.

Frank, M.R., Simon, A., Pettke, T., Candela, P.A., Piccoli, P.M., 2011. Gold and copper partitioning between vapour and liquid at $800{ }^{\circ} \mathrm{C}$ and $100 \mathrm{MPa}$. Geochimica et Cosmochimica Acta 75, 2470-2482.

Fryer, B.J., Jackson, S.E., Longerich, H.P., 1995. Design, operation and role of the laser-ablation microprobe coupled with an inductively-coupled plasma - mass-spectrometer (LAM-ICP-MS) in the earth sciences. Canadian Mineralogist 33, 303-312.

Gagnon, J., Samson, I., Fryer, B., 2003. LA-ICP-MS analysis of fluid inclusions. In: Fluid inclusions: Analysis and interpretation (Samson, I.M., Anderson, A., Marshall, D., eds.). Mineralogical Association of Canada Short Course Series Volume 32, 291-318.

Glaus, R., Kaegi, R., Krumeich, F., Günther, D., 2010. Phenomenological studies on structure and elemental composition of nanosecond and femtosecond laser-generated aerosols with implications on laser ablation inductively coupled plasma mass spectrometry. Spectrochimica Acta Part B-Atomic Spectroscopy 65, 812-822.

Goldstein R.H., Reynolds T.J., 1994. Systematics of fluid inclusions in diagenetic minerals. Society for Sedimentary Geology Short Course 31, 199p.

Green T.H., 1981. Experimental evidence for the role of accessory phases in magma genesis. Journal of Volcanology and Geothermal Research 10, 405-422.

Guillong, M., Günther, D., 2002. Effect of particle size distribution on ICP-induced elemental fractionation in laser ablation-inductively coupled plasma-mass spectrometry. Journal of Analytical Atomic Spectrometry 17, 831-837.

Guillong, M., Heinrich, C.A., 2007a. Sensitivity enhancement in laser ablation ICP-MS using small amounts of hydrogen in the carrier gas. Journal of Analytical Atomic Spectrometry 22, 1488-1494.

Guillong, M., Heinrich, C.A., 2007b. La-ICP-MS analysis of inclusions: improved ablation and detection. $19^{\text {th }}$ Biennial Conference "European Current Research on Fluid Inclusions, ECROFI-XIX", Bern, 82.

Guillong, M., Latkoczy, C., Seo, J.H., Günther, D., Heinrich, C.A., 2008a. Determination of sulfur in fluid inclusions by laser ablation ICP-MS. Journal of Analytical Atomic Spectrometry 23, 1581-1589.

Guillong, M., Meier, D.L., Allan, M.M., Heinrich, C.A., Yardley, B.W.D., 2008b. SILLS: A MATLAB-based program for the reduction of laser ablation ICP-MS data of homogeneous materials and inclusions. In: Laser ablation ICPMS in the Earth Sciences: Current practices and outstanding issues (Sylvester, P., ed.). Mineralogical Association of Canada Short Course Series Volume 40, 328-333.

Guillong, M., Pettke, T., Danyushevsky, L., 2011. Fluid inclusion analysis by Laser ablation ICPMS: How consistent are element ratios? Abstract. Goldschmidt 2011 Conference, Prague, August 14-19.

Günther, D., 2001. Quantitative fluid inclusion analysis using a $193 \mathrm{~nm}$ Excimer laser-ablation system coupled to ICPMS. In: Laser ablation ICP-MS in the Earth Sciences (Sylvester, P., ed.). Mineralogical Association of Canada Short Course Series Volume 29, 47-62.

Günther, D., Hattendorf, B., 2005. Solid sample analysis using laser ablation inductively coupled plasma mass spectrometry. TRAC - Trends in Analytical Chemistry 24, 255-265.

Günther, D., Heinrich, C.A., 1999. Enhanced sensitivity in laser ablation-ICP mass spectrometry using helium-argon mixtures as aerosol carrier - Plenary Lecture. Journal of Analytical Atomic Spectrometry 14, 1363-1368.

Günther, D., Audétat, A., Frischknecht, R., Heinrich, C.A., 1998. Quantitative analysis of major, minor and trace elements in fluid inclusions using laser ablation inductively coupled plasma mass spectrometry. Journal of Analytical Atomic Spectrometry 13, 263-270.

Günther, D., Frischknecht, R., Heinrich, C.A., Kahlert, H.J., 1997. Capabilities of an argon fluoride 193 nm Excime laser for laser ablation inductively coupled plasma mass spectrometry microanalysis of geological materials Journal of Analytical Atomic Spectrometry 12, 939-944.

Hack, A.C., Mavrogenes, J.A., 2006. A synthetic fluid inclusion study of copper solubility in hydrothermal brines from 525 to $725^{\circ} \mathrm{C}$ and 0.3 to $1.7 \mathrm{GPa}$. Geochimica et Cosmochimica Acta 70, 3970-3985.

Halter, W., Pettke, T., Heinrich, C.A., 2002a. The origin of Cu/Au ratios in porphyry type ore deposits. Science 296, 1844-1846.

Halter, W.E., Pettke, T., Heinrich, C.A., Rothen-Rutishauser, B., 2002b. Major to trace element analysis of melt inclusions by laser-ablation ICP-MS: methods of quantification. Chemical Geology 183, 63-86.

Hanley, J.J., Mungall, J.E., Pettke, T., Spooner, E.T.C., Bray, C.J., 2005a. Ore metal redistribution by hydrocarbonbrine and hydrocarbon-halide melt phases, North Range footwall of the Sudbury Igneous Complex, Ontario, Canada. Mineralium Deposita 40, 237-256. 
Hanley, J.J., Pettke, T., Mungall, J.E., Spooner, E.T.C., 2005b. Investigations of the behavior and distribution of platinum and gold in silicate melt - brine mixtures at $1.5 \mathrm{kbar}, 600$ to $800^{\circ} \mathrm{C}$ using synthetic fluid inclusions methods: a laser ablation ICPMS pilot study. Geochimica et Cosmochimica Acta 69, 2593-2611.

Hanley, J.J., Mungall, J.E., Pettke, T., Spooner, E.T.C., Bray, C.J., 2008. Fluid and halide melt inclusions of magmatic origin in the ultramafic and lower banded series, Stillwater Complex, Montana, USA. Journal of Petrology 49, 1133-1160.

Heijlen, W., Banks, D.A., Muchez, P., Stensgard, B.M., Yardley, B.W.D., 2008. The nature of mineralizing fluids of the Kipushi Zn-Cu deposit, Katanga, Democratic Repubic of Congo: quantitative fluid inclusion analysis using laser ablation ICP-MS and bulk crush-leach methods. Economic Geology 103, 1459-1482.

Heinrich C.A., Günther D., Audétat A., Ulrich T., Frischknecht R., 1999. Metal fractionation between magmatic brine and vapor, determined by microanalysis of fluid inclusions. Geology 27, 755-758.

Heinrich, C.A., Pettke, T., Halter, W.E., Aigner-Torres, M., Audétat, A., Günther, D., Hattendorf, B., Bleiner, D., Guillong, M., Horn, I., 2003. Quantitative multi-element analysis of minerals, fluid and melt inclusions by laserablation inductively-coupled-plasma mass- spectrometry. Geochimica et Cosmochimica Acta 67, 3473-3497.

Heinrich, C.A., Ryan, C.G., Mernagh, T.P., Eadington, P.J., 1992. Segregation of ore metals between magmatic brine and vapor - a fluid inclusion study using PIXE microanalysis. Economic Geology 87, 1566-1583.

Hemley, J.J., Cygan, G.L., Fein, J.B., Robinson, G.R., d'Angelo, W.M., 1992. Hydrothermal ore-forming processes in the light of studies in rock-buffered systems: I. Iron-copper-zinc-lead sulfide solubility relations. Economic Geology, 87, 1-22.

Hirata, T., Hayano, Y., Ohno, T., 2003. Improvements in precision of isotopic ratio measurements using laser ablation-multiple collector-ICP-mass spectrometry: reduction of changes in measured isotopic ratios. Journal of Analytical Atomic Spectrometry 18, 1283-1288.

Horn, I., von Blanckenburg, F., 2007. Investigation on elemental and isotopic fractionation during $196 \mathrm{~nm}$ femtosecond laser ablation multiple collector inductively coupled plasma mass spectrometry. Spectrochimica Acta Part B-Atomic Spectroscopy 62, 410-422.

Jackson, M.G., Hart, S.R., 2006. Strontium isotopes in melt inclusions from Samoan basalts: Implications for heterogeneity in the Samoan plume. Earth and Planetary Science Letters 245, 260-277.

Jochum, K. P., and 11 others. Determination of reference values for NIST SRM 610-617 glasses following ISO guidelines. Geostrand. Geoanal. Res., doi: 10.1111/j.1751-908X.2011.00120.x

Johnson, C.M., Lipman, P.W., Czamanske, G.K., 1990. H, O, Sr, Nd, and Pb isotope geochemistry of the Latir Volcanic Field and cogenetic intrusions, New-Mexico, and relations between evolution of a continental magmatic center and modifications of the lithosphere. Contributions to Mineralogy and Petrology 104, 99-124.

Kamenetsky, V.S., Wolfe, R.C., Eggins, S.M., Mernagh, T.P., Bastrakov, E., 1999. Volatile exsolution at the Dinkidi Cu-Au porphyry deposit, Philippines: A melt-inclusion record of the initial ore-forming process. Geology 27, 691694.

Kamenetsky V.S., Danyushevsky L.V., 2005. Metals in quartz-hosted melt inclusions: natural facts and experimental artifacts. American Mineralogist 90, 1674-1678.

Klemm, L., Pettke, T., Graeser, S., Mullis, J., Kouzmanov, K., 2004. Fluid mixing as the cause of sulphide precipitation at Albrunpass, Binn Valley, Central Alps. Schweizerische Mineralogische und Petrographische Mitteilungen 84, 189-212.

Klemm, L.M., Pettke, T., Heinrich, C.A., Campos, E., 2007. Hydrothermal evolution of the El Teniente deposit, Chile: porphyry Cu-Mo ore deposition from low-salinity magmatic fluids. Economic Geology 102, 1021-1045.

Klemm, L.M., Pettke, T., Heinrich, C.A., 2008. Fluid and source magma evolution of the Questa porphyry Mo deposit, New Mexico, USA. Mineralium Deposita 43, 533-552.

Koch, J., Günther, D., 2007. Femtosecond laser ablation inductively coupled plasma mass spectrometry: achievements and remaining problems. Analytical and Bioanalytical Chemistry 387, 149-153.

Kostova, B., Pettke, T., Driesner, T., Petrov, P., Heinrich, C.A., 2004. LA ICP-MS study of fluid inclusions in quartz from the Yuzhna Petrovitsa deposit, Madan ore field, Bulgaria. Schweizerische Mineralogische und Petrographische Mitteilungen 84, 25-36.

Kouzmanov, K., Pettke, T., Heinrich, C.A., 2010. Direct analysis of ore-precipitating fluids: combined IR microscopy and LA-ICP-MS study of fluid inclusions in opaque ore minerals. Economic Geology 105, 351-373.

Kramers, J.D., Tolstikhin, I.N., 1997. Two terrestrial lead isotope paradoxes, forward transport modelling, core formation and the history of the continental crust. Chemical Geology 139, 75-110.

Kurosawa, M., Shimano, S., Ishii, S., Shima, K., Nakajima, T., Kato, T., 2003. Quantitative PIXE analysis of single fluid inclusions in quartz vein: Chemical composition of hydrothermal fluids related to granite. Nuclear Instruments, Methods in Physics Research Section B- Beam Interactions with Materials and Atoms 210, 464467.

Lambrecht, G., Diamond, L.W., Pettke, T., 2008. Modification of gas speciation in quartz-hosted fluid inclusions by stray laser radiation during LA-ICPMS analysis. American Mineralogist 93, 1187-1190. 
Landtwing, M.R., Furrer, C., Redmond, P.B., Pettke, T., Guillong, M., Heinrich, C.A., 2010. The Bingham Canyon porphyry Cu-Mo-Au deposit. III. Zoned copper-gold ore deposition by magmatic vapor expansion. Economic Geology 105, 91-118.

Landtwing, M.R., Pettke, T., Halter, W.E., Heinrich, C.A., Redmond, P.B., Einaudi, M.T., Kunze, K., 2005. Copper deposition during quartz dissolution by cooling magmatic-hydrothermal fluids: the Bingham Porphyry. Earth and Planetary Science Letters 235, 229-243.

Leach A.M., Hieftje G.M., 2000. Methods for shot-to-shot normalization in laser ablation with an inductively coupled plasma time-of-flight mass spectrometer. Journal of Analytical Atomic Spectrometry 15, 1121-1124.

Lerchbaumer, L., Audétat, A., 2009. Partitioning of Cu between vapor and brine - An experimental study based on LA-ICP-MS analysis of synthetic fluid inclusions. $19^{\text {th }}$ Annual VM Goldschmidt Conference, Davos, Switzerland, A744.

Li, Y., Audétat, A., 2009. A method to synthesize large fluid inclusions in quartz at controlled times and under favorable growth conditions. American Mineralogist 94, 367-371.

Li, Y., Audétat, A., Lerchbaumer, L., Xiong, X.L., 2009. Rapid Na, Cu exchange between synthetic fluid inclusions and external aqueous solutions: evidence from LA-ICP-MS analysis. Geofluids 9, 321-329.

Longerich, H.P., Jackson, S.E., Günther, D., 1996. Laser ablation inductively coupled plasma mass spectrometric transient signal data acquisition and analyte concentration calculation. Journal of Analytical Atomic Spectrometry 11, 899-904.

Loucks, R.R., Mavrogenes, J.A., 1999. Gold solubility in supercritical hydrothermal brines measured in synthetic fluid inclusions. Science 284, 2159-2163.

Lüders, V., Reutel, C., Hoth, P., Banks, D.A., Mingram, B., Pettke, T., 2005. Fluid and gas migration in the North German Basin: fluid inclusion and stable isotope constraints. International Journal of Earth Sciences 94, 9901009

Mank, A.J.G., Mason, P.R.D., 1999. A critical assessment of laser ablation ICP-MS as an analytical tool for depth analysis in silica-based glass samples. Journal of Analytical Atomic Spectrometry 14, 1143-1153.

Manning, C.E., 1994. The solubility of quartz in $\mathrm{H}_{2} \mathrm{O}$ in the lower crust and upper mantle. Geochimica et Cosmochimica Acta 58, 4831-4839.

Manning, C.E., Boettcher, S.L., 1994 Rapid-quench hydrothermal experiments at mantle pressures and temperatures. American Mineralogist 79, 1153-1158.

Marschall, H.R., Ludwig, T., 2004. The low-boron contest: minimising surface contamination and analysing boron concentrations at the ng/g-level by secondary ion mass spectrometry. Mineralogy and Petrology 81, $265-278$.

Mason, P.R.D., Nikogosian, I.K., vanBergen, M.J., 2008. Major and trace element analysis of melt inclusions by laser ablation ICP-MS. In: Laser ablation ICP-MS in the Earth Sciences: Current practices and outstanding issues (Sylvester, P., ed). Mineralogical Association of Canada Short Course Series Volume 40, 219-240.

Mavrogenes, J.A., Bodnar, R.J., 1994. Hydrogen movement into and out of fluid inclusions in quartz: experimental evidence and geologic implications. Geochimica et Cosmochimica Acta 58, 141-148.

Moissette, A., Shepherd, T.J., Chenery, S.R., 1996. Calibration strategies for the elemental analysis of individual aqueous fluid inclusions by laser ablation inductively coupled plasma mass spectrometry. Journal of Analytical Atomic Spectrometry 11, 177-185.

Mutchler, S.R., Fedele, L., Bodnar, R.J., 2008. Analysis management system (AMS) for reduction of laser ablation ICP-MS data. In: Laser ablation ICP-MS in the Earth Sciences: Current practices and outstanding issues (Sylvester, P., ed). Mineralogical Association of Canada Short Course Series Volume 40, 328-333.

Nagaseki, H., Hayashi, K-I., 2008. Experimental study of the behavior of copper and zinc in a boiling hydrothermal system. Geology 36, 27-30.

Nambu M., Sato T., 1981. The analysis of fluid inclusions in the microgram range with an ion microanalyzer. Bulletin de Minéralogie 104, 827-833.

Nathans, M.W., Leider, M.J. 1962. Studies on bismuth alloys. I. Liquidus curves of the bismuth-copper, bismuth-silver and bismuth-gold systems. Physical Chemistry 66, 2012-2015.

Nebel, O., Mezger, K., Scherer, E.E., Münker, C. 2005. High precision determinations of ${ }^{87} \mathrm{Rb} /{ }^{85} \mathrm{Rb}$ in geologic materials by MC-ICP-MS. International Journal of Mass Spectrometry 246, 10-18

Newton, R.C., Manning, C.E., 2000. Quartz solubility in concentrated aqueous $\mathrm{NaCl}$ solutions at deep crust-upper mantle metamorphic conditions: 2-15 kbar and 500-900 ${ }^{\circ} \mathrm{C}$. Geochimica et Cosmochimica Acta 64, $2993-3005$.

Newton, R.C., Manning, C.E., 2002. Experimental determination of calcite solubility in $\mathrm{H}_{2} \mathrm{O}-\mathrm{NaCl}$ solutions at deep crust/upper mantle pressures and temperatures: implications for metasomatic processes in shear zones. American Mieralogist 87, 1401-1409.

Oberthür T., Weiser T.W., 2008: Gold-bismuth-telluride-sulphide assemblages at the Viceroy mine, Harare-BinduraShamva greenstone belt, Zimbabwe. Mineralogical Magazine 72, 953-970.

Paul, B., Woodhead, J.D., Hergt, J., 2005. Improved in situ isotope analysis of low-Pb materials using LA-MC-ICPMS with parallel ion counter and Faraday detection. Journal of Analytical Atomic Spectrometry 20, 1350-1357. 
Pettke, T., 2006. In situ laser-ablation ICPMS analysis of melt inclusions and prospects for constraining subduction zone magmatism. In: Melt Inclusions in Plutonic Rocks (Webster, J. D., ed.). Mineralogical Association of Canada Short Course Series Volume 36, 51-80.

Pettke, T., 2008. Analytical protocols for element concentration and isotope ratio measurements in fluid inclusions by LA-(MC)-ICP-MS. In: Laser ablation ICP-MS in the Earth Sciences: Current practices and outstanding issues (Sylvester, P., Ed). Mineralogical Association of Canada Short Course Series Volume 40, 189-218.

Pettke, T., Diamond, L.W., 1995. Rb-Sr isotopic analysis of fluid inclusions in quartz: evaluation of bulk extraction procedures and geochronometer systematics using synthetic fluid inclusions. Geochimica et Cosmochimica Acta 59, 4009-4027.

Pettke, T., Frei, R., 1996. Isotope systematics in vein gold from Brusson, Val d'Ayas (NW Italy), 1. Pb/Pb evidence for a Piemonte metaophiolite Au source. Chemical Geology 127, 111-124.

Pettke, T., Diamond, L.W., Kramers, J.D., 2000a. Mesothermal gold lodes in the north-western Alps: a review of genetic constraints from radiogenic isotopes. European Journal of Mineralogy 12, 213-230.

Pettke, T., Halter, W.E., Webster, J.D., Aigner-Torres, M., Heinrich, C.A., 2004. Accurate quantification of melt inclusion chemistry by LA-ICPMS: a comparison with EMP and SIMS and advantages and possible limitations of these methods. Lithos 78, 333-361.

Pettke, T., Heinrich, C.A., Ciocan, A.C., Günther, D., 2000b. Quadrupole mass spectrometry and optical emission spectroscopy: detection capabilities and representative sampling of short transient signals from laser-ablation. Journal of Analytical Atomic Spectrometry 15, 1149-1155.

Pettke, T., Oberli, F., Audétat, A., Wiechert, U., Heinrich, C.A., 2011. Quantification of transient signals in multiple collector inductively coupled plasma mass spectrometry: Accurate lead isotope ratio determination by laser ablation of individual fluid inclusions. Journal of Analytical Atomic Spectrometry 26, 475-492.

Pettke, T., Oberli, F., Heinrich, C.A., 2010. The magma and metal source of giant porphyry-type ore deposits, based on lead isotope microanalysis of individual fluid inclusions. Earth and Planetary Science Letters 296, $267-277$.

Portnyagin, M., Almeev, R., Matveev, S., Holtz, F., 2008. Experimental evidence for rapid water exchange between melt inclusions in olivine and host magma. Earth and Planetary Science Letters 272, 541-552.

Ramsey, M.H., Coles, B.J., Wilkinson, J.J., Rankin, A.H., 1992. Single fluid inclusion analysis by laser ablation inductively coupled plasma atomic emission spectrometry - quantification and validation. Journal of Analytical Atomic Spectrometry 7, 587-593.

Rankin, A.H., Ramsey, M.H., Coles, B., Vanlangevelde, F., Thomas, C.R., 1992. the composition of hypersaline, ironrich granitic fluids based on laser-ICP and synchrotron-XRF microprobe analysis of individual fluid inclusions in topaz, Mole Granite, eastern Australia. Geochimica et Cosmochimica Acta 56, 67-79.

Redmond, P.B., Einaudi, M.T., Inan, E.E., Landtwing, M.R., Heinrich, C.A., 2004. Copper deposition by fluid cooling in intrusion-centered systems: New insights from the Bingham porphyry ore deposit, Utah. Geology 32, $217-220$.

Richard, A., Pettke, T., Cathelineau, M., Boiron, M.C., Mercadier, J., Cuney, M., Derome, D., 2010. Brine-rock interaction in the Athabasca basement (McArthur River U deposit, Canada): consequences for fluid chemistry and uranium uptake. Terra Nova 22, 303-308.

Roedder, E., 1984. Fluid Inclusions. In: Reviews In Mineralogy (Ribbe, P.H., ed.) Mineralogical Society of America Volume 12, 646p.

Rusk, B., Reed, M., Dilles, J.H., 2008. Fluid inclusion evidence for magmatic-hydrothermal fluid evolution in the porphyry copper-molybdenum deposit, Butte, Montana. Economic Geology 103, 307-334.

Rusk, B.G., Reed, M.H., Dilles, J.H., Klemm, L.M., Heinrich, C.A., 2004. Compositions of magmatic hydrothermal fluids determined by LA-ICP-MS of fluid inclusions from the porphyry copper-molybdenum deposit at Butte, Mt. Chemical Geology 210, 173-199.

Rusk, B., Koenig, A., Lowers, H., 2011. Visualizing trace element distribution in quartz using cathodoluminescence, electron microprobe, and laser ablation-inductively coupled plasma-mass spectrometry. American Mineralogist 96, 703-708.

Scambelluri, M., Bottazzi, P., Trommsdorff, V., Vannucci, R., Hermann, J., Gomez-Pugnaire, M.T., Vizcaino, V.L.S., 2001a. Incompatible element-rich fluids released by antigorite breakdown in deeply subducted mantle. Earth and Planetary Science Letters 192, 457-470.

Scambelluri, M., Muntener, O., Ottolini, L., Pettke, T., Vannucci, R., 2004a. The fate of B, Cl and Li in the subducted oceanic mantle and in the antigorite breakdown fluids. Earth and Planetary Science Letters 222, $217-234$.

Seo, J.H., Guillong, M., Heinrich, C.A., 2009. The role of sulphur in the formation of magmatic-hydrothermal coppergold deposits. Earth and Planetary Science Letters 282, 323-328.

Seo, J.H., Guillong, M., Aerts, M., Zajacz, Z., Heinrich, C.A., 2011. Microanalysis of S, Cl, and Br in fluid inclusions by LA-ICP-MS. Chemical Geology 284, 35-44.

Seydoux-Guillaume, A.M., Freydier, R., Poitrasson, F., d'Abzac, F.X., Wirth, R., Datas, L., 2010. Dominance of mechanical over thermally induced damage during femtosecond laser ablation of monazite. European Journal of Mineralogy 22, 235-244. 
Seyfried, W.E. jr., Janecky, D.R., Berndt, M.E., 1987. Rocking autoclaves for hydrothermal experiments II. Fixedvolume systems. In: Hydrothermal experimental techniques (UImer, G.C., Barnes, H.L. eds.). Hydrothermal experimental techniques. John Wiley \& Sons.

Shepherd, T.J., Chenery, S.R., 1995. Laser-ablation ICP-MS elemental analysis of individual fluid inclusions - an evaluation study. Geochimica et Cosmochimica Acta 59, 3997-4007.

Simon, A.C., Pettke, T., 2009. Platinum solubility and partitioning in a felsic melt - vapor - brine assemblage. Geochimica et Cosmochimica Acta 73, 438-454.

Simon, A.C., Candela, P.A., Piccoli, P.M., Englander, L., 2008a. The effect of crystal - melt partitioning on the budgets of copper, gold, and silver. American Mineralogist 93, 1437-1448.

Simon, A.C., Frank, M.R., Pettke, T., Candela, P.A., Piccoli, P.M., Heinrich, C.A., 2005. Gold partitioning in meltvapor-brine systems. Geochimica et Cosmochimica Acta 69, 3321-3335.

Simon, A.C., Pettke, T., Candela, P.A., Piccoli, P.M., Heinrich, C.A., 2004. Magnetite solubility and iron transport in magmatic-hydrothermal environments. Geochimica et Cosmochimica Acta 68, 4905-4914.

Simon, A.C., Pettke, T., Candela, P.A., Piccoli, P.M., Heinrich, C.A., 2006. Copper partitioning in sulphur bearing magmatic systems. Geochimica et Cosmochimica Acta 70, 5583-5600.

Simon, A.C., Pettke, T., Candela, P.A., Piccoli, P.M., Heinrich, C.A., 2007. The partitioning behavior of As and Au in a haplogranite - vapor at magmatic conditions in sulphur-free and sulphur bearing systems. Geochimica et Cosmochimica Acta 71, 1764-1782.

Simon, A.C., Pettke, T., Candela, P.A., Piccoli, P.M., Heinrich, C.A., 2008b. The partitioning behavior of silver in a vapor - brine - rhyolite melt assemblage. Geochimica et Cosmochimica Acta 72, 1638 -1659.

Spandler, C., Mavrogenes, J., Hermann, J., 2007. Experimental constraints on element mobility from subducted sediments using high-P synthetic fluid/melt inclusions. Chemical Geology 239, 228-249.

Stein, H.J., Hannah, J.L., 1985. Movement and origin of ore fluids in Climax-type systems. Geology 13, $469-474$.

Sterner, S.M. (1992). Synthetic fluid inclusions: Part XI. Notes on the application of synthetic fluid inclusions to high P-T experimental aqueous geochemistry. American Mineralogist 77, 156-167.

Sterner, S.M., Bodnar, R.J., 1984. Synthetic fluid inclusions in natural quartz: I. Compositional types synthesized and applications to experimental geochemistry. Geochimica et Cosmochimica Acta 48, 2659-2668.

Sterner, S.M., Bodnar, R.J., 1989. Synthetic fluid inclusions. 7. Re-equilibration of fluid inclusions in quartz during laboratory-simulated metamorphic burial and uplift. Journal of Metamorphic Geology 7, 243-260.

Stoffell, B., Wilkinson, J.J., Jeffries, T.E., 2004. Metal transport and deposition in hydrothermal veins revealed by $213 \mathrm{~nm}$ UV laser ablation microanalysis of single fluid inclusions. American Journal of Science 304, 533-557.

Stoffell, B., Appold, M.S., Wilkinson, J.J., McClean, N.A., Jeffries, T.E., 2008. Geochemistry and evolution of Mississippi Valley-Type mineralizing brines from the Tri-state and Northern Arkansas Districts determined by LA-ICP-MS microanalysis of fluid inclusions. Economic Geology 103, 1411-1435.

Su, W.C., Heinrich, C.A., Pettke, T., Zhang, X.C., Hu, R.Z., Xia, B., 2009. Sediment-hosted gold deposits in Guizhou, China: products of wall-rock sulfidation by deep crustal fluids. Economic Geology 104, 73-93.

Tanner, M., 2010. Shorter signals for improved signal to noise ratio, the influence of Poisson distribution. Journal of Analytical Atomic Spectrometry 25, 405-407.

Tanner, M., Günther, D., 2009. Short transient signals, a challenge for inductively coupled plasma mass spectrometry, a review. Analytica Chimica Acta 633, 19-28

Tooth, B., Brugger J., Ciobanu C., Liu W., 2008. Modeling of gold scavenging by bismuth melts coexisting with hydrothermal fluids. Geology 36, 815-818.

Tsui, T.F., Holland, H.D., 1979. Analysis of fluid inclusions by laser microprobe. Economic Geology 74, $1647-1653$.

Ulrich, T., Günther, D., Heinrich, C.A., 1999. Gold concentrations of magmatic brines and the metal budget of porphyry copper deposits. Nature 399, 676-679.

Ulrich, T., Günther, D., Heinrich, C.A., 2002. Evolution of a porphyry Cu-Au deposit, based on LA-ICP-MS analysis of fluid inclusions: Bajo de la Alumbrera, Argentina (Vol 96, Pg 1743, 2001). Economic Geology 97, 1888-1920.

Ulrich, T., Mavrogenes, J., 2008. An experimental study of the solubility of molybdenum in $\mathrm{H}_{2} \mathrm{O}$ and $\mathrm{KCl}-\mathrm{H}(2) \mathrm{O}$ solutions from 500 degrees C to 800 degrees C, and 150 to $300 \mathrm{MPa}$. Geochimica et Cosmochimica Acta 72 2316-2330.

Volk, H., Fuentes, D., Fuerbach, A., Miese, C., Koehler, W., Barsch, N., Barcikowski, S., 2010. First on-line analysis of petroleum from single inclusion using ultrafast laser ablation. Organic Geochemistry 41, 74-77.

Vroon, P.Z., van der Wagt, B., Koornneef, J.M., Davies, G.R., 2008. Problems in obtaining precise and accurate Sr isotope analysis from geological materials using laser ablation MC-ICPMS. Analytical and Bioanalytical Chemistry 390, 465-476.

Waight, T., Baker, J., Peate, D., 2002. Sr isotope ratio measurements by double-focusing MC-ICPMS: techniques, observations and pitfalls. International Journal of Mass Spectrometry 221, 229-244. 
Whitney, J.A., Hemley, J.J., Simon, F.O., 1985. The concentration of iron in chloride solutions equilibrated with synthetic granite compositions: the sulphur-free system. Economic Geology 80, 444-460.

Wilkinson, J.J., Stoffell, B., Wilkinson, C.C., Jeffries, T.E., Appold, M.S., 2009. Anomalously metal-rich fluids form hydrothermal ore deposits. Science 323, 764-767.

Williams, C.D., Ripley, E.M., Li, C.S., 2010. Variations in Os isotope ratios of pyrrhotite as a result of water-rock and magma-rock interaction: constraints from Virginia Formation-Duluth Complex contact zones. Geochimica et Cosmochimica Acta 74, 4772-4792.

Wood, S.A., Crerar, D.A., Borcsik, M.P., 1987. Solubility of the assemblage pyrite-pyrrhotite-magnetite-sphaleritegalena-gold-stibnite-bismuthinite-argentite-molybdenite in $\mathrm{H}_{2} \mathrm{O}-\mathrm{NaCl}-\mathrm{CO}_{2}$ solutions from 200 to $350^{\circ} \mathrm{C}$. Economic Geology 82, 1864-1887.

Woodhead, J., Swearer, S., Hergt, J., Maas, R., 2005. In situ Sr-isotope analysis of carbonates by LA-MC-ICP-MS iinterference corrections, high spatial resolution and an example from otolith studies. Journal of Analytical Atomic Spectrometry 20, 22-27.

Zacharias, J., Wilkinson, J.J., 2007) Exlam 2000: Excel VBA application for processing of transient signals from laser ablation (LA-ICP-MS) of fluid inclusions and solid phases. $19^{\text {th }}$ Biennial Conference "European Current Research on Fluid Inclusions, ECROFI-XIX", Bern, 194

Zajacz, Z., Halter, W.E., Pettke, T., Guillong, M., 2008. Determination of fluid/melt partition coefficients by LA-ICPMS analysis of co-existing fluid and silicate melt inclusions: controls on element partitioning. Geochimica et Cosmochimica Acta 72, 2169-2197.

Zajacz, Z., Hanley, J.J., Heinrich, C.A., Halter, W.E., Guillong, M., 2009. Diffusive reequilibration of quartz-hosted silicate melt and fluid inclusions: Are all metal concentrations unmodified? Geochimica et Cosmochimica Acta 73, 3013-3027.

Zajacz, Z., Seo, J.H., Candela, P.A., Piccoli, P.M., Heinrich, C.A., Guillong, M., 2010. Alkali metals control the release of gold from volatile-rich magmas. Earth and Planetary Science Letters 297, 50-56.

Zajacz, Z., Seo, J.H., Candela, P.A., Piccoli, P.M., Tossell, J.A., 2011. The solubility of copper in high-temperature magmatic vapors: a quest for the significance of various chloride and sulfide complexes. Geochimica et Cosmochimica Acta 75, 2811-2827.

Zartman, R.E., 1974. Lead isotopic provinces in Cordillera of western United-States and their geologic significance. Economic Geology 69, 792-805. 


\section{Figure Captions}

1844 Fig. 1 Examples of fluid inclusions. (A) illustrates a homogeneous fluid inclusion assemblage. The phase proportions of water, vapour and tiny halite crystal are

Fig. 2 Sketch illustrating the general principle and fast transient signal obtained from the uniform, indicating that the phase assemblage formed during closed-system cooling of a fluid of constant composition. (B) shows a close-up of an individual fluid inclusion with tiny daughter crystals (note also the needle in the vapour bubble) that may contain the bulk mass of certain trace elements. (C) shows a heterogeneous fluid assemblage documenting stable coexistence of a high-density, saline aqueous liquid with a low-density, low-salinity aqueous vapour. Phase proportions are variable, representing variable liquid plus vapour mixtures; only the highest and lowest salinity inclusions are representative for the compositions of the respective one-phase end members. The boiling assemblage represents an experimental run product (Frank et al., 2011). LA-ICP-MS analysis of an individual inclusion (part of signal displayed in Fig. 4). Three signal intervals are mandatory for proper inclusion quantification, the signal backgrounds with laser off (interval 1), the inclusion interval and an interval of pure host mineral. The latter is taken either before the inclusion or, to minimize downhole fractionation effects and inhomogeneities in host composition, as the mean from an interval before and one after the inclusion (i.e., intervals 2 and 4). The inclusion signal (interval 3 ) actually represents a mixture of inclusion plus host mineral in a priori unknown proportions; hence, a host mineral correction is mandatory for obtaining accurate data, except for host minerals that do not contain any of the solutes as for example for diamond-hosted silicate inclusions.

Data of Table 1 plotted as $(A)$ element concentrations (labelled to the right of the graph) and $(B)$ element abundance ratios $(M /(N a+K+F e))$, where $M$ represents the metal as labelled to the right of the graph). In (A) the major cations $\mathrm{Na}, \mathrm{K}$ and $\mathrm{Fe}$ are uniform across the 4 successively entrapped assemblages; hence, they can be used for normalization of metal abundances as shown in (B). Copper documents a ca. $95 \%$ decrease in concentration across these 4 assemblages, and Au may have a lower concentration in assemblage 4 when compared to the uniform assemblages 1,2 and 3 . Note that the pattern of the data points is identical in figures $(A)$ and $(B)$; the pattern of data points in figure $(B)$ can thus be obtained without the use of an internal standard because the element abundance ratios are uniquely defined by use of external standardization only (see text for discussion). Also note that outliers in assemblages can be identified quickly in both absolute concentration and element abundance ratio data. The width of the bands for $\mathrm{Cu}$ represents 2 standard deviation uncertainties on assemblage average concentrations. 
Fig. 4 Plot A illustrates the ideal signal of a multiphase fluid inclusion of ca. $45 \mathrm{wt} \% \mathrm{NaCl}$ equivalent bulk salinity. The "Gaussian-shape" signal intensities of the different solutes evolve non-parallel; therefore, signal quantification can only be done by bulk signal integration. The rise and notably the decay of the inclusion analyte signals are slower than those of $\mathrm{Si}$ (the latter illustrates the washout speed of the ablation chamber), thus imaging the controlled layer-by-layer ablation of the fluid inclusion content. The dwell time was 10 ms except for Au for which 100 ms were employed to lower the limit of detection. Signal intensities are processed in cps (counts per second) to account for such differences in dwell time between analytes. The stepwise increase of the ${ }^{29} \mathrm{Si}$ signal (grey line) monitors the stepwise increase of beam size (black numbers, in $\mu \mathrm{m}$ ) prior to fluid inclusion opening. The fluid inclusion is then liberated by the straight ablation technique, i.e., drilling through the entire inclusion without change in laser beam size. Plot B illustrates a typical signal as obtained from uncontrolled rupturing of the fluid inclusion. In this case, the inclusion exploded upon the last beam size increase as could be observed on video screen. The signal shape also provides clues to whether the inclusion ablation was controlled or not. The transient signal peak is fast with notably rapid signal decay. Note the dashed line labelled $\mathrm{Na}$ ' that runs parallel to the signal decay of $\mathrm{Si}$ after laser beam off, demonstrating that the signal decay of $\mathrm{Na}$ (as all other analyte signals) is entirely controlled by the washout characteristics of the ablation chamber and not the result from controlled layer-by layer ablation of the fluid inclusion. This indicates an instantaneous release of inclusion material into the ablation cell. It therefore remains unconstrained how much of the fluid inclusion material (e.g., crystals) was lost upon explosion. Therefore, data from uncontrolled fluid inclusion ablations are likely heavily compromised. Both analyses were acquired with $\mathrm{H}_{2}$ admixed to the aerosol carrier gas.

Transient signal characteristically obtained from the LA-ICP-MS analysis of a mixed aqueo-carbonic fluid inclusion containing $\mathrm{H}_{2} \mathrm{O}_{\text {liq }}, \mathrm{CO}_{2 \text {,liq }}$ and $\mathrm{CO}_{2 \text {,vap }}$ (blue, dark and light green in the inset, respectively). "Background", "Host" and "Inclusion" refer to the respective signal intervals used for quantification. The signal resulted from the straight ablation method, using a $44 \mu \mathrm{m}$ beam (black numbers next to Si signal). Invariably, such aqueo-carbonic fluid inclusions show an extremely fast transient signal "spike" upon inclusion opening (see enlargement of signal in Fig. B), followed by the controlled ablation of the remaining inclusion content producing a signal hump. This initial, rapid release of most of the inclusion content results from an internal overpressure in the inclusion at room temperature that may be further increased due to laser beam heating prior to inclusion opening. Note the signal increases notably in $\mathrm{Na}$ and $\mathrm{Sr}$ upon beam size increase, testifying to surface contamination (in this case deposits from previous fluid inclusion ablations nearby) because similar signals are not observed when reducing the beam size to $44 \mu \mathrm{m}$ for 
inclusion ablation. The inset illustrates the ablation procedure employed here for deep-seated inclusions. After stepwise increase of the beam size, the $60 \mu \mathrm{m}$ beam is used to ablate excessive quartz above the inclusion in order to minimize negative side effects encountered for craters with large depth to diameter ratios and to eliminate surface contamination (sometimes referred to as "pre-ablation"). The 44 $\mu \mathrm{m}$ beam is then used for fluid inclusion ablation, thereby maximizing the mass proportion of inclusion in the mixed inclusion + host signal interval. The signal shown in Fig. 4a was produced in the same way. Analysis acquired without $\mathrm{H}_{2}$ admixed to the aerosol carrier gas. Sample is from the orogenic gold district of Brusson (Diamond, 1990; Pettke et al., 2000a). Modified from Pettke (2008).

Comparison of results for $L_{C}$ and $L_{D}$ (in counts per second) as a function of background count rate for equal background intervals of 50 replicates (sweeps) each. $L_{C}$ was calculated for $99.9 \%$ confidence (equation 3 in text), thus corresponding closely to the LOD formulation of Longerich et al. (1996; equation 2 in text), and $L_{D}$ was calculated using equation 6 in text at $95 \%$ confidence. Dwell time was set to $0.01 \mathrm{~s}$ and sensitivity was kept constant.

Plot of "LOD"s (in $\mu \mathrm{g} / \mathrm{g}$ ) as a function of the numbers of readings (sweeps) in the 1938 sample signal interval using equations 2 and 6 (see text), employing fixed parameters as given in the figure. Note that LOD values calculated following IUPAC recommendations (equation 6) are always higher (simply because $L_{D} \geq 2{ }^{*} L_{C}$ ), more so for short transient signals (i.e., for $<100$ signal readings in the sample interval).

Fig. 8 Plot of LODs for Au calculated using equation 2 (at $99.9 \%$ confidence level) and equation 6 (at $95 \%$ confidence level) for natural fluid inclusion analyses (Tables 2 and 3 ) as a function of the duration of the fluid inclusion signal $(\mathrm{N}(\mathrm{an}))$. Note that equation 6 returns variably higher LOD values as documented for constant parameters in Fig. 7.

(A) Transient fluid inclusion signal with a constant background interval and variably long signal intervals ( 5 to $25 \mathrm{~s}$ ). Data were recorded at $0.276 \mathrm{~s}$ duration per sweep. (B) Ratio of "LOD"s calculated by equation 2 and equation 6 as a function of the signal durations from 5 to $25 \mathrm{~s}$ as illustrated in Fig. A. Note that different confidence levels (equation 2, $99.9 \%$; equation 6, $95 \%$ ) are compared. See text for discussion.

LA-ICP-MS signal of a bismuth inclusion drilled out of topaz (sample Bism3.3; analysis $99 \mathrm{Mz} 12 \mathrm{~d} 10$ ). Trace element signals are inhomogeneously distributed, illustrating the presence of minor phases exsolved from the bismuth melt after entrapment. The $\mathrm{Cu}$ signal has been slightly shifted to the right to render it visible behind the Au signal. Their perfect overlap indicates the presence of a Cu-Au alloy 
in the Bi-inclusion at room temperature that formed upon cooling of a homogeneous Bi melt. The signal was integrated from $\sim 42$ to $\sim 55$ seconds to obtain the bulk composition. Gold was recorded with $30 \mathrm{~ms}$ dwell time, all other analytes with 10 ms.

1963

1964

1965

1966

1967

1968

1969

1970

1971

1972

1973

1974

1975

1976

1977

1978

1979

1980

1981

1982

1983

1984

1985

1986

1987

1988

1989

1990

1991

1992

1993

1994

1995

1996

1997

Fig. 11 Transient $\mathrm{Pb}$ isotope signal from ablation of a $20 * 20 * 15 \mu \mathrm{m}$ synthetic $\mathrm{Na}-\mathrm{K}-\mathrm{Cl}$ inclusion of $17 \mathrm{wt} \%$ bulk salinity and ca. $5700 \mu \mathrm{g} \mathrm{g}^{-1} \mathrm{~Pb}$ concentration. After recording the instrumental background, a desolvated aerosol containing SRM 997 TI required for mass bias correction is admixed to the ablation chamber gas at $85 \mathrm{~s}$. Once the $\mathrm{Tl}$ signal is stable, laser ablation of quartz host started at $150 \mathrm{~s}$, as indicated by low, scattered $\mathrm{Pb}$ isotope signals originating from surface deposits of previous inclusion ablations. The inclusion is opened at $175 \mathrm{~s}$, and ablation is terminated at $225 \mathrm{~s}$. Note the steady, low background signal of $\mathrm{Hg}$, allowing for accurate quantification of ${ }^{204} \mathrm{~Pb}$, too. Modified from Pettke et al. (2011).

Fig. 12 External reproducibility plots for ${ }^{208} \mathrm{~Pb} /{ }^{206} \mathrm{~Pb}(\mathrm{~A})$ and ${ }^{207} \mathrm{~Pb} /{ }^{204} \mathrm{~Pb}$ (B) ratios for 20 individual fluid inclusion (20-25 $\mu \mathrm{m}$ diameter) analyses. Grey data points were discarded from the averaged data set, due to uncontrolled fluid inclusion ablation, which may generate precise measurements of unconstrained accuracy. Thick yellow lines represent nominal values for SRM 981 (Baker et al., 2004). The same data set was reduced in three different ways, set (i) in blue by the individual reading integration method (plus 2 SE measurement uncertainties), sets (ii) in green and (iii) in red by the bulk signal integration method (with error estimates based on a Gaussian combination of ion statistics and baseline noise). Sets (i) and (ii) use data not corrected for amplifier response, while for (iii) they were corrected using the stepping tau correction scheme (Pettke et al., 2011). Data obtained by the bulk signal integration method (ii and iii) are significantly more accurate and scatter less for isotope ratios normalized to ${ }^{206} \mathrm{~Pb}$ while this is not so obvious for isotope ratios normalized to ${ }^{204} \mathrm{~Pb}$, due to the low precision of the ${ }^{204} \mathrm{~Pb}$ measurements. Modified from Pettke et al. (2011), were detailed explanations are available.

Fig. 13 Comparison of fluid inclusion assemblage data obtained for the giant Bingham Canyon porphyry $\mathrm{Cu} \pm \mathrm{Au}-\mathrm{Mo}$ deposit. $\mathrm{A}$ uniform $\mathrm{Pb}$ isotopic composition characterizes the texturally distinct $\mathrm{Cu}-\mathrm{Au}$ (red symbols) and Mo (blue symbols) ore stages. Dashed lines separate inclusions from different samples (labels shown at the top of the diagram), identical symbols identify inclusions from the same fluid inclusion assemblage. Error bars are two standard error measurement uncertainties (2 s.e.), some of them smaller than symbol size. This $\mathrm{Pb}$ isotopic uniformity strongly suggests a common source for $\mathrm{Cu}, \mathrm{Au}$ and Mo. Modified from Pettke et al. (2010).

Fig. 14 Forward modelling of the uranogenic two-stage $\mathrm{Pb}$ isotope evolution (stage 1, solid green line; stage 2, dashed green line) that reproduces the measured $\mathrm{Pb}$ isotope signatures of Bingham ore fluids (red star at $38 \mathrm{Ma}$ ). $\mu$ values denote ${ }^{238} \mathrm{U} /{ }^{204} \mathrm{~Pb}$ 
ratios. Ages are in million years $(\mathrm{Ma})$ before present, the green stars marking the beginning of stages 1 and 2, respectively. The dashed MORB source mantle evolution line (Kramers and Tolstikhin, 1997) represents convecting, depleted mantle, the dotted line depicts primitive mantle. Data for other Mo-enriched porphyry deposits of the eastern Rocky Mountains, US (Area 1 of Zartman, 1974), are shown for comparison (Butte: Doe et al., 1968; Henderson: Stein and Hannah, 1985; hornblende andesite associated with Questa: Johnson et al., 1990; SEAZ: northern SE Arizona district Cu-Mo centres; Bouse et al., 1999). Modified from Pettke et al. (2010).

Fig. 15 Normalized, interference corrected ${ }^{87} \mathrm{Sr} /{ }^{86} \mathrm{Sr}$ ratios (black diamonds), ${ }^{86} \mathrm{Sr}$ (red squares, corrected for $\mathrm{Kr}$ interference) and ${ }^{85} \mathrm{Rb}$ (blue circles) beam intensities (right ordinate) recorded for transient LA signals from a synthetic fluid inclusion made up of $\mathrm{NaCl}$, SRM $987 \mathrm{Sr}$ and $\mathrm{Rb}(\mathrm{A}, \mathrm{B})$, and from a brine inclusion from the Sudbury igneous complex (C, D). ${ }^{87} \mathrm{Sr} /{ }^{86} \mathrm{Sr}$ ratios not corrected for amplifier response $(A, C)$ show substantial variation correlating with signal intensity gradients, whereas tau-corrected ratios ("quadratic correction") are essentially constant $(B, D)$. The units on the abscissa refer to number of individual readings integrated for $0.2 \mathrm{~s}$. The dashed vertical lines delimit the signal sections which would be selected for error optimization based on counting and baseline statistics (see text for details).

Plot of ${ }^{87} \mathrm{Sr} /{ }^{86} \mathrm{Sr}$ versus ${ }^{85} \mathrm{Rb} /{ }^{86} \mathrm{Sr}$ measured on a series of 51 synthetic fluid inclusions with variable $\mathrm{Rb}$ (SRM 984), $\mathrm{Sr}$ (SRM 987), $\mathrm{Na}$ and Ca contents. Both ratios were internally corrected for isobaric interference by $\mathrm{Kr}$ and $\mathrm{Rb}$ and normalized to ${ }^{86} \mathrm{Sr} /{ }^{88} \mathrm{Sr}=0.1194$. Mean ${ }^{87} \mathrm{Sr} /{ }^{86} \mathrm{Sr}$ ratios for individual fluid inclusions were calculated by data integration and optimization. The results show a significant residual sloping trend (solid line; least squares parameters) as a function of $\mathrm{Rb} / \mathrm{Sr}$, intersecting the ordinate at $0.71028 \pm 0.00019$, identical to the nominal value of 0.710245 for SRM 987 (dashed horizontal line). The dependence on $\mathrm{Rb} / \mathrm{Sr}$ suggests that mass 87 was undercorrected for contributions of ${ }^{87} \mathrm{Rb}$, which in turn suggests that the assumption of identical fractionation coefficients for $\mathrm{Rb}$ and $\mathrm{Sr}$ may not be valid (see text for details). All errors given at $95 \%$ c.l. 


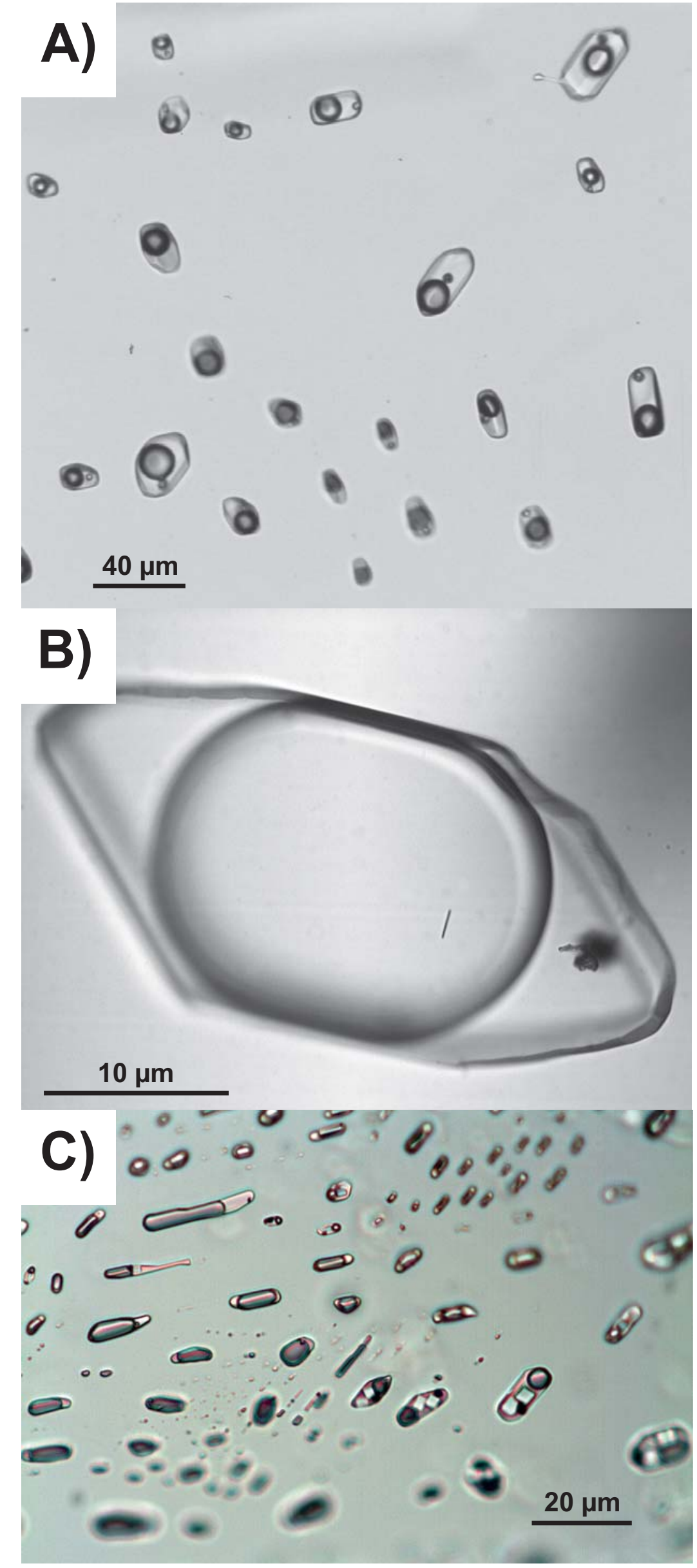

Figure 1 


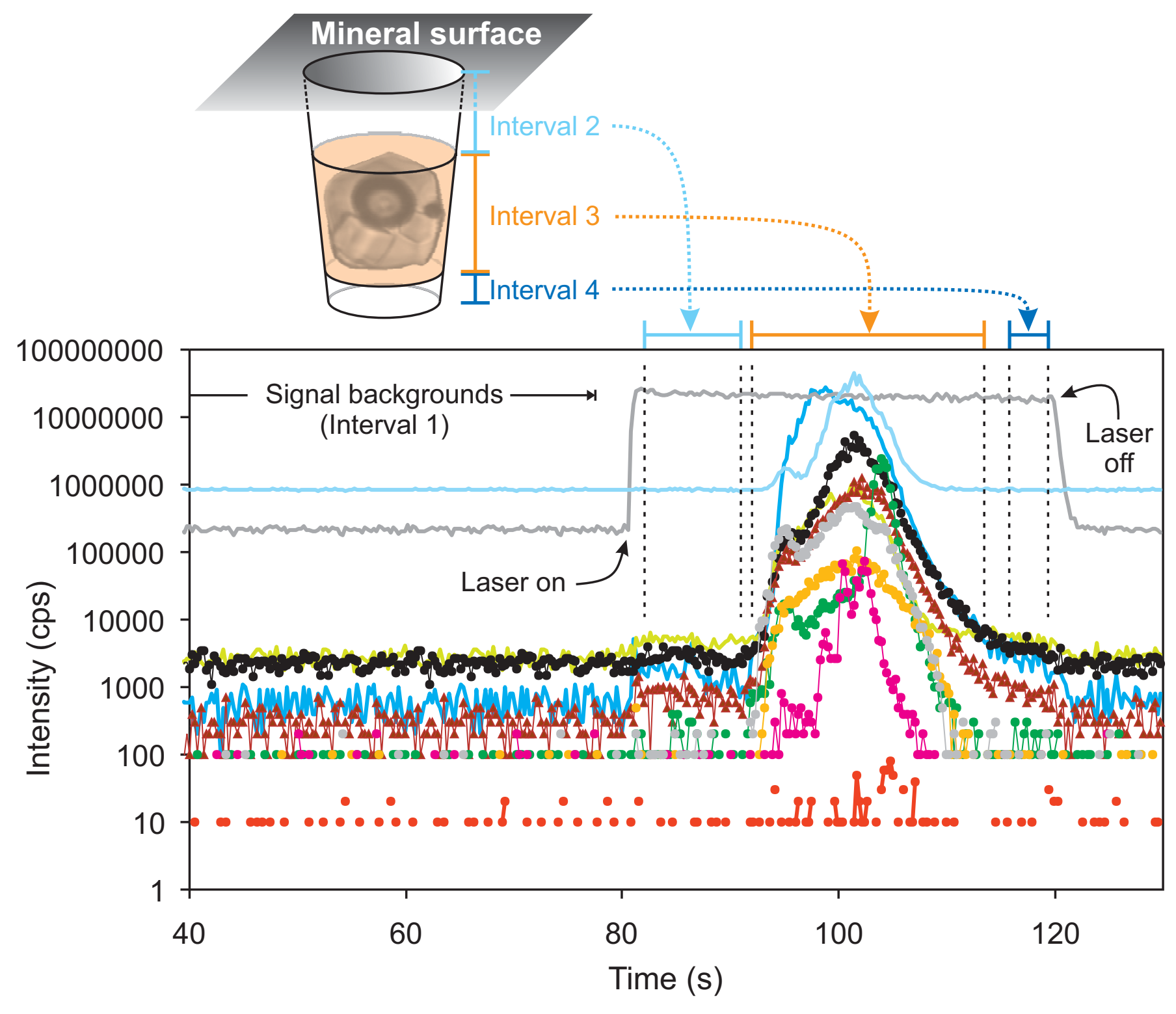

Figure 2 


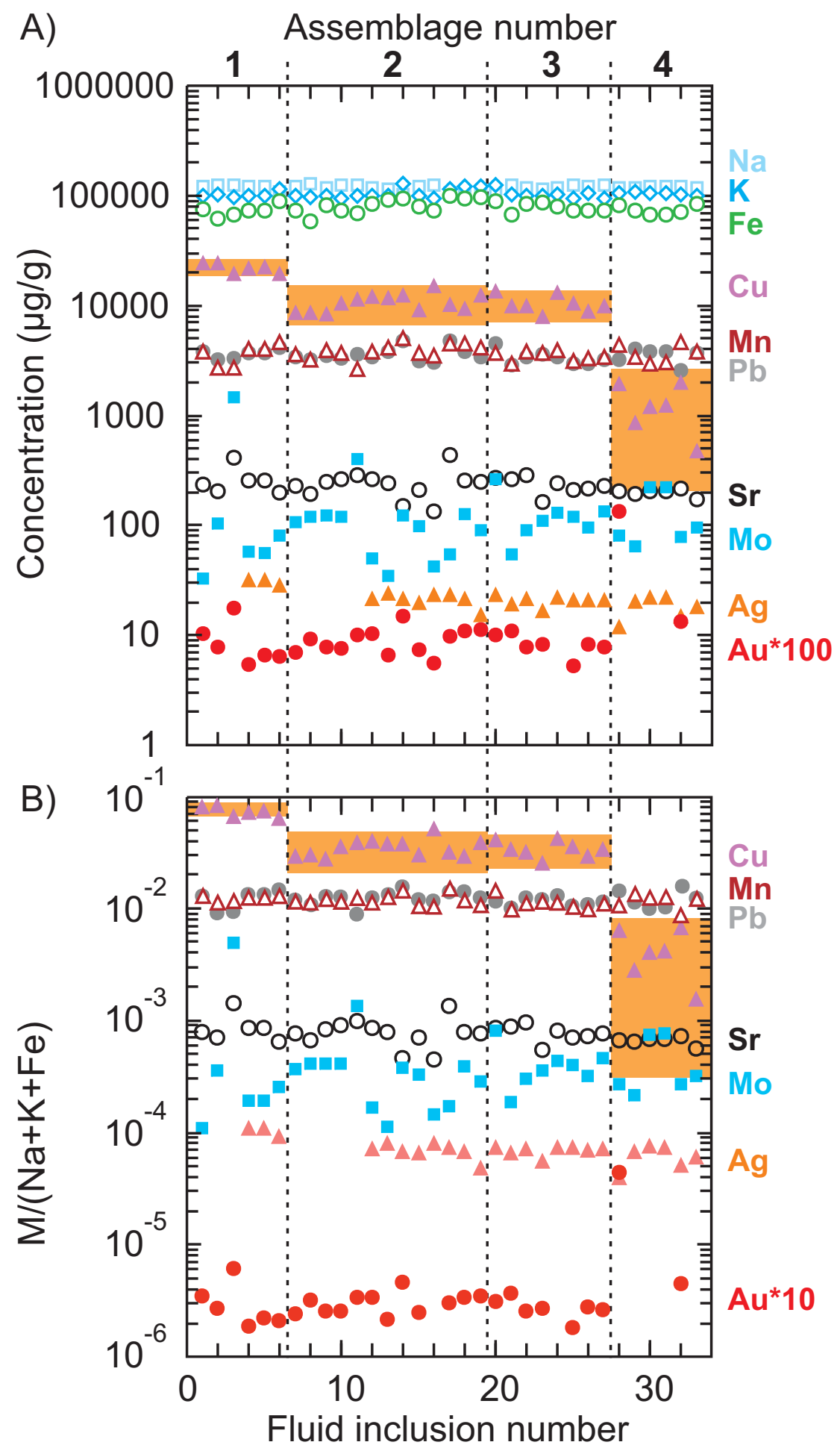

Figure 3 

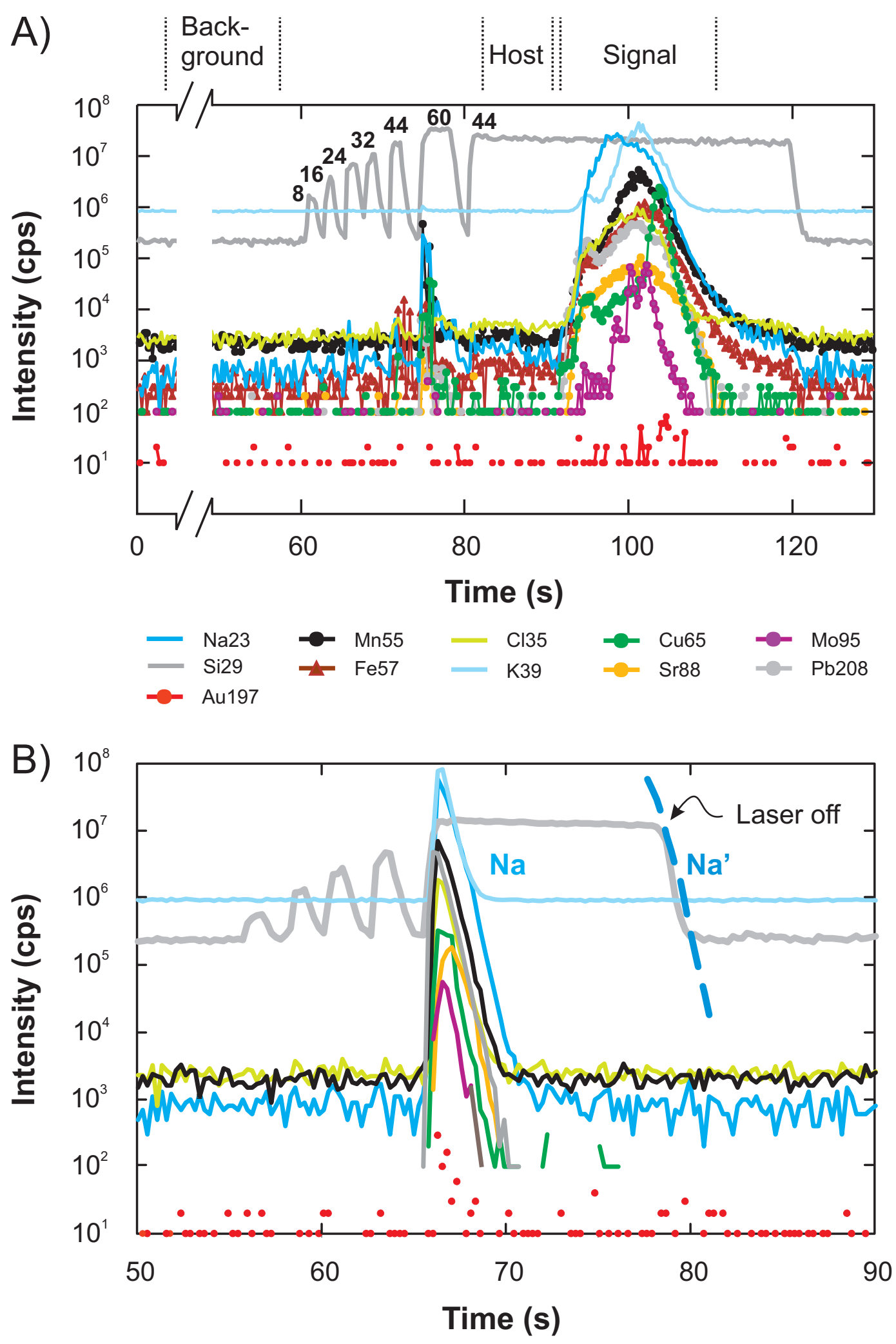

Figure 4 


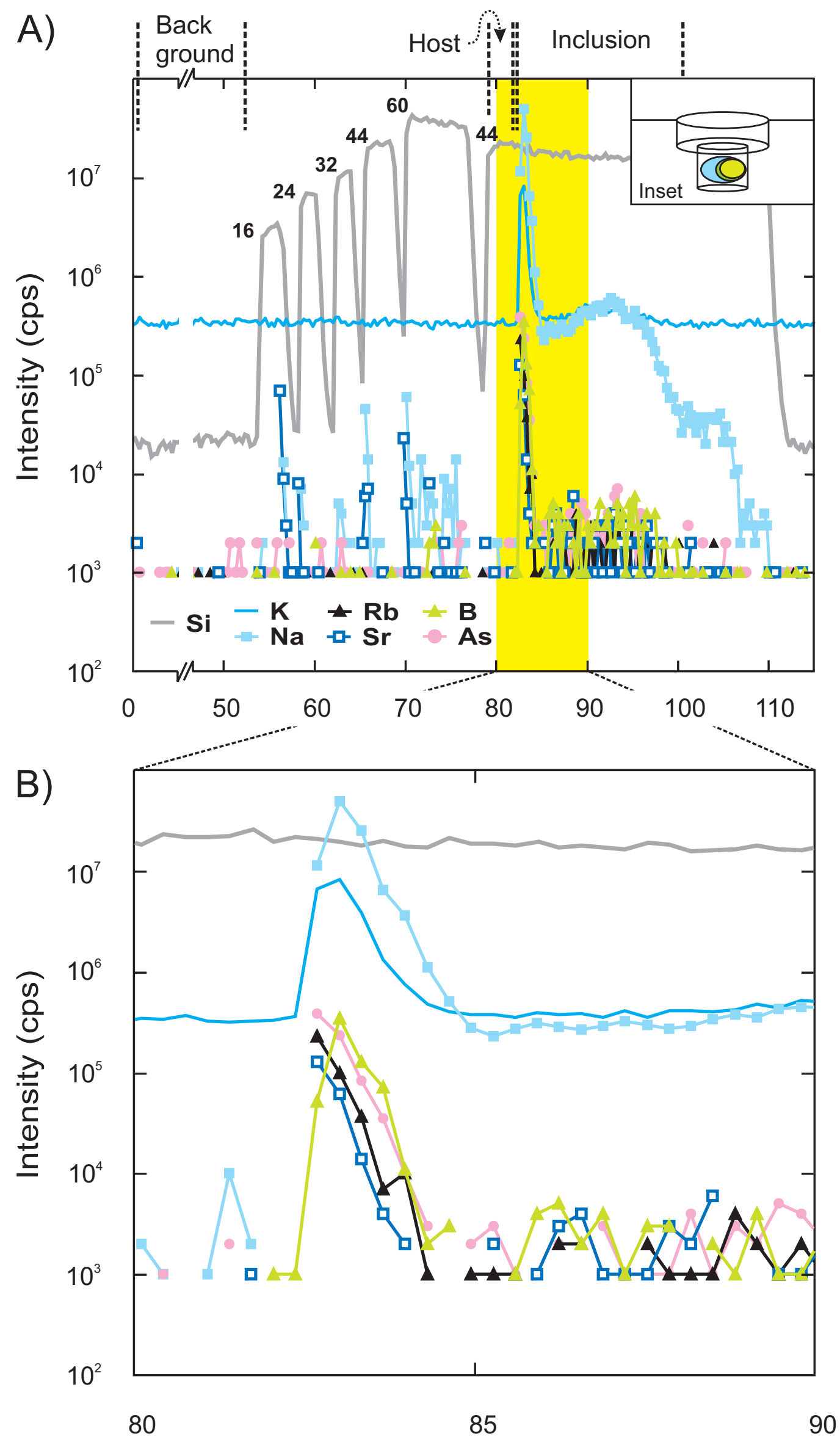

Time (s)

Figure 5 


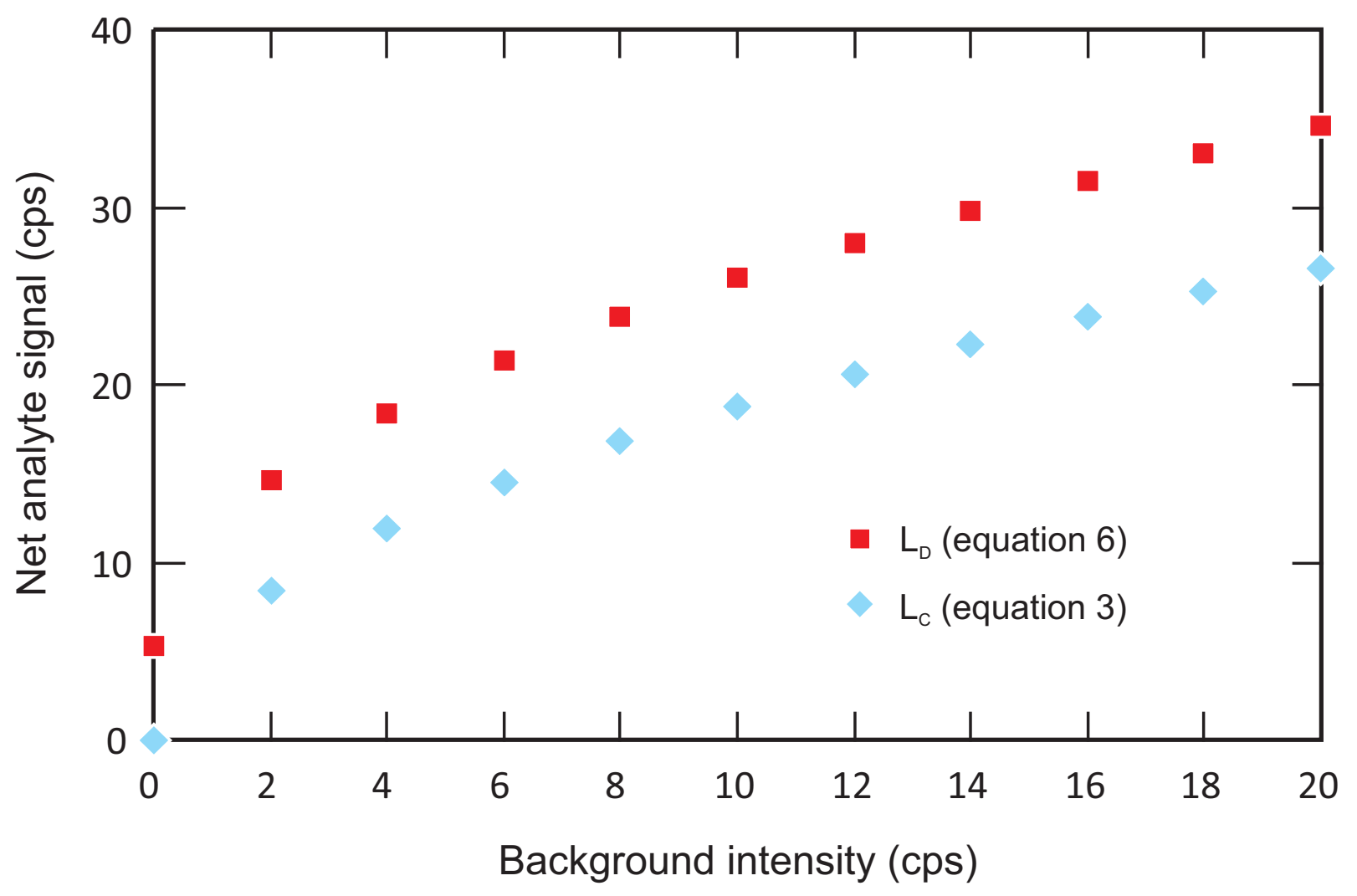

Figure 6 


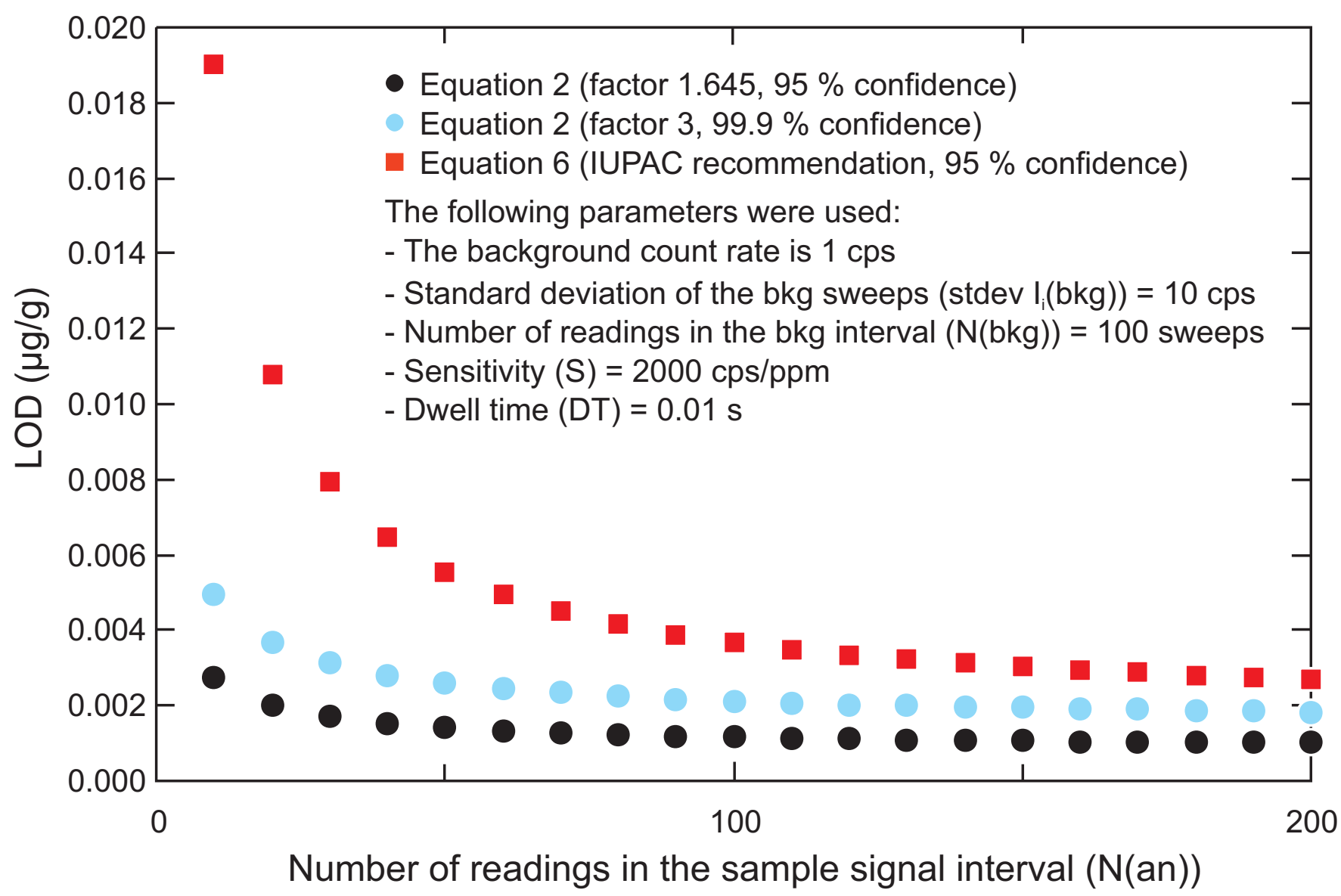

Figure 7 


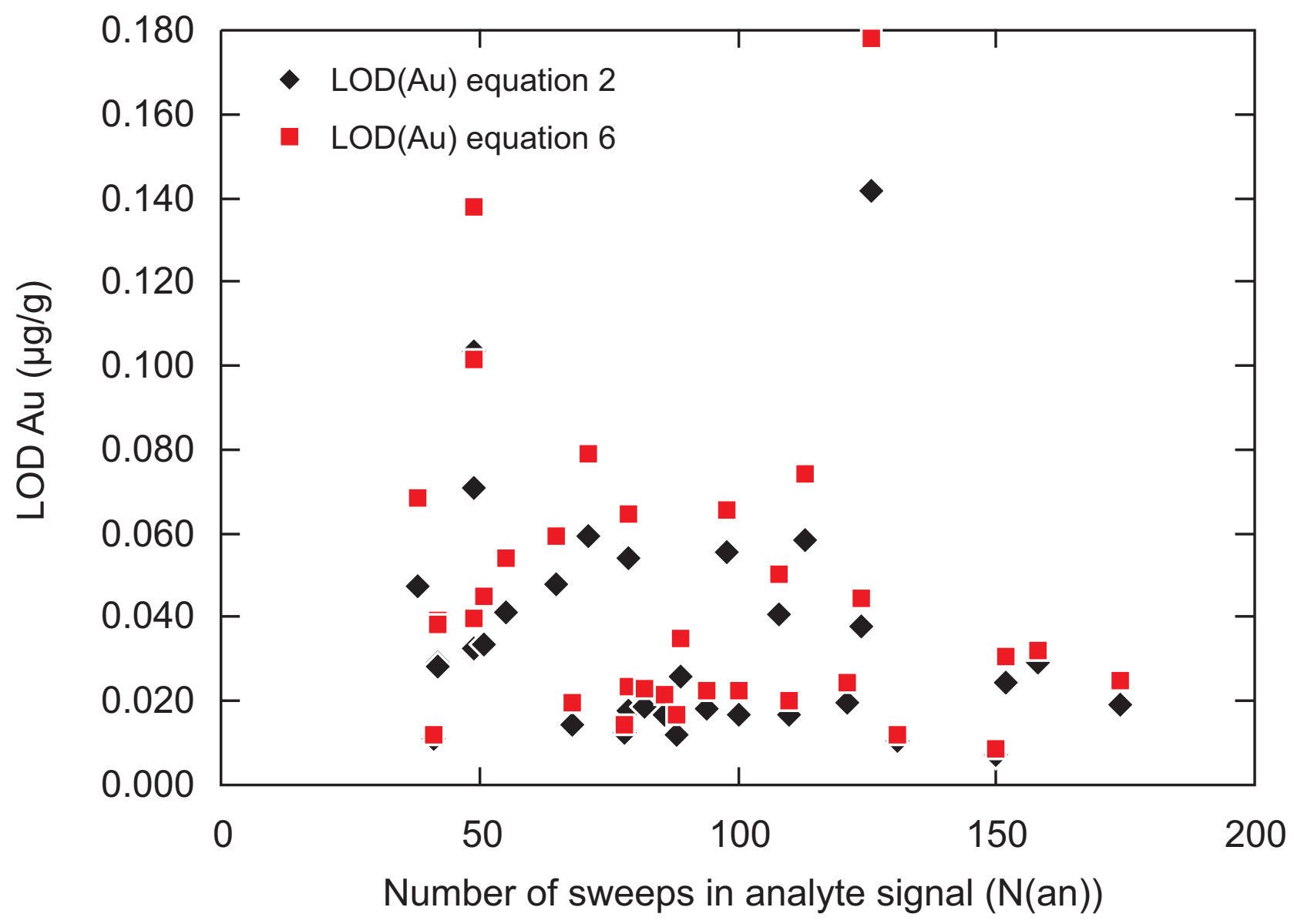

Figure 8 
A Signal interval
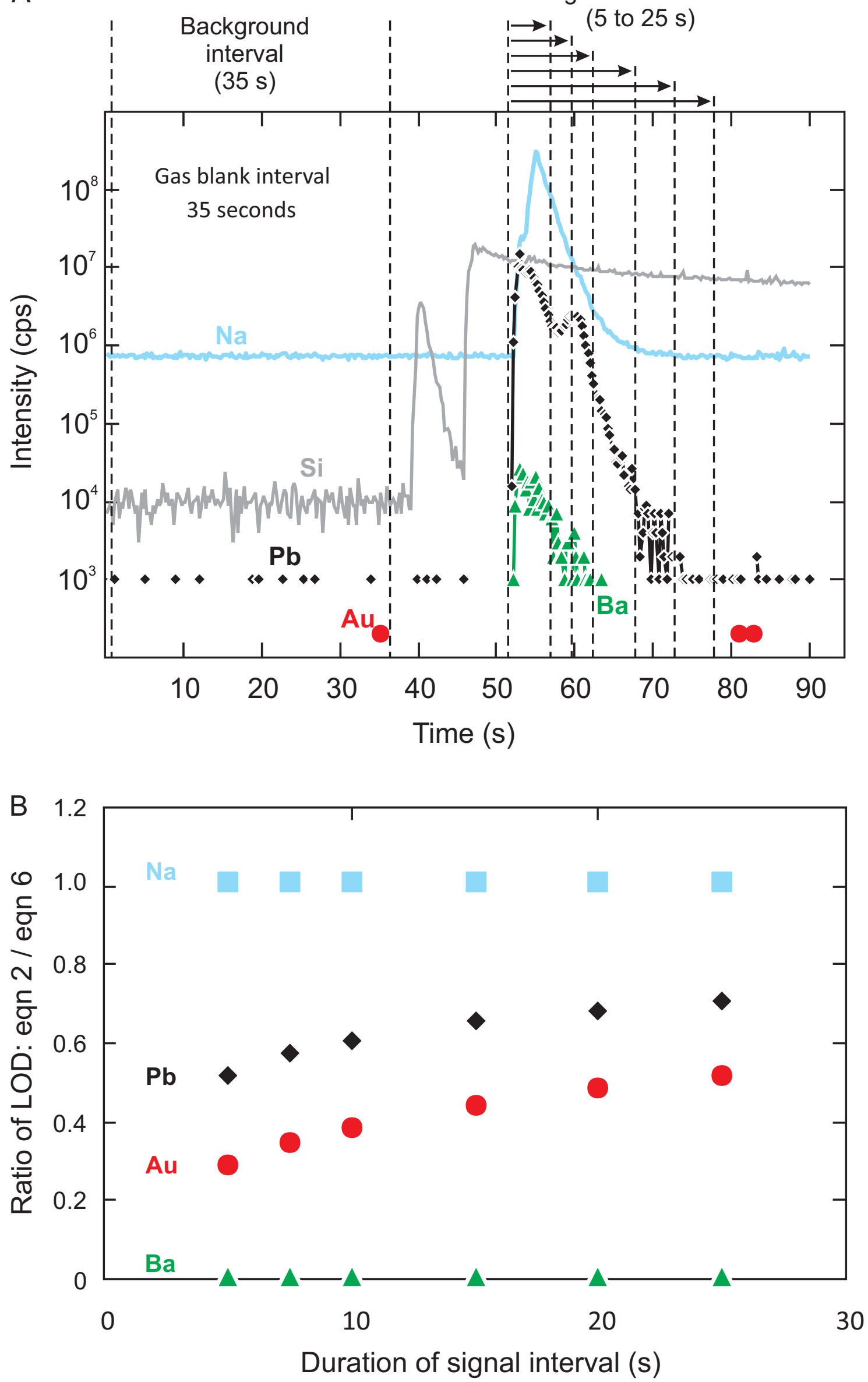

Figure 9 


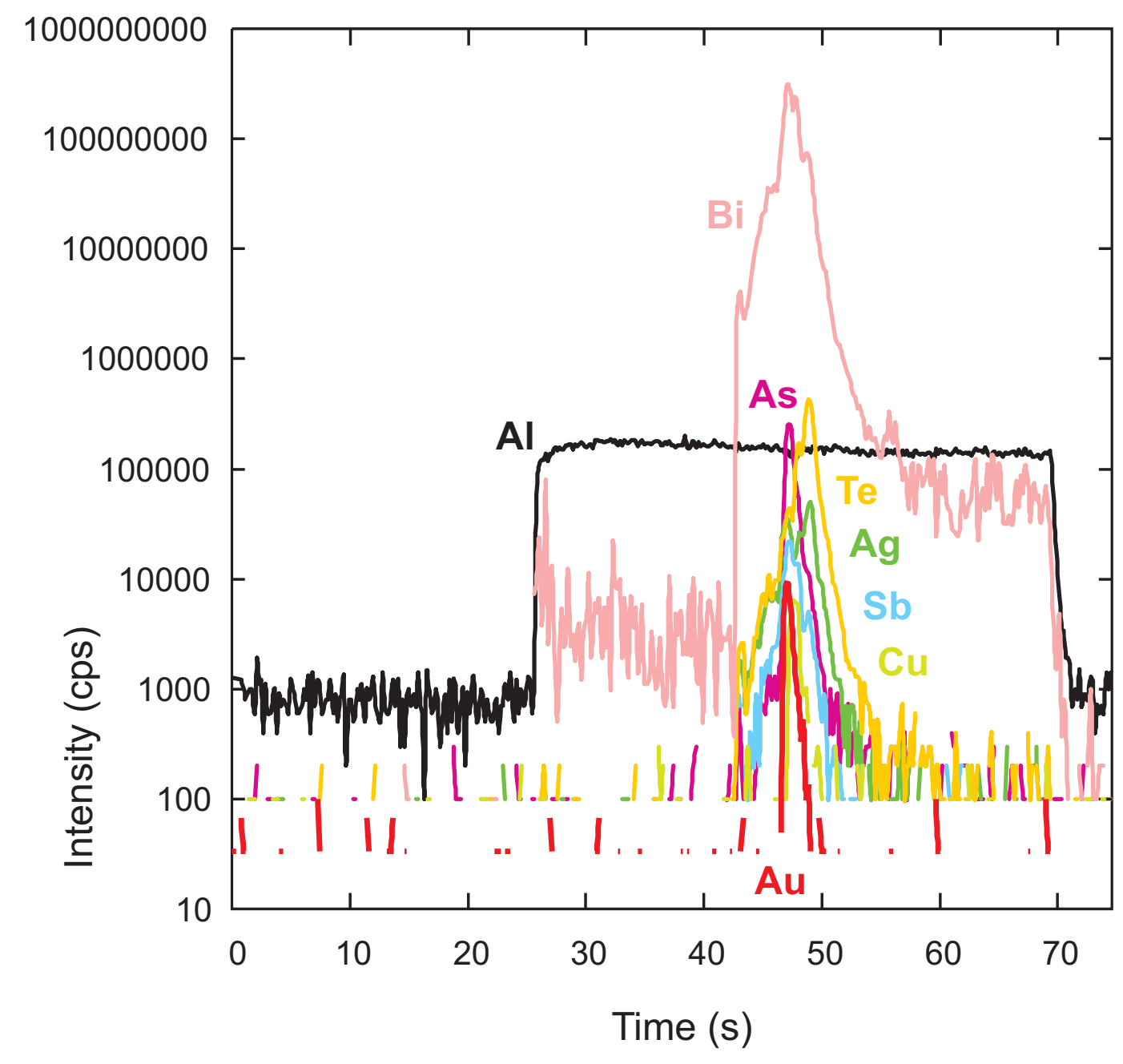

Figure 10 


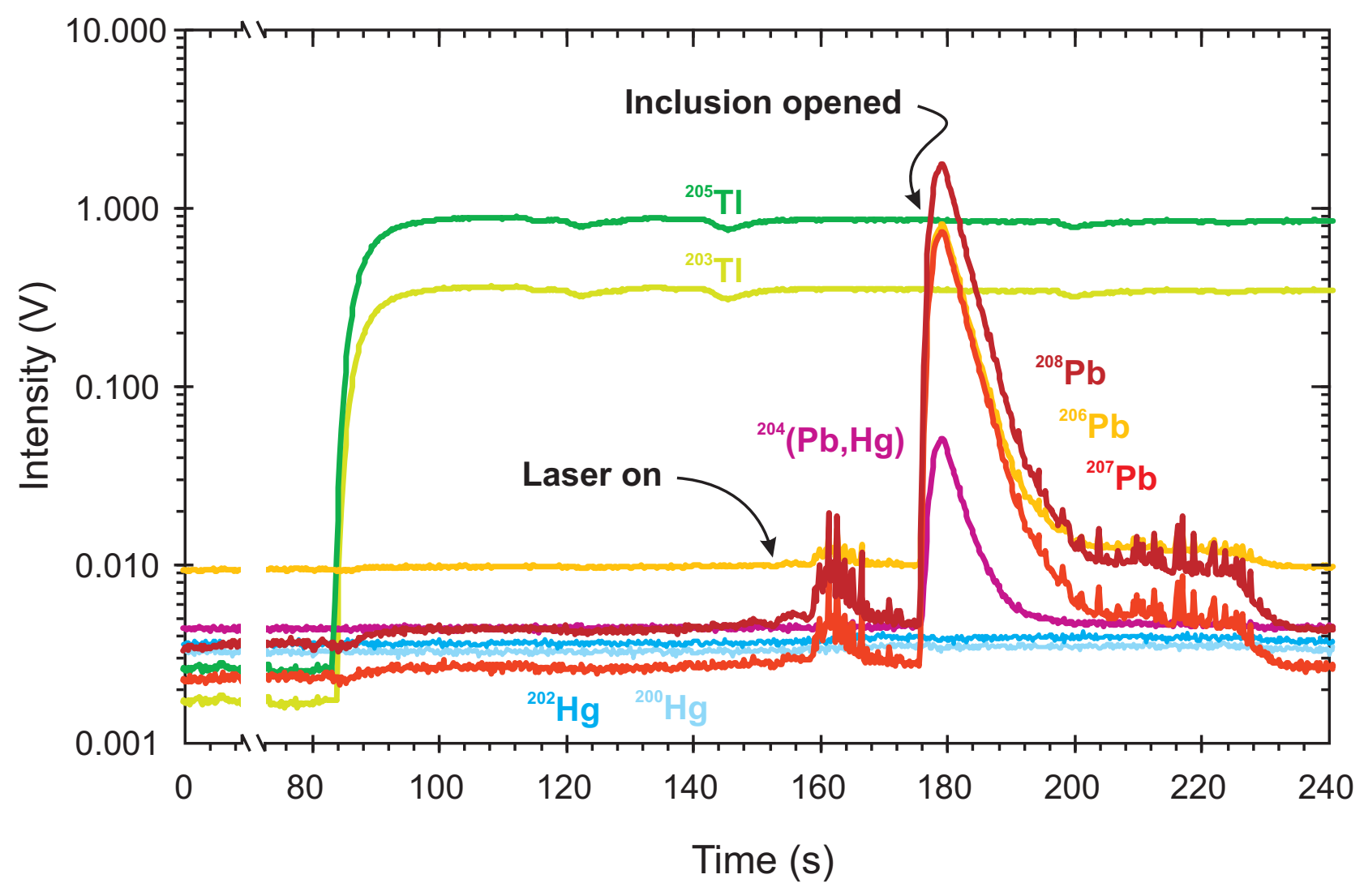

Figure 11 


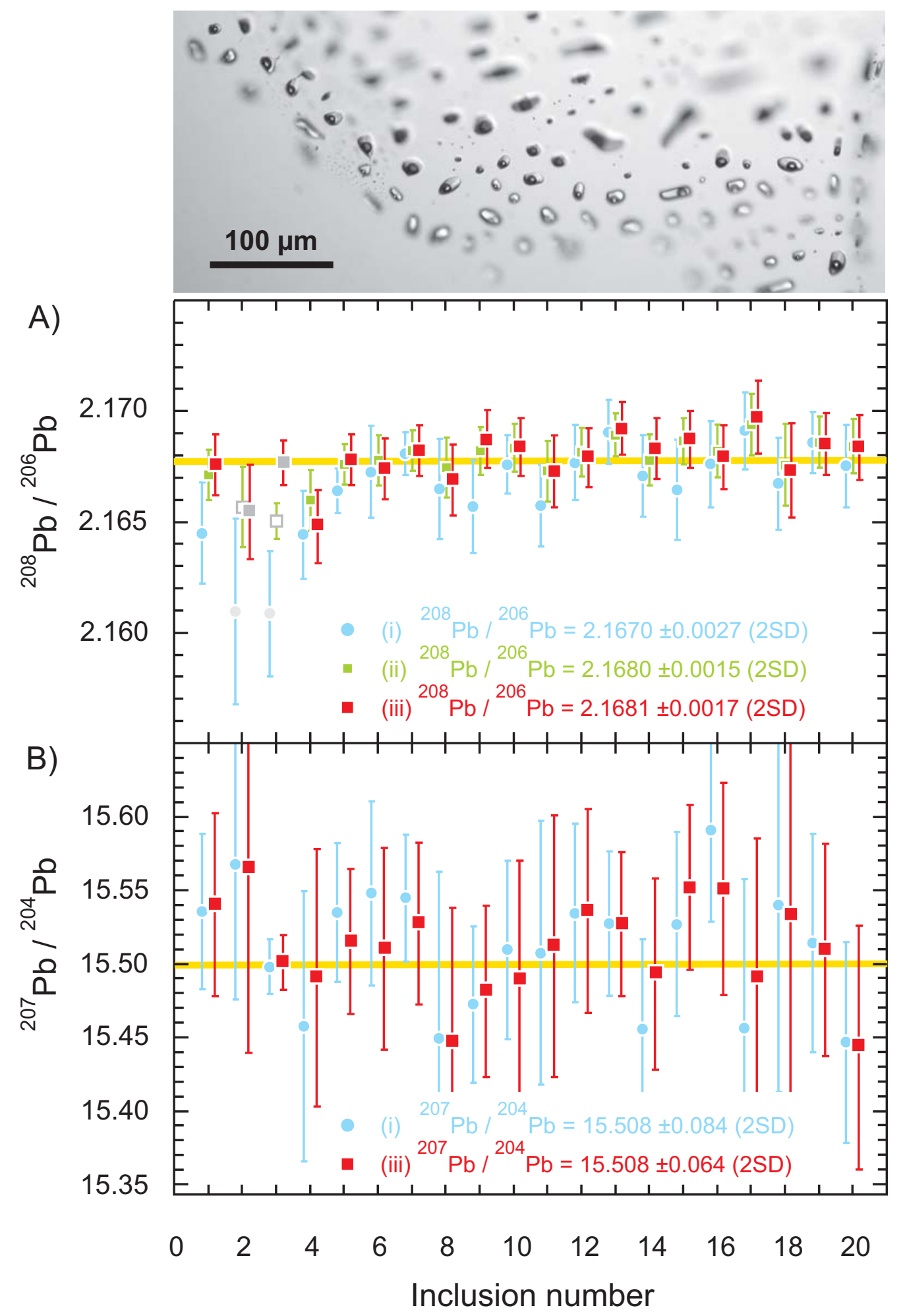

Figure 12 


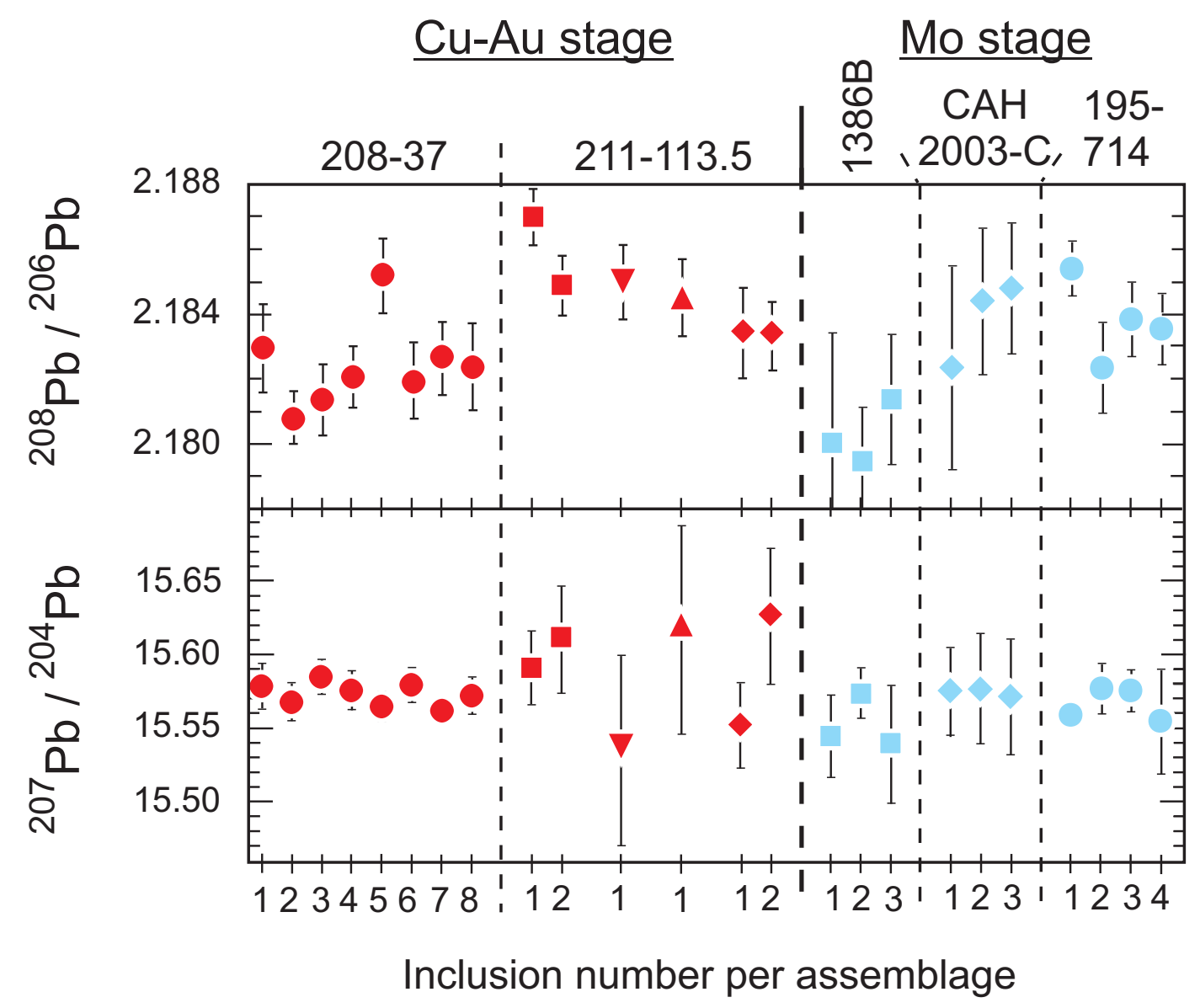

Figure 13 


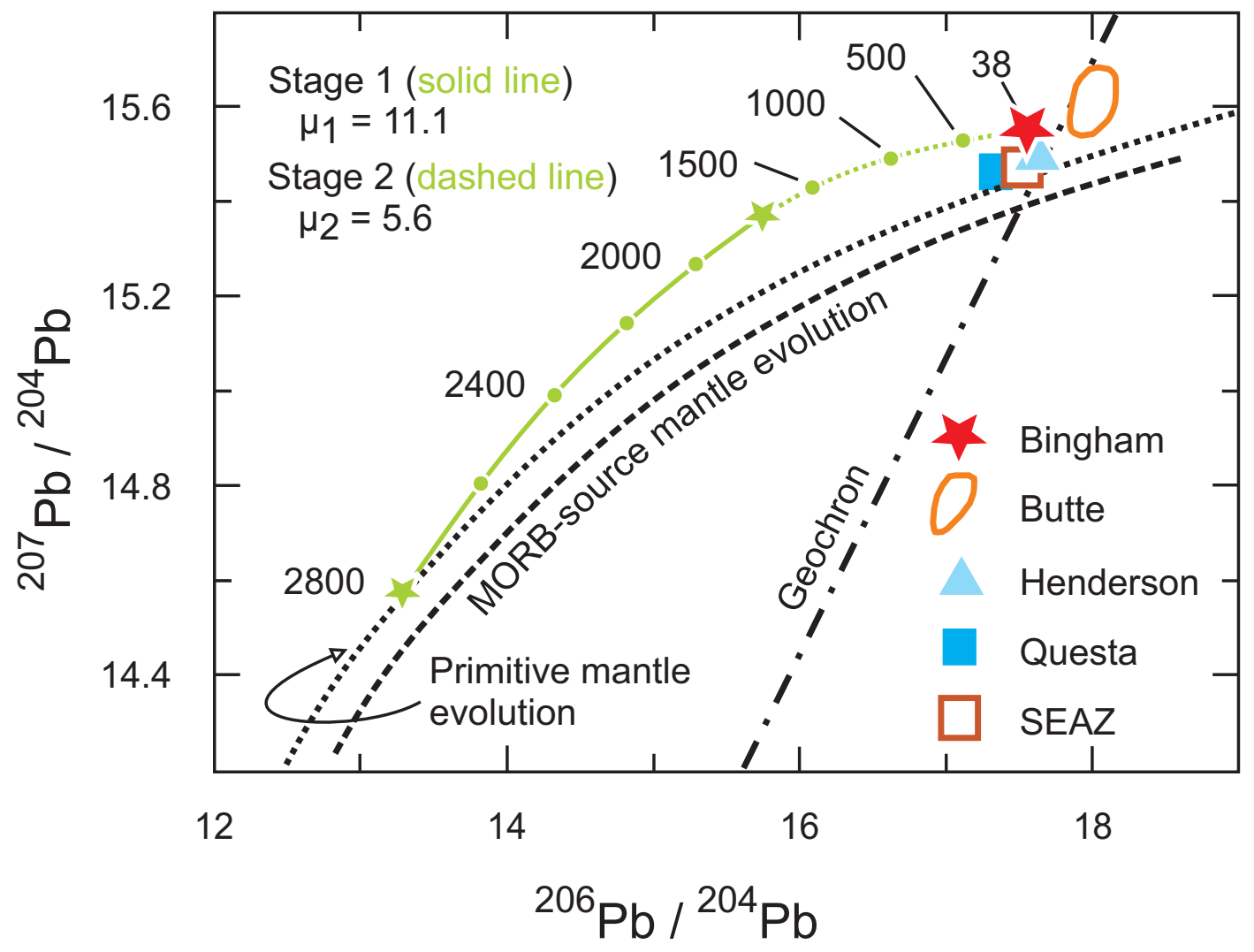

Figure 14 

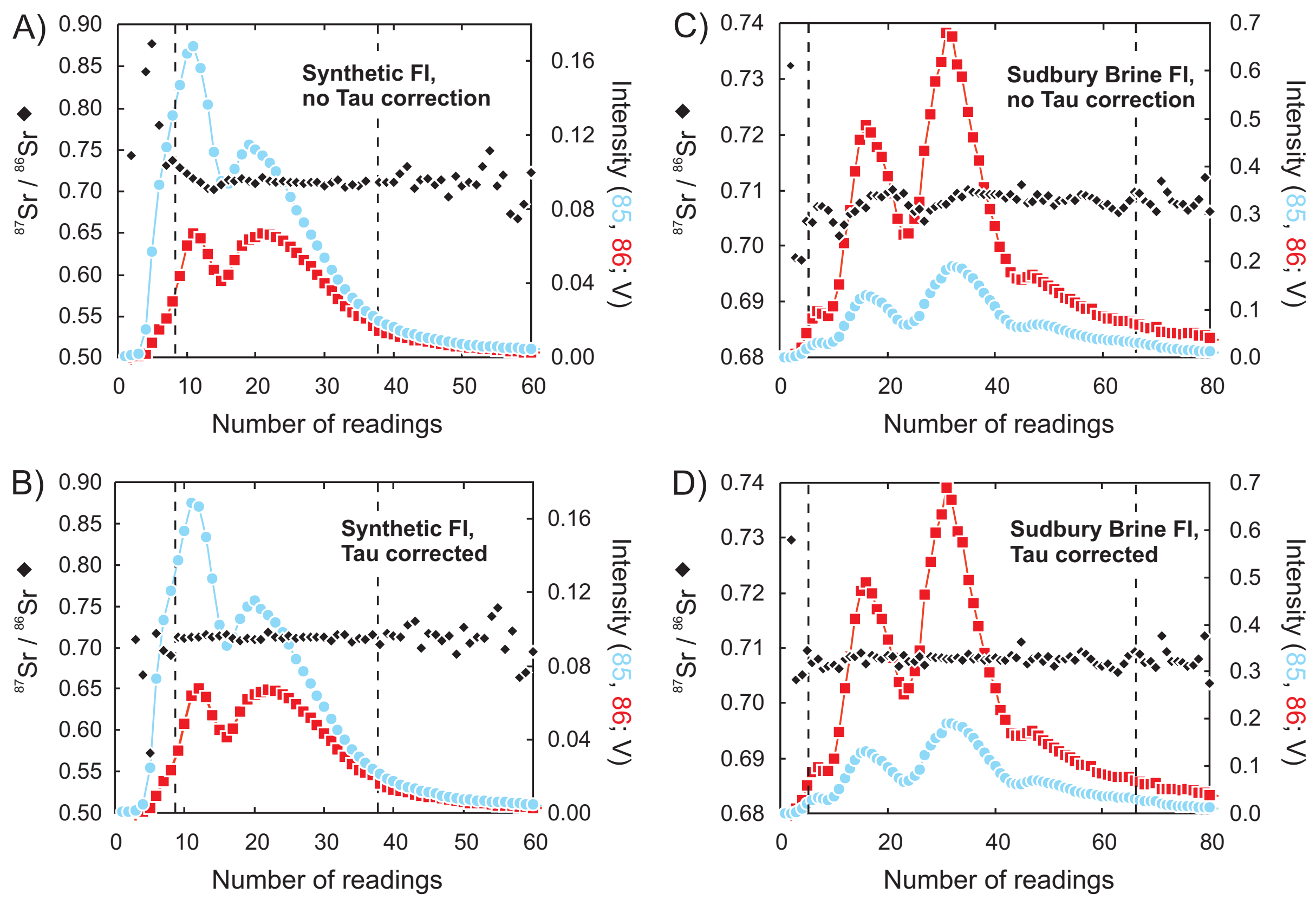

Figure 15 

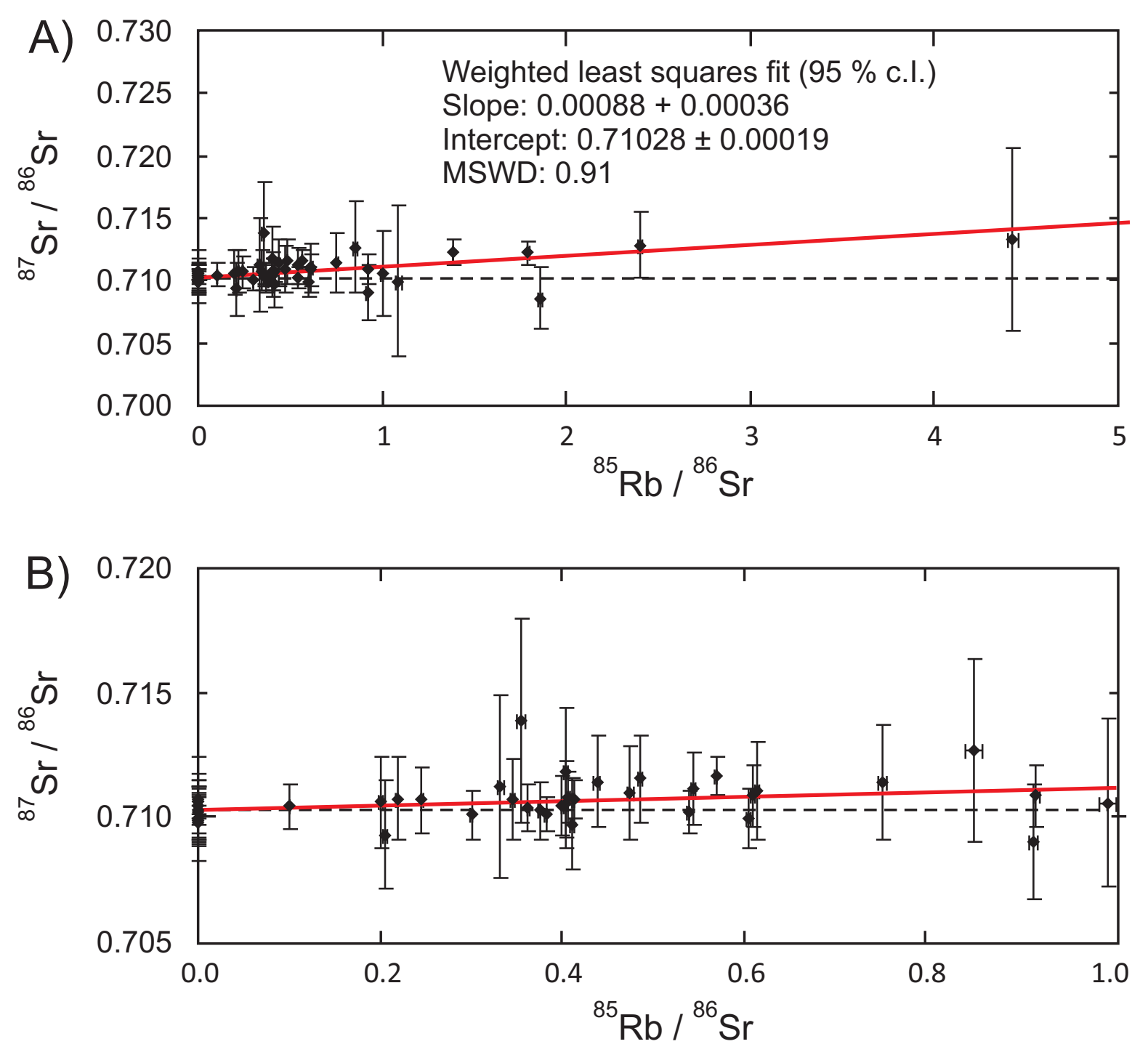

Figure 16 
Table 1: Element concentration data of individual fluid inclusions of

4 successively entrapped fluid inclusion assemblages from a porphyry stage quartz vein of Bingham

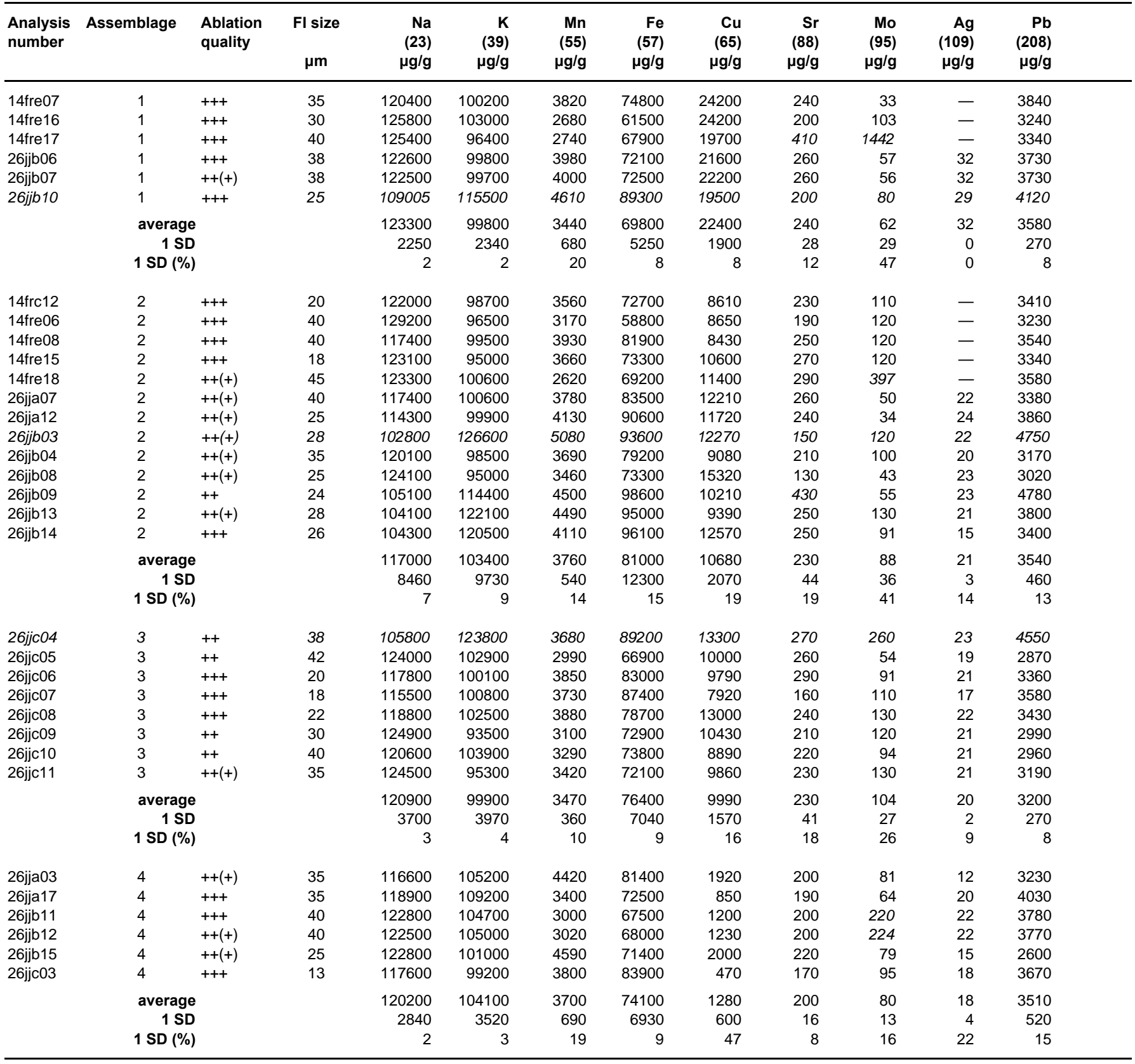

Sample used is 208-37. Equivalent $\mathrm{NaCl}$ concentration used as the internal standard for signal quantification is $49.1 \mathrm{wt} \%$.

Masses analyzed are listed in brackets in the table header

Fluid inclusion data are corrected for host quartz contribution, and salt correction (Heinrich et al., 2003) was effected for $\mathrm{KCl}$, FeCl and $\mathrm{PbCl}$

Values in italics are outliers and thus were not used for statistical calculations

$++\quad$ Indicates perfect ablation of fluid inclusion as judged on TV screen

$++(+) \quad$ Indicates good ablation of fluid inclusion with a very minor problem (e.g., signal tailing because the fluid inclusion was deep)

$+\quad$ Indicates acceptable ablation, with problems such as surficial quartz breakout or unclear signal boundary, e.g.,

because an underlying inclusion was hit before the first signal ended

- Analyte was not recorded 
Table 2: Gold concentration data, LODs and uncertainties of individual fluid inclusions from Bingham Canyon porphyry Cu-Au-Mo deposit

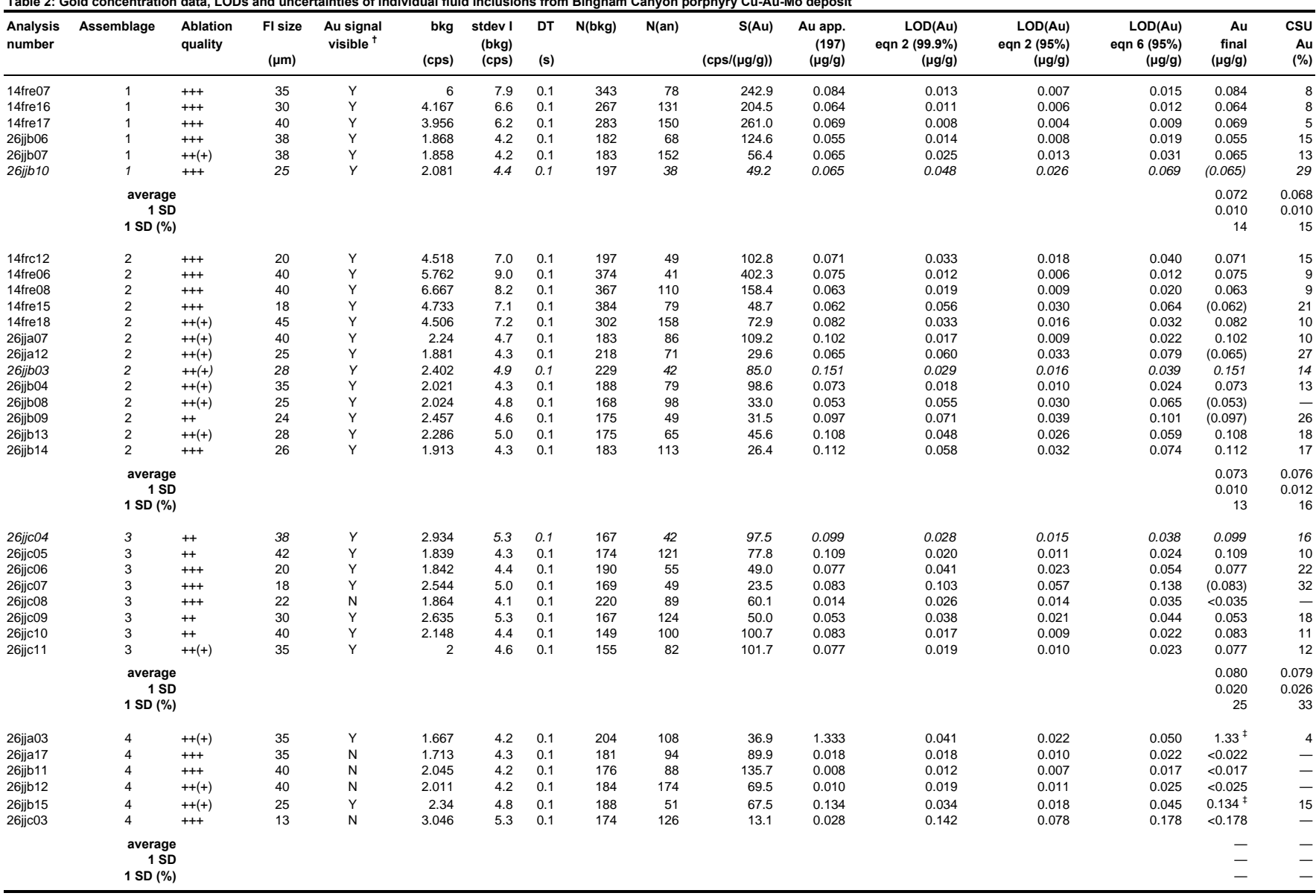

Sample used is 208-37; same inclusions as in Table 1. ${ }^{197} \mathrm{Au}$ was analyzed. CSU refers to counting statistics uncertainty for Au. Values in italic are deemed outliers based on bulk fluid inclusion data (Table 1) and thus were not used for statistical calculations.

Values in italic are deemed outliers based on bulk fluid inclusion data (Table 1 ) and thus were not used for statistical calcu
Definition of ablation quality: see Table 1

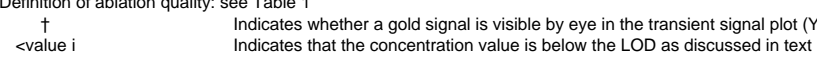

$\begin{array}{cll}<v a l u e ~ i & \text { Indicates that the concentration value is below the } \\ \ddagger & \text { Considered to be an outlier based on within assemblage statistics and thus not used for statistical calculations }\end{array}$

Au app. Represents the calculated Au concentration prior to LOD filtering

LOD(Au) LODs were calculated using equations 2 and 6 as explained in text (with different confidence levels for equation 2)

Au final Gold values in round brackets represent a gold signal visible by eye but below LOD (equation 6). Not used for statistical calculations.

$\begin{array}{ll}\text { CSU Au } & \text { Note that these apparent Au concentrations are only slightly by } \\ \text { Reports the counting statistics uncertainty for the Au signal }\end{array}$

Average and 1 SD values reported in the column "Au final" are simple averages, those in column "CSU Au" are counting statistics uncertainty weighted mean values at 95\% confidence 
Table 3. Experimental studies that used synthetic fluid inclusions to trap and recover aqueous fluid(s) at elevated pressure and temperature to constraining metal solubilities and speciation.

\begin{tabular}{|c|c|c|c|c|c|c|c|c|c|c|c|c|}
\hline $\begin{array}{c}\text { Phase } \\
\text { Assemblage }\end{array}$ & Fluid & $\begin{array}{l}\text { Element of } \\
\text { Interest }\end{array}$ & $\begin{array}{c}\text { Fluid } \\
\text { inclusion } \\
\text { host }\end{array}$ & $\begin{array}{c}\mathrm{T} \\
\left({ }^{\circ} \mathrm{C}\right)\end{array}$ & $\begin{array}{c}\mathrm{P} \\
(\mathrm{MPa})\end{array}$ & $f_{\mathrm{O}_{2}}$ & $f_{S_{2}}$ & $\begin{array}{c}\text { Bulk } \\
\text { salinity }\end{array}$ & $\begin{array}{l}\text { Vapor } \\
\text { salinity }\end{array}$ & $\begin{array}{l}\text { Brine } \\
\text { Salinity }\end{array}$ & Major Findings & Reference \\
\hline brine, po-mt \pm py & $\begin{array}{l}\mathrm{H}-\mathrm{O}-\mathrm{S}-\mathrm{KCl}- \\
\mathrm{FeCl}_{2}-\mathrm{HCl}\end{array}$ & $\mathrm{Au}$ & quartz & $\begin{array}{l}550- \\
725\end{array}$ & $\begin{array}{l}110- \\
400\end{array}$ & $\begin{array}{l}\text { po-mt-py, } \\
\text { po-mt }\end{array}$ & $\begin{array}{l}a_{H_{2} S}= \\
12.1- \\
46.4\end{array}$ & $\begin{array}{l}0 \text { to } 1 \mathrm{~m} \\
\mathrm{HCl}+\mathrm{KCl}\end{array}$ & & $\begin{array}{l}0 \text { to } 1 m \\
\mathrm{HCl}+\mathrm{KCl}\end{array}$ & $\begin{array}{l}\text { solubility of } \mathrm{Au} \text { in brine increases } \\
\text { signficantly with increasing } f\left(\mathrm{H}_{2} \mathrm{~S}\right)\end{array}$ & $\begin{array}{l}\text { Loucks and } \\
\text { Mavrogenes, } \\
1999\end{array}$ \\
\hline $\begin{array}{l}\text { granite melt + } \\
\text { mt + vapor + } \\
\text { brine }\end{array}$ & $\begin{array}{l}\text { O-H-NaCl- } \\
\mathrm{KCl}-\mathrm{FeCl}_{2}\end{array}$ & $\mathrm{Fe}$ & quartz & 800 & $\begin{array}{l}110 \\
130 \\
140 \\
145\end{array}$ & NNO & S-free & $\begin{array}{l}1,8-20 \\
\text { wt. \% } \\
\mathrm{NaCl} \text { eq. }\end{array}$ & $\begin{array}{l}2.1 \text { to } \\
19.2 \\
\text { wt. \% } \\
\mathrm{NaCl} \text { eq. }\end{array}$ & $\begin{array}{l}35-58 \\
\text { wt. \% } \\
\mathrm{NaCl} \text { eq. }\end{array}$ & $\begin{array}{l}D_{F e}^{v / s i-m t}=0.22,0.92,1.94,3.8 \\
D_{F e}^{b / s i-m t}=4.6,6.6,7.1,6.7 \\
D_{F e}^{v / b}=0.05,0.14,0.27,0.56\end{array}$ & $\begin{array}{l}\text { Simon et al., } \\
2004\end{array}$ \\
\hline $\begin{array}{l}\text { peraluminous } \\
\text { granite melt, } \\
\text { supercritical } \\
\text { O-H-Cl fluid }\end{array}$ & $\begin{array}{l}\mathrm{NaCl}, \mathrm{KCl}, \\
\mathrm{HCl}\end{array}$ & $\mathrm{Pt}$ & silicate glass & 800 & 150 & NNO & S-free & $\begin{array}{l}20 \text { and } 50 \\
\text { wt. \% } \\
\mathrm{NaCl} \text { eq. }\end{array}$ & & & $\begin{array}{l}D_{P t}^{v / s i-m t}=6.6 \times 10^{3} \text { to } 5.2 \times 10^{4} \\
D_{P t}^{v / s i-m t}=1 \times 10^{2} \text { to } 2.6 \times 10^{2} \\
D_{A u}^{v / s i-m t}=4.2 \times 10^{3} \text { to } 1.2 \times 10^{4}\end{array}$ & $\begin{array}{l}\text { Hanley et al., } \\
2005 \mathrm{~b}\end{array}$ \\
\hline $\begin{array}{l}\text { granite melt + } \\
\mathrm{mt}+\text { vapor + } \\
\text { brine }\end{array}$ & $\begin{array}{l}\mathrm{O}-\mathrm{H}-\mathrm{NaCl}- \\
\mathrm{KCl}-\mathrm{FeCl}_{2}\end{array}$ & $\mathrm{Au}$ & quartz & 800 & $\begin{array}{l}110 \\
130 \\
140 \\
145\end{array}$ & NNO & S-free & $\begin{array}{l}1,8-20 \\
\text { wt. \% } \\
\mathrm{NaCl} \text { eq. }\end{array}$ & $\begin{array}{l}2.1 \text { to } \\
19.2 \\
\text { wt. \% } \\
\mathrm{NaCl} \text { eq. }\end{array}$ & $\begin{array}{l}35-58 \\
\text { wt. \% } \\
\mathrm{NaCl} \text { eq. }\end{array}$ & $\begin{array}{l}D_{A u}^{v / s i-m t}=10,8,56,72 \\
D_{A u}^{b / s i-m t}=58,56,80,100 \\
D_{A u}^{v / b}=0.21,0.18,0.80,0.72\end{array}$ & $\begin{array}{l}\text { Simon et al., } \\
2005\end{array}$ \\
\hline $\begin{array}{l}\mathrm{Cu}+\mathrm{cpr}+\mathrm{tc}+ \\
\mathrm{qz} ; \mathrm{Cl} \text { added as } \\
\mathrm{CuCl}_{2} \text { or } \mathrm{Cu}+\mathrm{Mt} \\
+\mathrm{Hm}+\mathrm{Kf}+\mathrm{Qz} \\
+\mathrm{Sil} ; \mathrm{Cl} \text { added } \\
\text { as } \mathrm{KCl}\end{array}$ & $\mathrm{O}-\mathrm{H}-\mathrm{Cl}$ & $\mathrm{Cu}$ & quartz & $\begin{array}{l}630 \\
700\end{array}$ & $\begin{array}{l}313 \\
338 \\
341\end{array}$ & NR & S-free & $\begin{array}{l}14.6- \\
29.3 \text { wt. \% } \\
\mathrm{Cl}\end{array}$ & & & $\begin{array}{l}\text { Cu speciation in aqueous fluid at } \\
\text { elevated } \mathrm{T} \text { : Cu speciated as }\left[\mathrm{CuCl}_{2}\right]^{-} \\
\text {in } \mathrm{KCl} \text {-fluid with } \mathrm{Cu}: \mathrm{Cl}=1: 6 \text {, and in } \\
\mathrm{K} \text {-free fluid possibly as }\left[\mathrm{CuCl}_{4}\right]^{3} \text { in } \\
\mathrm{KCl} \text {-solutions with } \mathrm{Cu}: \mathrm{Cl}=1: 6\end{array}$ & $\begin{array}{l}\text { Berry et al., } \\
2006\end{array}$ \\
\hline $\begin{array}{l}\text { tc }+\mathrm{qtz}+\mathrm{cpr}+ \\
\mathrm{O}-\mathrm{H}-\mathrm{Cl} \text { fluid }+ \\
\mathrm{Cu}_{2} \mathrm{O}\end{array}$ & $\mathrm{O}-\mathrm{H}-\mathrm{CuCl}_{2}-$ & $\mathrm{Cu}$ & quartz & $\begin{array}{l}524 \\
\text { to } \\
710\end{array}$ & $\begin{array}{l}313 \text { to } \\
1703\end{array}$ & NR & S-free & $\begin{array}{l}0.775 \text { to } \\
13.4 \text { wt. } \% \\
\mathrm{Cl}\end{array}$ & & $\begin{array}{l}0.775 \text { to } \\
13.4 \text { wt. } \\
\% \mathrm{Cl}\end{array}$ & $\begin{array}{l}\text { Cu solubility in aqueous brine is } \sim 15 \\
\text { wt. } \% \text { at } 630 \mathrm{C} \text { and } 0.34 \mathrm{GPa} \text {; } \\
\text { modeled } \mathrm{Cu} \text { speciation as } \\
\mathrm{CuCu}(\mathrm{HCl})_{n-1}^{0} \text { where } \mathrm{n} \leq 4\end{array}$ & $\begin{array}{l}\text { Hack and } \\
\text { Mavrogenes, } \\
2006\end{array}$ \\
\hline $\begin{array}{l}\text { granite melt }+ \\
\mathrm{mt}+\text { vapor }+ \\
\text { brine }+\mathrm{CuCl} \pm \\
\text { po }\end{array}$ & $\begin{array}{l}\mathrm{O}-\mathrm{H}-\mathrm{NaCl}- \\
\mathrm{KCl}-\mathrm{HCl} \\
\pm \mathrm{S}\end{array}$ & $\mathrm{Cu}$ & $\begin{array}{l}\text { quartz and } \\
\text { silicate glass }\end{array}$ & 800 & 140 & NNO & $\begin{array}{l}\text { runs with } \\
\text { S: log } \\
f_{S_{2}}=-3 \\
\text { bars }\end{array}$ & $\begin{array}{l}20 \text { wt. \% } \\
\mathrm{NaCl} \text { eq. }\end{array}$ & $\begin{array}{l}8-9 \text { wt. } \\
\% \mathrm{NaCl} \\
\text { eq. }\end{array}$ & $\begin{array}{l}41-45 \\
\text { wt. \% } \\
\mathrm{NaCl} \text { eq. }\end{array}$ & $\begin{array}{l}D_{\mathrm{Cu}}^{v / s i-m t}=60 \pm 30 \\
D_{\mathrm{Cu}}^{b / s i-m t}=240 \pm 80 \\
D_{\mathrm{Cu}}^{v / b}=0.27 \pm 0.10 \\
\quad \text { S-bearing }\end{array}$ & $\begin{array}{l}\text { Simon et al., } \\
2006\end{array}$ \\
\hline
\end{tabular}




\begin{tabular}{|c|c|c|c|c|c|c|c|c|c|c|c|c|}
\hline & & & & & & & & & & & $\begin{array}{l}D_{\mathrm{Cu}}^{v / s i-m t}=320 \pm 20 \\
D_{\mathrm{Cu}}^{b / s i-m t}=440 \pm 70 \\
D_{\mathrm{Cu}}^{v / b}=0.69 \pm 0.16\end{array}$ & \\
\hline $\begin{array}{l}\text { pelite }+\mathrm{H}_{2} \mathrm{O} \\
\text { solid phases } \\
\text { included zrn, ap, } \\
\text { grt, rt }\end{array}$ & $\mathrm{H}_{2} \mathrm{O}$ & $\begin{array}{l}\mathrm{Al}, \mathrm{Ca}, \mathrm{Na}, \\
\mathrm{K}, \mathrm{Ti}, \mathrm{Rb}, \\
\mathrm{Sr}, \mathrm{Y}, \mathrm{Zr}, \\
\mathrm{Nb}, \mathrm{Cs}, \mathrm{Ba}, \\
\mathrm{La}, \mathrm{Gd}, \mathrm{Yb}, \\
\mathrm{Ta}, \mathrm{Pb}, \mathrm{Th}, \\
\text { U }\end{array}$ & quartz & $\begin{array}{l}600- \\
750\end{array}$ & $\begin{array}{l}1000, \\
1500, \\
2200\end{array}$ & NNO & NR & $\begin{array}{l}4-5.5 \\
\text { wt. } \% \text { total } \\
\text { solutes }\end{array}$ & & & $\begin{array}{l}\text { quantified } D_{i}^{v / \text { solids }} \text { for } \\
\text { Al, Ca, Na, K, Ti, Rb, Sr, Y, Zr, Nb, } \\
\text { Cs, Ba, La, Gd, Yb, Ta, Pb, Th, U }\end{array}$ & $\begin{array}{l}\text { Spandler et } \\
\text { al., } 2007\end{array}$ \\
\hline $\begin{array}{l}\text { granite melt + } \\
\text { mt + vapor + } \\
\text { apy }\end{array}$ & $\begin{array}{l}\text { O-H-NaCl- } \\
\mathrm{KCl}-\mathrm{HCl} \\
\pm \mathrm{S}\end{array}$ & $\mathrm{Au}, \mathrm{As}$ & silicate glass & 800 & 120 & NNO & $\begin{array}{l}\text { runs with } \\
\text { S: log } \\
f_{S_{2}}=-3 \\
\text { bars }\end{array}$ & $\begin{array}{l}1.8 \\
\text { wt. \% } \\
\mathrm{NaCl} \text { eq. }\end{array}$ & $\begin{array}{l}1.8 \\
\text { wt. \% } \\
\mathrm{NaCl} \text { eq. }\end{array}$ & & $\begin{array}{l}D_{A u}^{v / s i-m t}=15 \pm 2.5 \\
D_{A s}^{v / s i-m t}=1 \pm 0.1 \\
D_{A u}^{v / s i-m t}=\underline{\text { S-free }} \\
D_{A s}^{v / s i-m t}=2.5 \pm 0.3\end{array}$ & $\begin{array}{l}\text { Simon et al., } \\
2007\end{array}$ \\
\hline $\begin{array}{l}\text { Supercritical } \\
\text { fluid }+ \text { cst } \\
( \pm \mathrm{NaF} \text { melt })\end{array}$ & $\begin{array}{l}\text { O-H-NaCl- } \\
\text { NaF-HF-HCl }\end{array}$ & Sn & quartz & 700 & 140 & NNO & S-free & $\begin{array}{l}5-35 \text { wt. \% } \\
\mathrm{NaCl} \text { eq.; } \\
0.5-3.2 \mathrm{~m} \\
\mathrm{HF} ; 0.8- \\
0.5-4.4 \mathrm{~m} \\
\mathrm{HCl}\end{array}$ & & & $\begin{array}{l}D_{\mathrm{Sn}}^{\text {fluid / si-mt }}=0.1-4 \text {, controlled } \\
\text { primarily by } \mathrm{HCl} \text { concentration of } \\
\text { the fluid; } \mathrm{Sn} \text { solubility up to } 11 \mathrm{wt} \% \\
\text { in } \mathrm{HCl} \text {-rich fluids; formation of } \mathrm{Sn}- \\
\text { rich melt phase in NaF-bearing } \\
\text { experiments; } \mathrm{Sn} \text { dissolution likely as } \\
\mathrm{Sn}(\mathrm{OH}) \mathrm{Cl}, \mathrm{SnCl}_{2} \text { and } \mathrm{SnF}_{2}\end{array}$ & $\begin{array}{l}\text { Duc-Tin et al., } \\
2007\end{array}$ \\
\hline $\begin{array}{l}\text { granite melt + } \\
\text { vapor + brine }\end{array}$ & $\begin{array}{l}\mathrm{O}-\mathrm{H}-\mathrm{NaCl}- \\
\mathrm{KCl}-\mathrm{HCl}\end{array}$ & $\mathrm{Ag}$ & $\begin{array}{l}\text { quartz and } \\
\text { silicate glass }\end{array}$ & 800 & $\begin{array}{l}100, \\
140\end{array}$ & NNO & S free & $\begin{array}{l}1.8,5.5 \\
20 \\
\text { wt. \% } \\
\mathrm{NaCl} \text { eq. }\end{array}$ & $\begin{array}{l}1.2-9.7 \\
\text { wt. \% } \\
\mathrm{NaCl} \text { eq. }\end{array}$ & $\begin{array}{l}41-67 \\
\text { wt. \% } \\
\mathrm{NaCl} \text { eq. }\end{array}$ & $\begin{array}{l}D_{A g}^{v / s i-m t}=32 \pm 30 \\
D_{A g}^{b / s i-m t}=1150 \pm 240 \\
D_{A g}^{v / b}=0.026 \pm 0.004 \\
D_{A g}^{v / s i-m t}=\frac{100 \mathrm{MPa}}{32 \pm 10} \\
D_{A g}^{b / s i-m t}=410 \pm 170 \\
D_{A g}^{v / b}=0.06 \pm 0.03\end{array}$ & $\begin{array}{l}\text { Simon et al., } \\
2008\end{array}$ \\
\hline
\end{tabular}




\begin{tabular}{|c|c|c|c|c|c|c|c|c|c|c|c|c|}
\hline Mo-KCl- $\mathrm{H}_{2} \mathrm{O}$ & $\mathrm{O}-\mathrm{H}-\mathrm{KCl}$ & Mo & quartz & $\begin{array}{l}500- \\
800\end{array}$ & $\begin{array}{l}150- \\
300\end{array}$ & NNO & S-free & $\begin{array}{l}1-24 \mathrm{wt} \\
\% \mathrm{KCl}\end{array}$ & $\mathrm{NA}$ & NA & $\begin{array}{l}\text { Mo solubilities up to } 1.6 \text { wt } \% \text { in } \\
\mathrm{KCl} \text {-solutions; up to } 0.8 \text { wt } \% \text { in } \\
\text { pure } \mathrm{H}_{2} \mathrm{O} \text {; solubilities are pressure } \\
\text { independent but temperature } \\
\text { dependent and correlate positively } \\
\text { with } \mathrm{KCl} \text {, likely as molybdic acid and } \\
\text { Mo-oxo-chloride complexes }\end{array}$ & $\begin{array}{l}\text { Ulrich and } \\
\text { Mavrogenes, } \\
2008\end{array}$ \\
\hline S-anthracene & $\begin{array}{l}\mathrm{H}-\mathrm{O}-\mathrm{S}-\mathrm{CuCl}- \\
\mathrm{ZnCl}_{2}-\mathrm{Nacl}, \\
\mathrm{HCl}\end{array}$ & $\mathrm{Cu}$ & quartz & $\begin{array}{l}600 \\
700\end{array}$ & $\begin{array}{l}50 \\
100\end{array}$ & NNO & $\begin{array}{l}\text { buffered } \\
\text { by bn }+ \\
\text { iss @ } \\
\text { NNO }\end{array}$ & $\begin{array}{l}\text { brine / } \\
\text { vapor } \\
\text { density } \\
2.0 \text { to } 8.0\end{array}$ & NR & NR & $\begin{array}{l}D_{i}^{v / b}=\leq 0.39 \text { and } \leq 0.18 \\
\mathrm{H}_{2} \mathrm{~S} \text { was not observed to enhance } \\
\text { solubility of Cu in vapor relative to } \\
\text { brine at experimental conditions }\end{array}$ & $\begin{array}{l}\text { Lerchbaumer } \\
\text { and Audétat, } \\
2009\end{array}$ \\
\hline $\begin{array}{l}\text { bn-iss-bt-mt-or- } \\
\text { and } \\
\pm a b, \pm \text { anh }\end{array}$ & $\begin{array}{l}\mathrm{H}-\mathrm{O}-\mathrm{S}-\mathrm{KCl}- \\
\mathrm{FeCl}_{2}-\mathrm{HCl} \\
\pm \mathrm{NaCl}\end{array}$ & $\mathrm{Cu}$ & quartz & $\begin{array}{l}\text { 600, } \\
700\end{array}$ & $\begin{array}{l}50 \\
100\end{array}$ & NNO & $\begin{array}{l}\text { buffered } \\
\text { by bn }+ \\
\text { iss @ } \\
\text { NNO }\end{array}$ & NR & NR & NR & $D_{C u}^{v / b}=0.1$ to 0.2 & $\begin{array}{l}\text { Lerchbaumer } \\
\text { and Audétat, } \\
2009\end{array}$ \\
\hline S-anthracene & $\begin{array}{l}\mathrm{H}-\mathrm{O}-\mathrm{S}-\mathrm{NaCl}, \\
\mathrm{CuCl}-\mathrm{ZnCl}_{2-} \\
\mathrm{HCl}\end{array}$ & $\mathrm{Cu}, \mathrm{Zn}$ & quartz & $\begin{array}{l}500 \\
600 \\
650\end{array}$ & $\begin{array}{l}140 \\
\text { to } 167\end{array}$ & NR & NR & $\begin{array}{l}\text { brine / } \\
\text { vapor } \\
\text { density } \\
2.03 \text { to } \\
7.85\end{array}$ & NR & NR & $\begin{array}{l}D_{\mathrm{Cu}}^{v / b}=0.026(\mathrm{n}=1) \text { to } 32 \pm 4 \\
D_{\mathrm{Zn}}^{v / b}=0.006(\mathrm{n}=1) \text { to } 0.13 \pm 0.89 \\
\mathrm{H}_{2} \mathrm{~S} \text { enhances solubility of } \mathrm{Cu} \text { in } \\
\text { vapor relative to brine at } \\
\text { experimental conditions }\end{array}$ & $\begin{array}{l}\text { Nagaseki and } \\
\text { Hayashi, } 2009\end{array}$ \\
\hline $\begin{array}{l}\text { granite melt, } \\
\text { vapor, brine }\end{array}$ & $\begin{array}{l}\mathrm{NaCl}, \mathrm{KCl} \\
\mathrm{HCl}\end{array}$ & $\mathrm{Pt}$ & silicate glass & 800 & 100 & NNO & S-free & $\begin{array}{l}10 \text { wt. \% } \\
\mathrm{NaCl} \text { eq. }\end{array}$ & $\begin{array}{l}2 \text { wt. \% } \\
\mathrm{NaCl} \text { eq. }\end{array}$ & $\begin{array}{l}63 \text { wt. \% } \\
\mathrm{NaCl} \text { eq. }\end{array}$ & $\begin{array}{l}D_{P t}^{v / s i-m t}=2.9 \pm 1.0 \\
D_{P t}^{b / s i-m t}=6.8 \pm 2.4 \\
D_{P t}^{v / b}=0.15 \pm 0.05\end{array}$ & $\begin{array}{l}\text { Simon and } \\
\text { Pettke, } 2009\end{array}$ \\
\hline $\begin{array}{l}\text { granite melt, } \\
\text { vapor, brine }\end{array}$ & $\begin{array}{l}\mathrm{NaCl}, \mathrm{KCl}, \\
\mathrm{HCl}\end{array}$ & $\mathrm{Pt}$ & silicate glass & 800 & 140 & NNO & S-free & $\begin{array}{l}10 \text { wt. \% } \\
\mathrm{NaCl} \text { eq. }\end{array}$ & $\begin{array}{l}2 \text { wt. \% } \\
\mathrm{NaCl} \text { eq. }\end{array}$ & $\begin{array}{l}63 \text { wt. \% } \\
\mathrm{NaCl} \text { eq. }\end{array}$ & $\begin{array}{l}D_{P t}^{v / s i-m t}=1.0 \pm 0.2 \\
D_{P t}^{b / s i-m t}=70 \pm 30 \\
D_{P t}^{v / b}=0.13 \pm 0.05\end{array}$ & $\begin{array}{l}\text { Simon and } \\
\text { Pettke, } 2009\end{array}$ \\
\hline $\begin{array}{l}\text { supercritical fluid } \\
\text { - gold }\end{array}$ & $\begin{array}{l}\mathrm{NaCl}, \mathrm{KCl}, \\
\mathrm{HCl}, \mathrm{SO}_{2}, \\
\mathrm{H}_{2} \mathrm{~S}\end{array}$ & $\mathrm{Au}$ & quartz & 1000 & 150 & $\begin{array}{l}\text { NNO-0.6 } \\
\text { to } \\
\text { NNO+1.9 }\end{array}$ & $\begin{array}{l}\text { varied } \\
f_{\mathrm{S}_{2}} \\
f_{\mathrm{H}_{2} \mathrm{~S}} \\
f_{\mathrm{SO}_{2}}\end{array}$ & $\begin{array}{l}\text { variable } \\
\mathrm{NaCl}, \mathrm{KCl}, \\
\mathrm{HCl} ; \mathrm{S} \\
\text { from } \sim 1 \text { to } \\
\sim 10 \text { wt. } \%\end{array}$ & & & $\begin{array}{l}\text { data consistent with gold- } \\
\text { hydrosulfide complex dominating } \\
\text { over gold-chloride complex; alkali } \\
\text { chlorides amplify stability of gold- } \\
\text { hydrosulfide-alkali complex }\end{array}$ & $\begin{array}{l}\text { Zajacz et al., } \\
2010\end{array}$ \\
\hline $\begin{array}{l}\text { granite melt- iss- } \\
\text { po-vapor-brine } \\
\pm b n\end{array}$ & $\begin{array}{l}\mathrm{NaCl}, \mathrm{KCl}, \\
\mathrm{HCl}, \mathrm{FeCl}_{2}\end{array}$ & $\mathrm{Cu}, \mathrm{Au}$ & quartz & 800 & 100 & NNO & $\begin{array}{l}\log a_{S_{2}}^{\text {sys }} \\
=3.5 \mathrm{x} \\
10^{-2} \text { and }\end{array}$ & $\begin{array}{l}5 \text { wt. \% } \\
\mathrm{NaCl} \text { eq. }\end{array}$ & $\begin{array}{l}2.7-3.6 \\
\text { wt. \% } \\
\mathrm{NaCl} \text { eq. }\end{array}$ & $\begin{array}{l}66.5- \\
68.5 \mathrm{wt} . \\
\% \mathrm{NaCl} \\
\text { eq. }\end{array}$ & $\begin{array}{l}\text { Increasing activity of } \mathrm{S} \text { in fluid } \\
\text { correlated with increase in } \\
\text { measured } \mathrm{Au} \text { and } \mathrm{Cu} \\
\text { concentrations in the fluid; } \mathrm{Cu} \text { and } \\
\text { Au behave similar with no observed } \\
\text { fractionation }\end{array}$ & $\begin{array}{l}\text { Frank et al., } \\
2011\end{array}$ \\
\hline
\end{tabular}




\begin{tabular}{|c|c|c|c|c|c|c|c|c|c|c|}
\hline & & & & & & & $\begin{array}{l}\log a_{S_{2}}^{\text {sys }} \\
=1.2 \mathrm{x} \\
10^{-4}\end{array}$ & & & \\
\hline $\begin{array}{l}\text { supercritical fluid } \\
\text { - gold }\end{array}$ & $\begin{array}{l}\mathrm{NaCl}, \mathrm{KCl}, \\
\mathrm{HCl}, \mathrm{FeCl}_{2} \\
\mathrm{SO}_{2}, \mathrm{H}_{2} \mathrm{~S}\end{array}$ & $\mathrm{Cu}$ & quartz & 1000 & 150 & $\begin{array}{l}\text { NNO-0.6 } \\
\text { to } \\
\text { NNO+1.9 }\end{array}$ & $\begin{array}{l}\text { varied } \\
f_{\mathrm{S}_{2}} \\
f_{\mathrm{H}_{2} \mathrm{~S}} \\
f_{\mathrm{SO}_{2}} \\
\end{array}$ & $\begin{array}{l}\text { variable } \\
\mathrm{NaCl}, \mathrm{KCl}, \\
\mathrm{HCl} ; \mathrm{S} \\
\text { from } \sim 1 \text { to } \\
\sim 10 \text { wt. \% }\end{array}$ & $\begin{array}{l}\text { Solubility of } \mathrm{Cu} \text { in the aqueous fluid } \\
\text { increases with increasing } f_{\mathrm{O}_{2}} \\
\text { addition of } \mathrm{S} \text { to a } \mathrm{Na} / \mathrm{K} / \mathrm{H} / \mathrm{Fe}-\mathrm{Cl} \text { fluid } \\
\text { does not result in increased } \mathrm{Cu} \\
\text { solubility relative to a S-free alkali- } \\
\text { chloride fluid }\end{array}$ & $\begin{array}{l}\text { Zajacz et al., } \\
2011\end{array}$ \\
\hline $\begin{array}{l}\text { Uraninite, } \\
\text { thorite, } \\
\text { supercritical fluid }\end{array}$ & $\begin{array}{l}\mathrm{H}-\mathrm{O}-\mathrm{NaCl}- \\
\mathrm{Cs}-\mathrm{Rb}-\mathrm{Ba}- \\
\mathrm{Co}\end{array}$ & $\mathrm{U}, \mathrm{Th}$ & Quartz & 800 & $\begin{array}{l}710- \\
2610\end{array}$ & $\begin{array}{l}\mathrm{Fe}-\mathrm{FeO}, \\
\mathrm{Co}-\mathrm{CoO}, \\
\mathrm{Ni}-\mathrm{NiO}, \\
\mathrm{Re}-\mathrm{ReO}_{2}\end{array}$ & S-free & $\begin{array}{l}0-14.1 \\
\text { wt. \% } \\
\mathrm{NaCl} \text { eq. }\end{array}$ & $\begin{array}{l}\text { U solubility increases with } f_{O_{2}} \text { and } \\
\text { NaCl; Th solubility in fluid } \\
\text { independent of } \mathrm{NaCl} \text { and little } \\
\qquad f_{\mathrm{O}_{2}} \text {; data indicate } \\
\text { dependend on } \\
\text { that degassing of subducted slab } \\
\text { can fractionate } \mathrm{U} / \mathrm{Th} \text { at } \\
\text { QFM- } 0.5 \text { to QFM }+3.35\end{array}$ & Bali et al., 2011 \\
\hline $\begin{array}{l}\text { liquid only, and } \\
\text { vapor only }\end{array}$ & $\begin{array}{l}\text { Liquid: } \mathrm{NaCl}, \\
\mathrm{Na}_{2} \mathrm{SO}_{4}^{*} 10( \\
\left.\mathrm{H}_{2} \mathrm{O}\right), \mathrm{NaBr}, \\
\mathrm{CsCl} \\
\text { Vapor: } \mathrm{H}_{2} \mathrm{O}, \\
\mathrm{S}, \mathrm{NaCl} \\
\mathrm{NaBr}, \mathrm{CsCl} \\
\mathrm{RbCl}\end{array}$ & $\mathrm{S}, \mathrm{Cl}, \mathrm{Br}$ & Quartz & $\begin{array}{l}\text { liquid } \\
\text { at } \\
600, \\
\text { vapor } \\
\text { at } \\
160- \\
170\end{array}$ & $\begin{array}{l}950- \\
1000\end{array}$ & NR & $\begin{array}{l}\mathrm{H}_{2} \mathrm{~S} \\
\text { dominant }\end{array}$ & $\begin{array}{l}3.6-9.0 \\
\text { wt. \% total } \\
\text { dissolved } \\
\text { solids }\end{array}$ & $\begin{array}{l}\text { Quantification of } \mathrm{S}, \mathrm{Br}, \mathrm{Cl} \text { in } \\
\text { synthethic fluid inclusions can be } \\
\text { performed with good accuracy; } \\
\text { analytical uncertainty for } \mathrm{S} \text { is } 17- \\
44 \% \mathrm{RSD} \text {, and } 6-26 \% \text { for } \mathrm{Br} / \mathrm{Cl} \\
\text { ratios. LODs are in the range of } 60 \\
\text { ppm for } \mathrm{S}, 250 \mathrm{ppm} \text { for } \mathrm{Cl}, 15 \mathrm{ppm} \\
\text { for } \mathrm{Br}\end{array}$ & Seo et al., 2011 \\
\hline
\end{tabular}

$\mathrm{NR}=$ not reported; $\mathrm{NNO}=\mathrm{NiNiO} ; \mathrm{IW}=$ iron-wüstite; $\mathrm{CCO}=\mathrm{CoCoO} ; \mathrm{RRO}=\mathrm{ReReO} ; \mathrm{f}=$ fugacity; $\mathrm{a}=\mathrm{activity} ; \mathrm{v}=\mathrm{vapor} ; \mathrm{b}=\mathrm{brine} ;$ si-mt $=$ silicate melt; $\mathrm{bn}=$ bornite; iss = intermediate solid solution; $a b=$ albite; and = andalusite; anh = anhydrite; $a p=$ apatite; $a p y=$ arsenopyrite; bn = bornite; bt = biotite; cst = cassiterite; grt = garnet; or = orthoclase; rt = rutile; $z r n=$ zircon; anthracene is a reductant with the formula $\mathrm{C}_{14} \mathrm{H}_{10}$ 
Table 4: Bismuth inclusion element concentration data for 3 localities in the Sn-W mineralized Mole Granite, NSW, Australia

\begin{tabular}{|c|c|c|c|c|c|c|c|c|c|c|c|c|c|c|c|c|c|c|c|c|c|c|c|c|}
\hline $\begin{array}{l}\text { Analysis } \\
\text { number }\end{array}$ & Sample & $\begin{array}{l}\text { host } \\
\text { mineral }\end{array}$ & $\begin{array}{l}\text { Ablation } \\
\text { quality }\end{array}$ & $\begin{array}{r}\mathrm{Bi} \\
(209) \\
\mathrm{wt} \%\end{array}$ & $\begin{array}{l}\text { As } \\
(75) \\
\text { wt\% }\end{array}$ & $\begin{array}{r}\mathrm{Te} \\
(126) \\
\mathrm{wt} \%\end{array}$ & $\begin{array}{r}\mathrm{Te} \\
(128) \\
\mathrm{wt} \%\end{array}$ & $\begin{array}{l}\text { Co } \\
\text { (59) } \\
\text { ppm }\end{array}$ & $\begin{array}{l}\mathrm{Ni} \\
(61) \\
\mathrm{ppm}\end{array}$ & $\begin{array}{r}\mathrm{S} \\
(32) \\
\mathrm{ppm}\end{array}$ & $\begin{array}{r}\mathrm{S} \\
(34) \\
\mathrm{ppm}\end{array}$ & $\begin{array}{c}\mathrm{Cu} \\
(65) \\
\mathrm{ppm}\end{array}$ & $\begin{array}{c}\mathrm{Zn} \\
(66) \\
\mathrm{ppm}\end{array}$ & $\begin{array}{c}\mathrm{Ga} \\
(69) \\
\mathrm{ppm}\end{array}$ & $\begin{array}{c}\mathrm{Ge} \\
(72) \\
\mathrm{ppm}\end{array}$ & $\begin{array}{c}\mathrm{Se} \\
(78) \\
\mathrm{ppm}\end{array}$ & $\begin{array}{r}\mathrm{Ag} \\
(107) \\
\mathrm{ppm}\end{array}$ & $\begin{array}{r}\mathrm{Cd} \\
(111) \\
\mathrm{ppm}\end{array}$ & $\begin{array}{r}\text { In } \\
(115) \\
\text { ppm }\end{array}$ & $\begin{array}{c}\mathrm{Sn} \\
(118) \\
\mathrm{ppm}\end{array}$ & $\begin{array}{c}\mathrm{Sb} \\
(121) \\
\mathrm{ppm}\end{array}$ & $\begin{array}{c}W \\
(182) \\
\text { ppm }\end{array}$ & $\begin{array}{c}\mathrm{Au} \\
(197) \\
\mathrm{ppm}\end{array}$ & $\begin{array}{c}\mathrm{Pb} \\
(208) \\
\mathrm{ppm}\end{array}$ \\
\hline 99Mz17b03 & Taro20 incl.1 & Fluorite & exploded & 95.1 & 3.4 & 1.5 & 1.5 & 8800 & 7100 & n.a. & п.а. & 310 & $<200$ & $<30$ & n.a. & n.a. & 4150 & n.a. & $<21$ & 840 & 3900 & 270 & 34 & 1580 \\
\hline 99Mz17b04 & Taro20 incl.2 & Fluorite & * & 97.3 & 1.4 & 1.3 & 1.3 & 3900 & 5500 & n.a. & n.a. & 180 & $<120$ & $<20$ & n.a. & n.a. & 2350 & n.a. & $<15$ & 530 & 1660 & $<58$ & 19 & 520 \\
\hline $99 \mathrm{Mz} 17 \mathrm{~b} 07$ & Taro20 incl.5 & Fluorite & 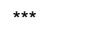 & 99.0 & 0.1 & 0.9 & 1.0 & 5200 & 3400 & n.a. & n.a. & $<18$ & $<46$ & 13 & n.a. & n.a. & 4890 & n.a. & $<5$ & 460 & 2060 & 130 & $<1$ & 640 \\
\hline 99Mz17b08 & Taro20 incl.6 & Fluorite & * & 94.7 & 3.9 & 1.4 & 1.4 & 38200 & 44000 & п.а. & n.a. & 1370 & 350 & $<26$ & n.a. & n.a. & 1660 & n.a. & $<22$ & 2100 & 2420 & 1890 & 42 & 420 \\
\hline $99 \mathrm{Mz} 17 \mathrm{~b} 09$ & Taro20 incl.7 & Fluorite & $* \star *$ & 97.3 & 1.5 & 1.2 & 1.2 & 1110 & 1140 & n.a. & n.a. & 270 & $<64$ & $<8$ & n.a. & n.a. & 1710 & n.a. & $<6$ & 230 & 2120 & 210 & 28 & 660 \\
\hline $99 \mathrm{Mz} 17 \mathrm{~b} 10$ & Taro20 incl.8 & Fluorite & $* * \star$ & 97.4 & 1.5 & 1.2 & 1.1 & 11200 & 10200 & n.a. & n.a. & 250 & $<190$ & $<30$ & n.a. & n.a. & 1600 & n.a. & $<22$ & 1210 & 2090 & 460 & 29 & 670 \\
\hline 99Mz17b11 & Taro20 incl.9 & Fluorite & 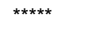 & 96.8 & 2.0 & 1.2 & 1.2 & 2650 & 3100 & n.a. & n.a. & 330 & $<29$ & $<4$ & n.a. & n.a. & 2140 & n.a. & 31 & 400 & 2140 & 220 & 15 & 610 \\
\hline $99 \mathrm{Mz} 17 \mathrm{~b} 12$ & Taro20 incl.10 & Fluorite & $* *$ & 96.9 & 1.7 & 1.4 & 1.4 & 28400 & 23600 & n.a. & n.a. & 350 & 950 & $<41$ & n.a. & n.a. & 4060 & n.a. & 35 & 5400 & 2090 & 1040 & 15 & 790 \\
\hline Average & & & & 97.4 & 1.4 & 1.2 & 1.2 & 8700 & 7800 & & & 280 & & & & & 2800 & & 33 & 570 & 2030 & 260 & 21 & 650 \\
\hline $1 \mathrm{SD}$ & & & & 0.8 & 0.7 & 0.2 & 0.1 & 10200 & 8300 & & & 70 & & & & & 1360 & & 3 & 380 & 1820 & 140 & 7 & 90 \\
\hline $99 \mathrm{Mz} 12 \mathrm{~d} 03$ & Bism3.3 incl.1 & Topaz & $* * *$ & 97.2 & 1.0 & 1.8 & n.a. & n.a. & n.a. & n.a. & n.a. & 530 & n.a. & n.a. & n.a. & n.a. & 1110 & $<200$ & n.a. & n.a. & 300 & n.a. & 71 & 76 \\
\hline $99 \mathrm{Mz} 12 \mathrm{~d} 04$ & Bism3.3 incl. 2 & Topaz & $* \star *$ & 97.5 & 0.9 & 1.5 & n.a. & n.a. & n.a. & n.a. & n.a. & 480 & n.a. & n.a. & n.a. & n.a. & 1240 & $<120$ & n.a. & n.a. & 270 & n.a. & 54 & 67 \\
\hline $99 \mathrm{Mz} 12 \mathrm{~d} 06$ & Bism3.3 incl 4 & Topaz & * & 97.6 & 0.9 & 1.6 & n.a. & n.a. & n.a. & n.a. & n.a. & $<1400$ & n.a. & n.a. & n.a. & n.a. & 1400 & $<530$ & n.a. & n.a. & 260 & n.a. & 55 & $<60$ \\
\hline $99 \mathrm{Mz} 12 \mathrm{~d} 07$ & Bism3.3 incl 5 & Topaz & ** & 97.5 & 0.9 & 1.5 & n.a. & n.a. & n.a. & n.a. & n.a. & 500 & n.a. & n.a. & n.a. & n.a. & 1270 & $<150$ & n.a. & n.a. & 270 & n.a. & 52 & 63 \\
\hline $99 \mathrm{Mz} 12 \mathrm{~d} 08$ & Bism3.3 incl. 6 & Topaz & ** & 97.3 & 1.0 & 1.7 & n.a. & n.a. & n.a. & n.a. & n.a. & $<4000$ & n.a. & n.a. & n.a. & n.a. & 1390 & $<250$ & n.a. & n.a. & 300 & n.a. & 48 & 76 \\
\hline $99 \mathrm{Mz} 12 \mathrm{~d} 09$ & Bism3.3 incl. 7 & Topaz & $* \star * *$ & 97.5 & 0.9 & 1.6 & n.a. & n.a. & n.a. & n.a. & n.a. & 520 & n.a. & n.a. & n.a. & n.a. & 1240 & $<65$ & n.a. & n.a. & 280 & n.a. & 54 & 62 \\
\hline 99Mz12d10 & Bism3.3 incl. 8 & Topaz & $\star \star \star \star \star *$ & 97.6 & 0.8 & 1.5 & n.a. & n.a. & n.a. & n.a. & n.a. & 500 & n.a. & n.a. & n.a. & n.a. & 1200 & $<51$ & n.a. & n.a. & 280 & n.a. & 48 & 74 \\
\hline $99 \mathrm{Mz} 12 \mathrm{e} 04$ & Bism3.3 incl. 9 & Topaz & 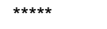 & 97.4 & 1.2 & 1.4 & n.a. & n.a. & n.a. & $<2100$ & $<4100$ & 300 & $<200$ & 67 & 750 & 1600 & 870 & $<67$ & n.a. & n.a. & 750 & n.a. & 49 & 15 \\
\hline $99 \mathrm{Mz} 12 \mathrm{e} 05$ & Bism3.3 incl. $1 \mathrm{C}$ & ( Topaz & $\star \star \star \star \star *$ & 97.5 & 0.9 & 1.6 & n.a. & n.a. & n.a. & $<1100$ & $<2700$ & 360 & $<120$ & 53 & 570 & 1100 & 1210 & $<49$ & n.a. & n.a. & 270 & n.a. & 59 & 72 \\
\hline Average & & & & 97.5 & 1.0 & 1.6 & & & & & & 460 & & 60 & 660 & 1350 & 1210 & & & & 330 & & 54 & 63 \\
\hline $1 \mathrm{SD}$ & & & & 0.1 & 0.1 & 0.1 & & & & & & 90 & & 10 & 127 & 350 & 160 & & & & 160 & & 7 & 20 \\
\hline 99Mz17a04 & Gold4 4 incl.2 & Quartz & exploded & 96.2 & 0.10 & 3.8 & 3.8 & 3200 & $<13500$ & n.a. & n.a. & $<810$ & $<1880$ & $<230$ & n.a. & n.a. & 430 & n.a. & $<190$ & 6650 & $<120$ & 6700 & 2030 & 290 \\
\hline $99 \mathrm{Mz} 17 \mathrm{a} 05$ & Gold4 incl.3 & Quartz & $* *$ & 95.3 & $<0.02$ & 4.7 & 4.4 & $<100$ & $<3500$ & n.a. & n.a. & $<1900$ & $<10000$ & $<47$ & n.a. & n.a. & 620 & n.a. & $<30$ & 1650 & 410 & 600 & 990 & 68 \\
\hline 99Mz17a06 & Gold4 incl.4 mit & il Quartz & * & 96.5 & 0.06 & 3.5 & 3.5 & 2000 & $<8600$ & n.a. & n.a. & $<360$ & $<830$ & $<120$ & n.a. & n.a. & 360 & n.a. & $<82$ & 2790 & 110 & 1550 & 1050 & 330 \\
\hline 99Mz17a08 & Gold4 incl.6 & Quartz & ** & 95.5 & $<0.07$ & 4.5 & 4.5 & 840 & $<6300$ & n.a. & n.a. & $<530$ & $<1360$ & $<150$ & n.a. & n.a. & 1440 & n.a. & $<100$ & 4520 & 220 & 5100 & 1780 & 520 \\
\hline $99 \mathrm{Mz} 17 \mathrm{a} 10$ & Gold4 incl.8 & Quartz & ** & 97.0 & 0.07 & 3.0 & 2.8 & 1860 & $<3200$ & n.a. & n.a. & $<190$ & $<420$ & 87 & n.a. & n.a. & 940 & n.a. & $<37$ & 2700 & 180 & 3700 & 1680 & 420 \\
\hline 99Mz17a11 & Gold4 incl.9 & Quartz & $* * *$ & 97.4 & $<0.05$ & 2.6 & 2.4 & 340 & $<4000$ & n.a. & n.a. & $<650$ & $<700$ & $<110$ & n.a. & n.a. & 790 & n.a. & $<81$ & 2840 & 120 & 4300 & 2090 & 320 \\
\hline Average & & & & 96.3 & 0.07 & 3.7 & 3.5 & 1260 & & & & & & & & & 830 & & & 2900 & 210 & 3050 & 1520 & 400 \\
\hline $1 \mathrm{SD}$ & & & & 0.9 & 0.01 & 0.9 & 1.0 & 800 & & & & & & & & & 400 & & & 1030 & 120 & 1900 & 480 & 90 \\
\hline
\end{tabular}

Notes: $\quad$ Bism 3.3 is a large topaz crystal within quartz-topaz greisen. Bismuth inclusions formed early, at $\geq 370^{\circ} \mathrm{C}$.

Gold 4 a quartz crystal from a Bi and Au-rich vein within quartz-topaz greisen. Inclusions formed late at ca. $250^{\circ} \mathrm{C}$.

Taro 20 is a sample from a sheeted vein system above a ridge in the Mole Granite. Inclusions formed early at $\geq 390^{\circ} \mathrm{C}$.

See Audetat et al. (2000 a,b) for more information on sample locations and characteristics.

The nubers in brackets below the elements represent the isotopes analyzed
The numbers of stars for ablation quality represents bad (*) to excellent $\left({ }^{\star \star * * \star}\right)$ as determined visually on TV screen during ablation

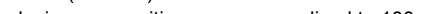

政

For locality Bism 3.3, two Te isotopes were

n.a. indicates not analyzed

Values prefixed by "<" were below LOD 